Portland State University

PDXScholar

$1-1-1986$

\title{
Synthetic and nitrogen-15 NMR studies of some heteroaromatic systems
}

Roger Martin Sheets

Portland State University

Follow this and additional works at: https://pdxscholar.library.pdx.edu/open_access_etds Let us know how access to this document benefits you.

\section{Recommended Citation}

Sheets, Roger Martin, "Synthetic and nitrogen-15 NMR studies of some heteroaromatic systems" (1986). Dissertations and Theses. Paper 218.

https://doi.org/10.15760/etd.218

This Dissertation is brought to you for free and open access. It has been accepted for inclusion in Dissertations and Theses by an authorized administrator of PDXScholar. Please contact us if we can make this document more accessible: pdxscholar@pdx.edu. 


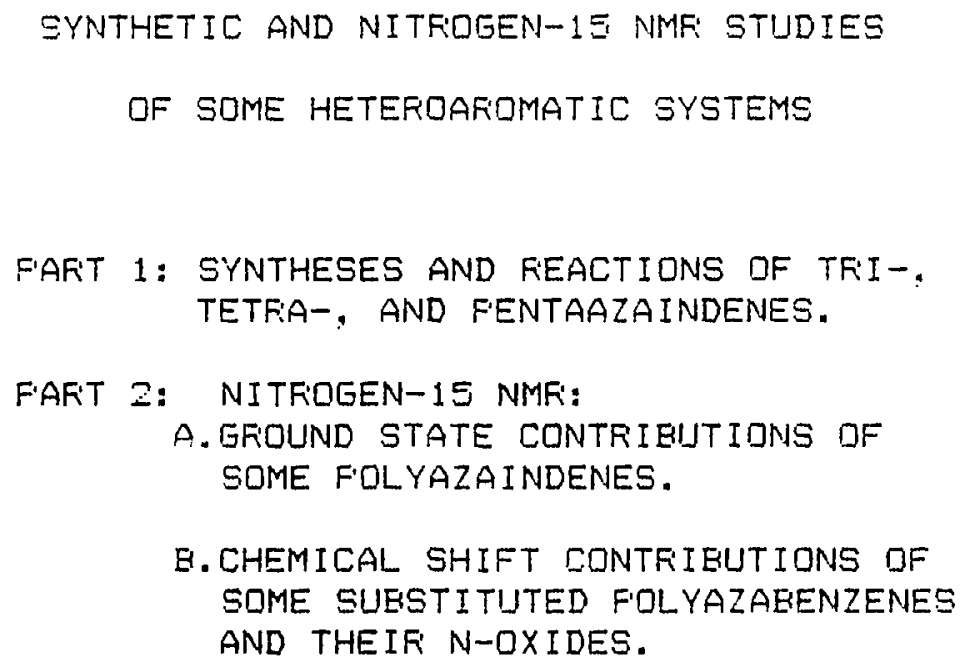

BY F FOGEF' MAFITIN SHEETS

a dissertation submitted in partial fulfillment of the requirements for the degree of

DOCTOR OF FHILOSOF'HY

in

ENUIFONMENTAL SCIENCE AND FESOURCES / CHEMISTFY

Fortland State University

1986 
TO THE OFFICE OF GRADUATE STUDIES AND RESEARCH:

The members of the Committee approve the dissertation of Roger Martin Sheets pregented April 24, 1986.

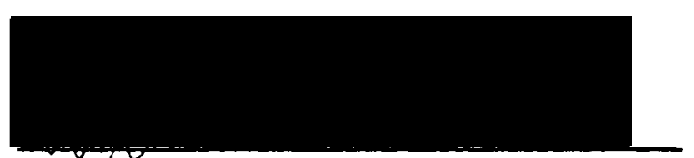

Will lam w. Paudler, Chalrperson
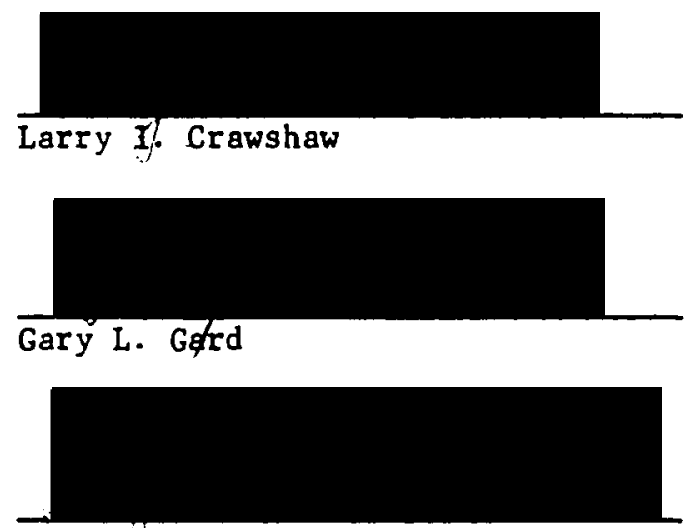

Alfredils. Levinson

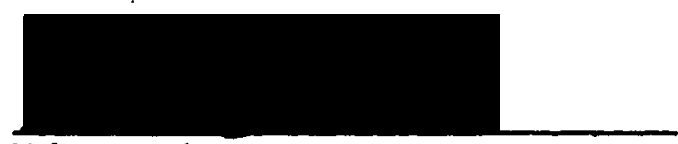

Makoto Takeo

\section{APPROVED:}
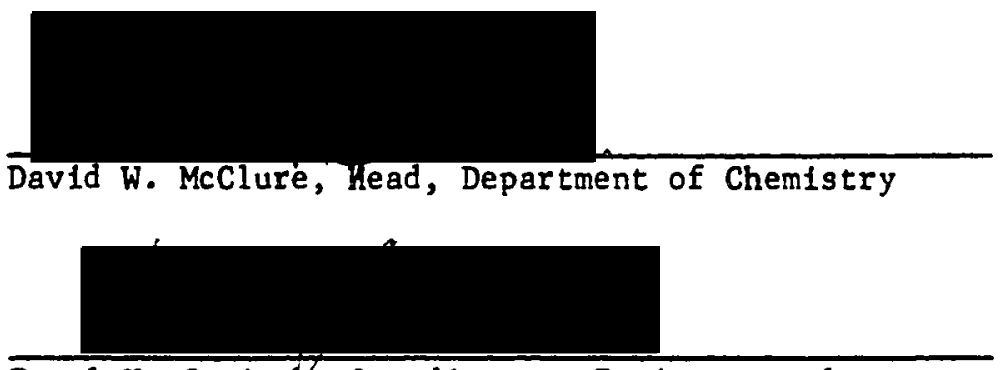

Pavel K. Smejtek, Coordinator, Environmental

Sciences and Resoures Ph.D. Program

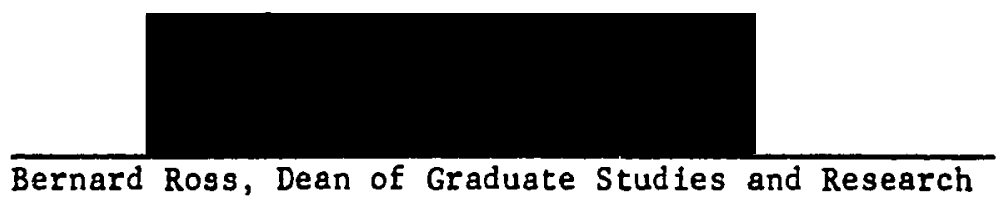


AN ABSTRACT OF THE DISSERTATION OF Roger Martin Sheets for the Doctor of Philosophy in Environmental Sciences and Resources:

Chemistry presented April 24, 1986.

Title: Synthetic and Nitrogen-15 NMR Studies of Some Heteroaromatic Systems.

Part 1: Syntheses and Reactions of Tri-, Tetra-, and Pentaazaindenes.

Part 2: Nitrogen-15 NMR.
A. Ground State Contributions of Some Polyazaindenes.
B. Chemical Shift Contributions of Some substituted Polyazabenzenes and Thetr $\mathrm{N}$-Oxides.

APPROVED BY MEMBERS OF THE DISSERTATION COMMITTEE:
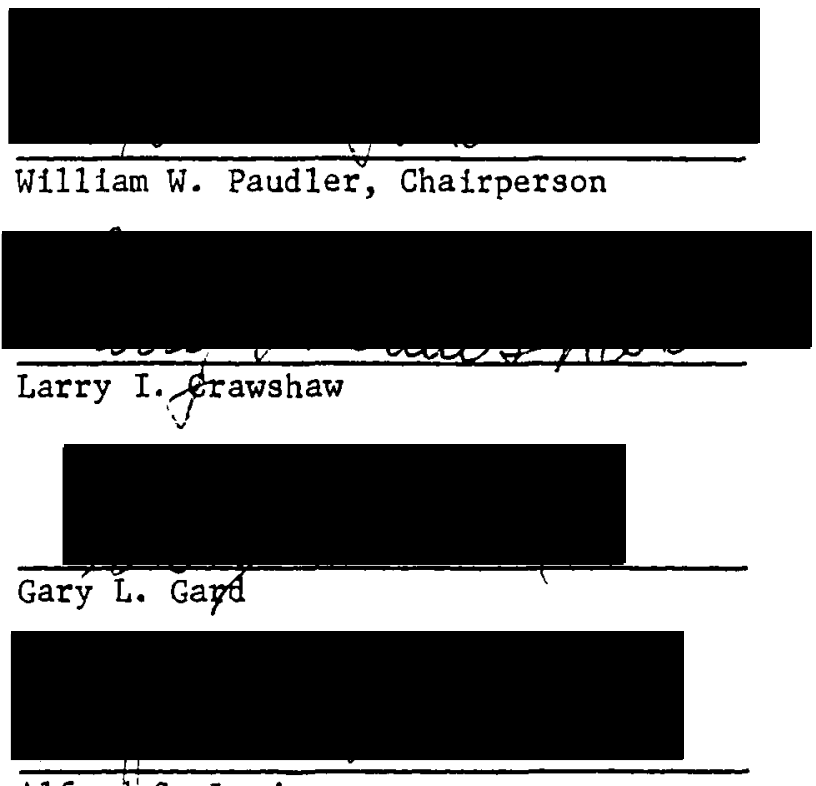

A1fred/S. Levinson

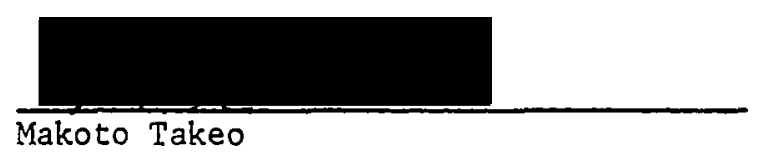


Beginning in the mid-1960"s synthetic nucleoside derivatives of polyazaindolizines and polyazaindenes were studied for their anticancer activities. The most promising nucleosides for anticancer activity were pyrrolo-, imidazo-; and s-triazolo- pyrimidines and triazines.

$$
\text { Syntheses of } 1,2,4-t r i a z o l o[5,4 c]-1,2,4-t r i a z i n e-7-
$$

oxide, 1,2,4-triazolo[3,4c]pyrazine-7-oxide and 1,2,4triazolo[2, Sc]pyrazine-7-oxide were achieved by the cyclization of the appropriate S-hydrazinoazine $\mathrm{N}-a x i d e$ with diethoxymethyl acetate. When different one carbon cyclization agents react with the J-hydrazinoazine-1-oxides they did not produce the expected polyazaindene-7-okides. The reaction of formic acid with S-hydrazino-1,2,4-triazine1-oxide or J-hydrazinopyrazine-1-oxide produced the :formylhydrazino derivatives. Similarly, the reactions of the E-hydrazino -pyrazine-1-oxide and -triazine-1-oxide with benzaldehyde, acetic anhydride, or phenylisothiocyanate produced the I-benzylideno, S-acetyl, and S-(4phenylthiosemicarbizide) derivatives, respectively.

The direct $N$-oxidation of imidazo[1,2a]pyrazine with metes-chloroperbenzoic acid produced the imidaza[J,4c]pyrazine-7-oxide.

Froton nuclear magnetic resonance analyses of the polyazaindenes $\mathrm{N}$-oxides has produced a set of shielding and deshielding parameters for ring protons. The mass spectral information abtained for the polyazaindene $\mathrm{N}$-oxides suggests 
that the five membered $\mathrm{ring}$ of polyazaindene $\mathrm{N}$-oxide has a decreased reactivity to electrophilic reagents when compared to the parent compound.

The nitrogen-15 nuclear magnetic resonance spectra obtained for selected polyazaindenes were used to predict the percentage of contribution between two ground state resonance contributing structures.

The nitrogen-15 nuclear magnetic resonance spectra of several substituted pyridine, pyrazine, pyrimidine and 1,2,4-triazine derivatives and their N-oxides were correlated with substituent contributions and ground state contributing structures. From this data, correlations between the nitrogen-15 chemical shifts and aromatic electron deficiency have been established. 


\section{ACKOWLEDGEMENTS}

The author extends gratitude to Dr. William W. Faudler, for his patience, guidance, and assistance. Additional appreciation is given to Dr. Harry L. Blewict for counsel and support during the long years, you were the first and I am the last. Additional appreciation is given to Dr. Gary L. Gard for his unblinding faith in the "Hurian Spirit". A special thanks to Dennis Grahn for bringing me back. 
ACKNOWLEDGEMENTS $\ldots \ldots \ldots \ldots \ldots \ldots \ldots \ldots \ldots \ldots \ldots \ldots \ldots$ i i

LIST OF TABLES $\ldots \ldots \ldots \ldots \ldots \ldots \ldots \ldots \ldots \ldots \ldots \ldots . \ldots \ldots$ vi

LIST OF FIGURES $\ldots \ldots \ldots \ldots \ldots \ldots \ldots \ldots \ldots \ldots \ldots \ldots \ldots \ldots \ldots$

FAFT 1

CHAPTER

I. HISTOFY OF THE F'OLYAZAINDENES ......... 1

I I. HISTORY OF THE FOLYAZAINDENE-N-OXIDES .... 9

III. DISCUSSION ..................... 19

SYNTHESES AND STRUCTURE DETERMINATION

DF THE F'ARENT S-TRIAZOLD[ $3,4 C]-$

AS-TFIAZINE-7-0XIDE AND S-

TFIAZOLOL $3,4 C J F Y R A Z I N E-7-O X I D E \ldots \ldots \ldots .21$

OTHER REACTIONS WITH Z-HYDRAZINO- AS-

TRIAZINE-1-QXIDE AND PYRAZINE-1-OXIDE ... 25

FEACTIONS OF S-TRIAZOLO[3, 4CJFYRAZINE

7-OXIDE AND S-TRIAZOLD[3,4C]-AS-

TRIAZINE-7-OXIDE ................. 30

SYNTHESIS OF IMIDAZO[2, 1C]PYRAZINE-7-

aXIDE ........................ 32

REACTIONS OF IMIDAZO[2, 1C]PYRAZINE-7-

OXIDE ....................... 32

MASS SPECTRAL INFORMATION .......... 3

NUCLEAR MAGNetic fiesonance ........... \$4

IV. EXFEFIMENTAL ................... $\$ 7$

$y$. REFERENCES $\ldots \ldots \ldots \ldots \ldots \ldots \ldots \ldots \ldots \ldots \ldots$ 
TAELE OF CONTENTS

(CONT INUED)

PART 2

CHAPTER F'AGE

I. HISTORY OF NITROGEN-15 NUCLEAR MAGNETIC RESDNANCE (NMF) ................. 69

BONDING EFFECTS ON NITROGEN-15

CHEMICAL SHIFTS ................ 72

A. SOLVENT EFFECTS .............. 73

E. FFIOTONATION OF NITROGEN .......... 75

C. N-OXIDATION ................... 75

LINEAF COFFELATIONS ............. 77

II. NITROGEN CHEMICAL SHIFTS ............. 80

A. AZOLE CHEMICAL SHIFTS .......... 81

B. AZINE CHEMICAL SHIFTS ........... 8.5

C. NITROGEN CHEMICAL SHIFTS of
POLYAZAINDENES .............. 89

III. DISCUSSION ..................... 91

A. N-15 CHEMICAL SHIFTS OF A NUMBER OF POLYAZAINDENES: CORRELATION WITH CHARGE SEPERATED RESONANCE CONRTRIBUTING STRUCTURES .......... 91

B. NITROGEN-15 CHEMICAL SHIFTS OF SOME FYFAZINE, 1, 2, 4-TFIAZINES AND THEIF N-OXIDES: CORRELATION WITH CARBON15 CHEMICAL SHIFTS AND SUESTITUTION PARAMETERS .................... 95

IV. EXFERIMENTAL ................... 100

v. FEFERENCES ..................... 110 


\section{LIST OF TABLES}

FART 1

TABLE

F'AGE

I. AFFLICATION OF SEVERAL FUSED FOLYAZAINDENES. 61

II. FROTON NUCLEAR MAGNETIC FESONANCE CHEMICAL SHIFTS OF SOME FOLYAZAINDENES AND THEIF N-OXIDES .................... 62

II I. CHANGES IN CHEMICAL SHIFTS OF DIMFOTH FIEARIFANGED AND NON FIEAFIFANGED COMFOUNDS . 64

IV. CHEMICAL SHIFTS OF 3-HYDFAZIND-ASTRIAZINE-1-OXIDES ............... ¿S

V. DIFFEFENCES EETWEEN FAFENT AND N-OXIDE FROTON CHEMICAL SHIFTS OF SOME F'OLYAZAINDENES

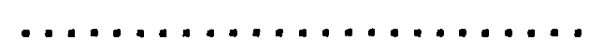

PART 2

TAELE F.AGE

I. COMPARISON OF NITROGEN-14 TO NITFOOGEN-15 11.3

II. NITFIDGEN-14,-15 CHEMICAL SHIFTS FOF: SOME AZOLES

III. NITROGEN-14,-15 CHEMICAL SHIFT DATA FOR AZINE-N-OXIDES

IV. NITROGEN-14 CHEMICAL SHIFTS OF SOME POLYAZAINDENES .................. 118

V. NITROGEN-15 CHEMICAL SHIFTS OF SOME POLYAZAINDENES .................. 119

VI. NITFOGEN-15 CHEMICAL SHIFT DATA DF SOME FYRAZINES AND THEIR N-OXIDES .......... 120

VII. NITROGEN-15 CHEMICAL SHIFT DATA OF SOME $1,2,4$-TRIAZINES AND THEIR N-OXIDES $\ldots \ldots . .121$ 


\section{LIST OF TABLE} (CONT INUED)

\section{FART 2}

TAELE

F'AGE

VIII. NITROGEN-15 CHEMICAL SHIFT DIFFERENCES EETWEEN F'AFIENT HETEFOCYCLIC COMFOUNDS AND SUESTITUTED HETEROCYCLIC ANOLOGS ....

IX. DIFFEFENCE IN NITFDGEN-15 SHIFT = SLOFE times (DIFFERENCE CARBON-13 SHIFTS INTEF:CEF'T)

$X$. NITROGEN-15 CHEMICAL SHIFT DIFFERENCE BETWEEN SOME SUESTITUTED HETEROCYCLIC COMPOUNDS AND THEIF $N$-OXIDES .......... 124 
TAELE OF FIGUFES

\section{FART 2}

FIGUFE

F'AGE

I. FLOT OF STRUCTURE A MINUS FARENT

6-MEMEEF FIING VS. BFIIDGE NITFIOGEN

CHEMICAL SHIFT

OF $A \ldots \ldots \ldots \ldots \ldots \ldots \ldots \ldots \ldots \ldots \ldots \ldots \ldots$

II. NITROGEN-15 CHEMICAL SHIFTS VS. CAFEON-

13 CHEMICAL SHIFTS ............... 120 
PART :

I. HISTOFY OF THE FOLYAZAINDENES

A. Syntheses from Aminoazines.

The condensation of aminoazines with alghanbromocarbonyl compounds can, in principle, produce two different products. However, only one of the possible compounds is obtained, unless a Dimroth rearrangement occurs. The initial step in this process involves attacl: at<smiles>Nc1ccccn1</smiles>

I<smiles>O=C(O)C(=O)Br</smiles><smiles>CC</smiles><smiles>[R]c1nc2ccccn2c1[Hg]</smiles>

I I

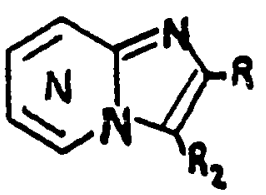

I I

the allgha-carbon of the halocarbonyl compound by the ring nitrogen of the aminoazine(I). This cyclization explains the substitution positions for imidazo[1,2a]pyridine (1).<smiles>Nc1ccccn1</smiles>

II I

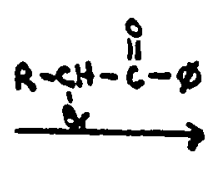<smiles>Oc1cn2ccccc2n1</smiles>

IV

Yoneda and coworl:ers prepared Z-amino-1-phenacylpyridazinium bromide (VI) by the condensation of aminopyridazine (V)<smiles>Nc1cccnn1</smiles>

v<smiles></smiles>

VI 
and phenacyl bromide (2). If both positions ortho to the amino-substitutent are nitrogens, then the possibility of the formation of isomeric products exists. The direction of this type of cyclization is controlled by the size of the substituents $\left(F^{-}-3\right.$ and $\left.F-4\right)$ and suggests that steric consideration contribute largely to the success of the eyclization process (3). The condensation yields may be increased by causing the reaction to occur in refluxing methanol, ethanol (3) or dimethylformamide in the presence of sodium bicarbonate (4). The reasons for the success these conditions do not appear to be clear.

The reaction of aminopyrazine (VII) with algha-halocarbonyl compounds results in relatively low yields of the imidazo[1,2a]pyrazines (VIII) (3). The use of alphaketoaldehydes in an acidic mixture (or formaldehyde and sodium cyanide) give better yields of the 3-substituted imidazo[1,2a]pyrazines (VIII) $(5,6)$.

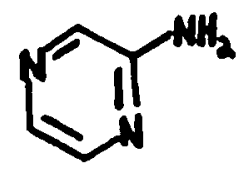

VII

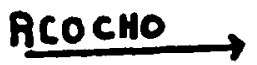<smiles>Oc1cnc2cnccn12</smiles>

VIII

The condensation of 2-aminopyrimidines (IX) with 3l1ghä-halocarbonyl compounds gives very good yields $160 \%-$ 80\%) of substituted imidazo[1,2a]pyrimidines (7). The direction of cyclization in 2-aminopyrimidines is controlled by the steric $(7 a, 8)$ and electronic (4) effects of the substi tuents. 

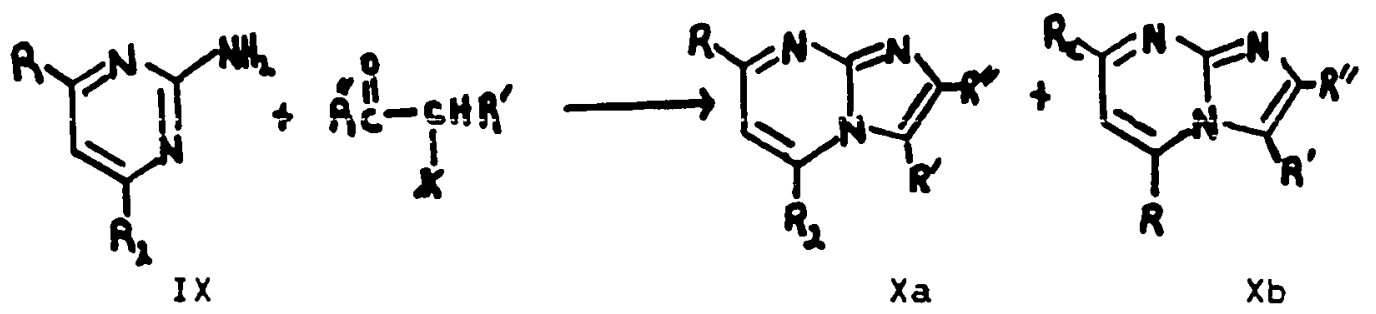

The reaction of 3-amino-1,2,4-triazine(XI) with 크hㅡㅡhalocarbonyl compounds can produce two different imidazo$1,2,4-t r i a z i n e s$ (XII,XIII) (9).

In deciding between assignments $\underline{X} \underline{I} \underline{I}$ or $\underline{X} \underline{I} \underline{I} \underline{I}$, Barton and Paudler obtained the proton NMR spectrum of the product produced by the reaction of 3-amino-5,6-dimethyl-1,2,4triazine(XI) with 3-bromo-2-butanone to produce $2,3,7,8$ tetramethyl-as-triazine (XII) or 2,3,5,6-tetramethyl-astriazine (XIII) (11). The proton NMR spectrum showed no
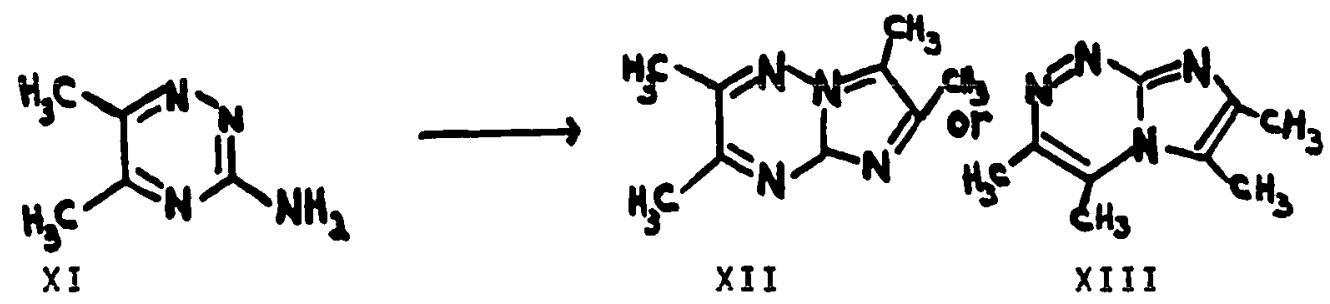

abnormal deshielding of the methyl groups. An observation which indicates that compound $\underline{X} I I I$ rather than compound $\underline{X} \underline{I}$ is formed since the peri-situated 3- and 5-methyl groups in XII would sterically interact causing a deshielding of both of the methyl groups (11). Similar cyclization of substituted 2-amino-s-triazine with 3-bromo-2-butanone by' Fusco and Rossi (9) and Loev and Goddman (10) eonfirm this interpretation 
B. Syntheses from Hydrazinoazines.

Cyclization of hydrazinoazine (XIX) with an activated one carbon cyclizing agents (i.e. ethyl orthoformate, ethyl

formate, diethoxymethyl acetate) is a direct and simple method for the synthesis of triazoloazines $(x x)$. However, the product produced in this reaction can rearrange to produce compound $\underline{x} \underline{x} \underline{I}$ vía a Dimroth rearrangement. This type of rearrangement is known to involve the breaking of the 4-5 bond in structure $\underline{x} \underline{x}$ (see Dimroth rearrangement).

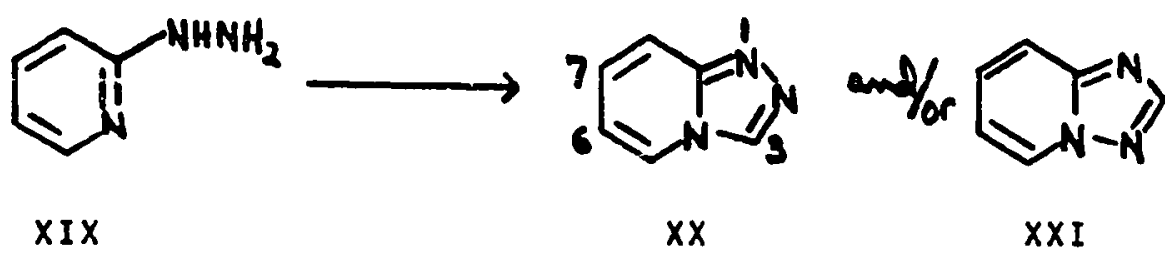

The cyclization of 2-hydrazinopyrimidine (XXII), 2hydrazino-1,3,5-triazine (XXV) and 3-hydrazino-1,2,4-triazine $(X X I X)$ with one carbon cyclization agents can produce two different products. The orientation of eyclization is influenced by the substituent and the reaction conditions. For example, the reaction of 3-hydrazino-5-hydroxy-6-methvl$1,2,4-t r i a z i n e$ with formic acid produces compound $\underline{x} \underline{x} \underline{x}$. When

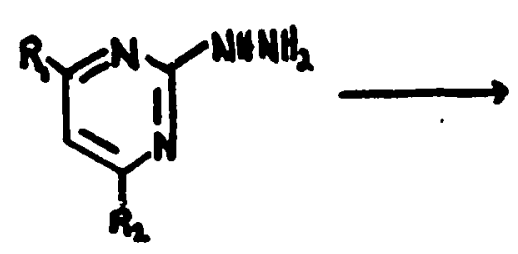

$X X I I$

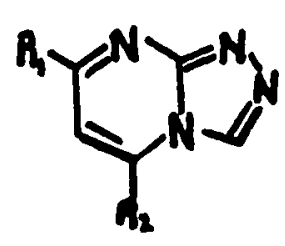

$X X I I I$

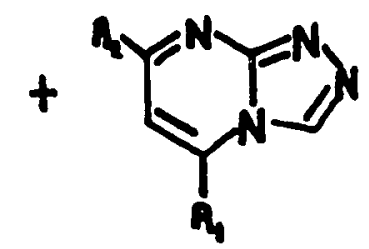

$X X I Y$ 
<smiles>CCPc1nc(P)nc(N(C)C)n1</smiles>

$X X V$

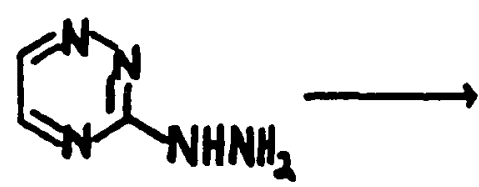

$X X I X$

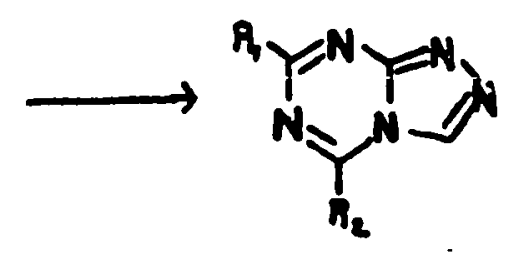

$X X V I$

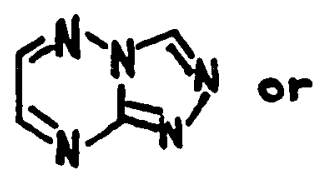

$x \times x$<smiles></smiles>

XXVI I

$\underline{X} \underline{x} \underline{I} \underline{X}$ is reacted under neutral conditions, compound $\underline{X} \underline{X} \underline{X} \underline{I}$ is produced(12). Cyelization of 2-benzylidenehydrazino-4methoxy-1,3,5-triazine $(X X X I I)$ is controlled by the steric and electronic effects of the methoxyl substituent and the major product is 7-methoxy-3-phenyl-1,2,4-triazolo[4,3a]$1,3,5-t r i a z i n e$ (13).

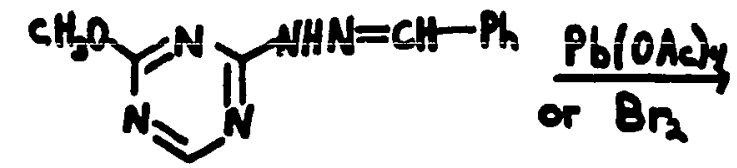

$X X X I I$

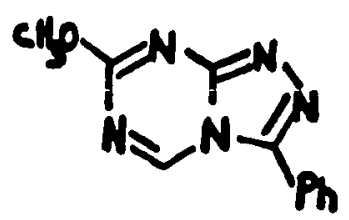

$x \times X I I 1$

Substitution at position 3 , in the pi-excessive ring of the triazoloazines, is controlled by the type of cyclization agent. For example, fromic acid and acetic anhydride produce the hydrogen- and methyl-derivatives, respectively. Other reagents that produce 3-hydrogen substitution are ethyl orthoformate, ethyl orthoacetate, or 
diethoxymethyl acetate. These compounds react under very mild conditions and thereby prevent the Dimroth rearrangement. However, these reagents can be used for the cyclization of hydrazinopyrazines (15) and hydrazinopyridazines (16). Condensation with cyanogen halides

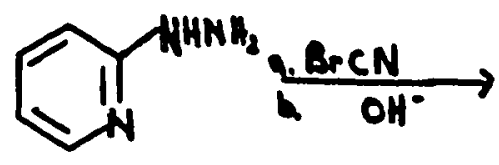

$X I X$<smiles>Nc1nnc2ccccn12</smiles>

$x x a$

at low temperature can produce the 3-aminotriazoloazines $(x \times a)(14,16,17)$. Similarly, the reaction of carbon disulfide, or the thermal decomposition of phenylisothideyanate Jerivatives (XIXa) produce the 3mercapto compounds $(X X b)(18-21,22 a)$.

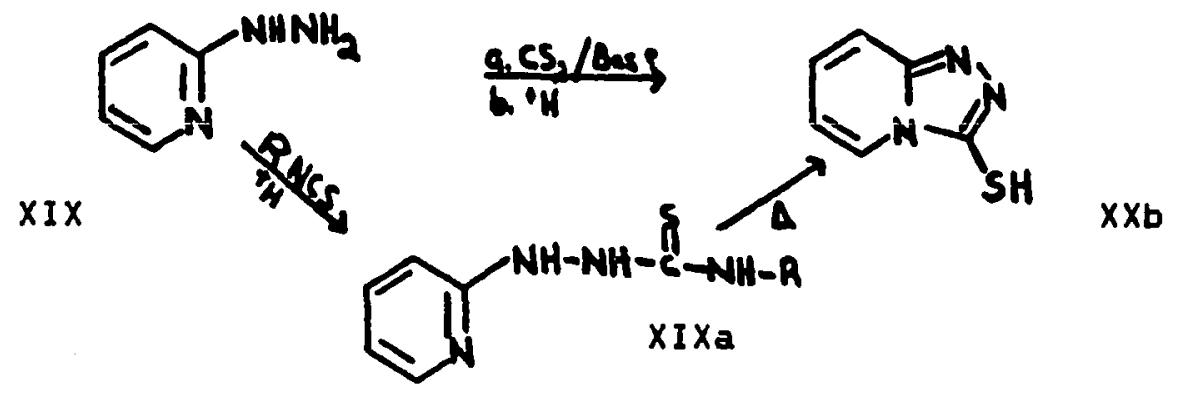

C. Dimroth Rearrangement

The Dimroth rearrangement is a general reaction which, when applied to appropriate polyazaindene rings, produces "different" azaindenes. This type of rearrangement can be base, acid, or thermally induced. 


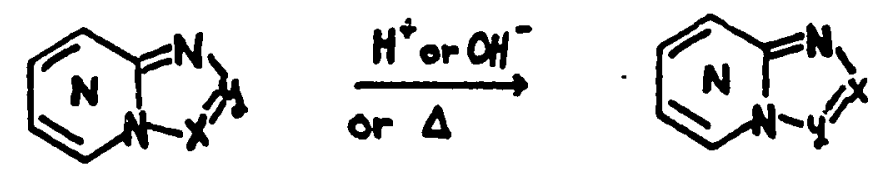

The generally accepted mechanism of the acid or basic catalyzed rearrangement involves the equilibrium-controlled<smiles></smiles>

XXI I I<smiles>OC1(O)C=CNc2nncn21</smiles>

$X X I I I a$<smiles>O=Cc1ccnc2ncnn12</smiles>

$X X I I I d$<smiles></smiles><smiles>[14C+]C1C=CC1</smiles><smiles>[Y14][R]C1(O)C=CNc2ncnn21</smiles>

covalent hydration at C-5. This is followed by tautomeric ring opening of the azine ring to a carbonyl intermediate (XXIIIb). Rotation of the 8-9 bond followed by cyclization produces the new polyazaindene structure (XXIIId) $(7 a, 22)$.

D. Biological and Medicinal Properties.

Only few polyazaindenes occur in nature. Alchernine, and alchornidine, which were isclated from Alchngrnea iavannensís are based on the hexahydroimidazo[1,2a]pyrimidine structure (23). The degradation of 


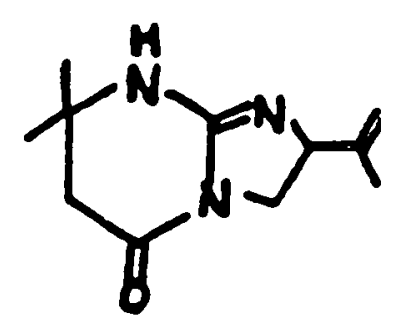

alchronine

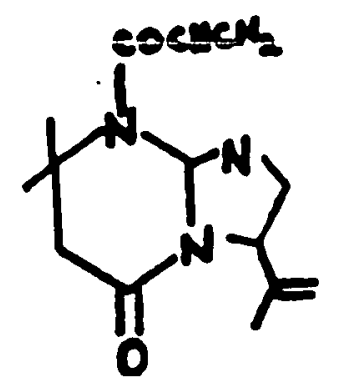

al chornidine

saxitoxin, a shellfish toxin isolated from Sazidgomus

giqantegus, produced a tetrahydropyrrolopyrimidine (24).

Based on the structural similarities with purine, many polyazaindene derivatives have been converted to their nucleoside counterparts. These derivatives held the potential of having biological activity due to their similarity with naturally occurring nucleosides. The anticancer activity of these nucleosides has been studied. Among the carbohydrate-base combinations that have been closely examined are the pyrazolo[2,3a]pyrimidine (26), $1,2,4-t r i a z o l o-[2,3 a]-$ and $-[4,3 a] p y r i m i d i n e(28)$ and $1,2,4-$ triazolo[2,3a]-1,3,5-triazine (27).

Table 1 gives the parent name and current uses of several polyazaindenes. These applications include both medicinal and industrial uses. 
II. HISTORY OF POLYAZAINDENE N-OXIDES

Syntheseses of Fol

Oxidation of polyazaindenes with potasium permangnate at room temperature yields substituted azoles (29).

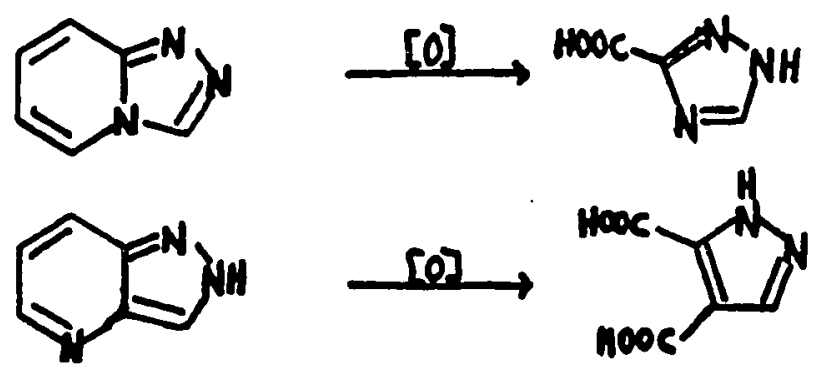

The oxidation of indolizines (pyrrolo[1,2a]pyridines) destrays the ring system and leads to algha-picolinic acid $\mathrm{N}$-oxide $(30)$.<smiles>c1ccn2cccc2c1</smiles><smiles>CC1CCC1</smiles><smiles></smiles>

In 1957, Lieber and coworkers found that orthonitrophenyl azides $(X X X I V)$ reacted with phenyl acetonitrile in the presence of sodium methoxide to produce $1,2,3-$ triazolo[5,16]1,2,4-triazine-5-oxide(XXXV) (31). Tennant repeated the reaction of 2-azidonitrobenzene with phenyl acetonitrile and concluded that the true product was the alternate structure $\underline{x} \underline{x} \underline{x} \underline{\underline{I}}$ (32). 


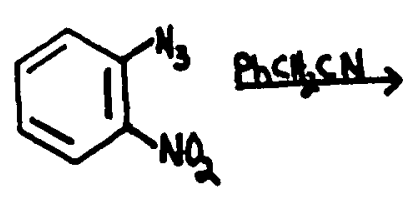

$X X X I V$

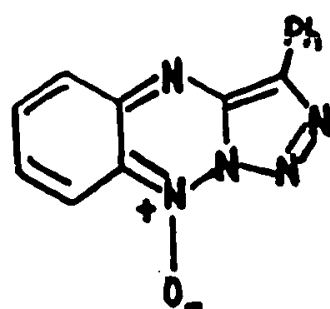

$x \times x V$<smiles>COc1ccccc1-n1nnc(O)c1N=Nc1ccccc1</smiles>

$X X X V I$

In 1968, the first parent polyazaindene $\mathrm{N}$-oxide was synthesized by Tisler and coworkers (33). The reaction of :hydrazinopyridazine-1-oxide(XXXVII) with diethoxymethyl acetate gave the 1,2,4-triazolo[4,36]pyridazine-5-oxide (XXXVIII)(33). Tisler also reacted the 3-hydrazinopyridazine-1-oxide(XXXVII) with different alkyl and aryl aldehydes to produce the corresponding alkyl-and arylidenes $(X X X I X)$. These alkylidenes $(X X X I X)$ and arylidenes $(X X X I X)$ can be oxidized with lead tetraacetate or bromine to

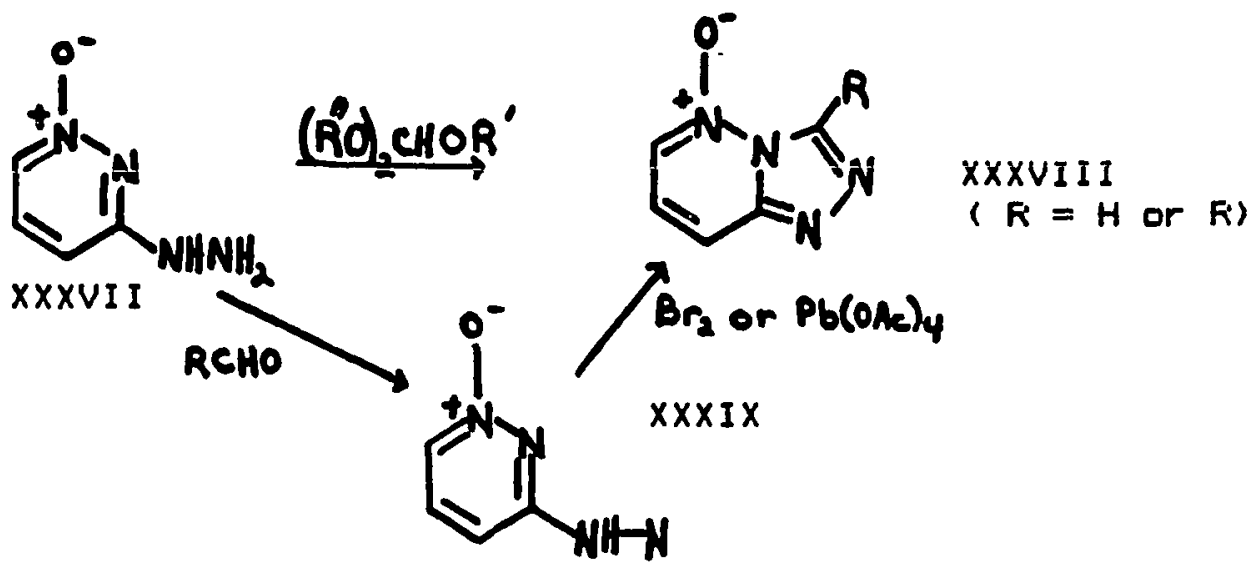

produce the 3-substituted triazolopyridazine N-oxides. Another synthesis of 3-substituted triazolopyridazines involved the direct cyclization of $\underline{x} \underline{x} \underline{x} \underline{\underline{I}} \underline{I} \underline{\underline{I}}$ with cyanogen bromide in the presence of triethylamine ( $X X X V I$ II, $R=N H 2)$ 
(33). Tisler and coworkers showed that ultraviolet irradiation or sunlight smoothly transformed the triazolopyridazine-N-oxides (XXXVIII) into the correspondilig 6-hydroxy-s-triazol o[3,4b]pyridazines. This rearrangement is

$X X X V I I$

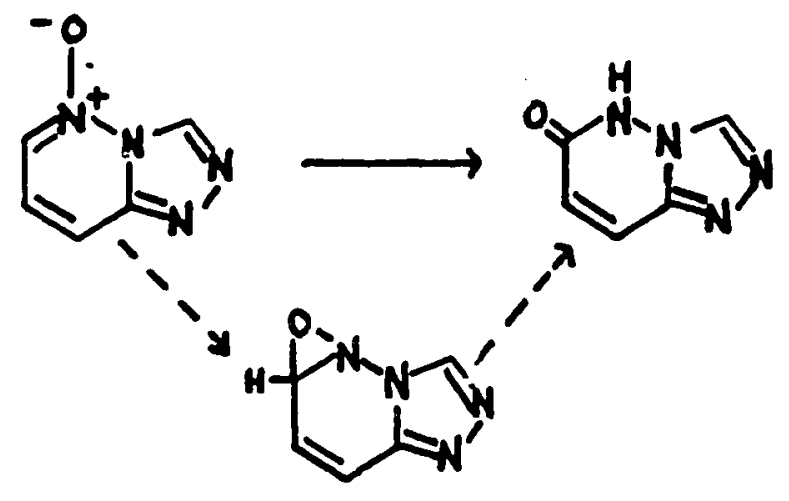

postulated to proceed through an oxaziridine intermediate (33).

In 1969, Glover and coworkers eyelized 1-12oximinoethyl)-2-(1,3-dioxolan-2-yl) thiazolium(XL) with sulfuric acid to produce thiazolo[2,3e]pyrazinium bromide-7oxide (XLI) (34).

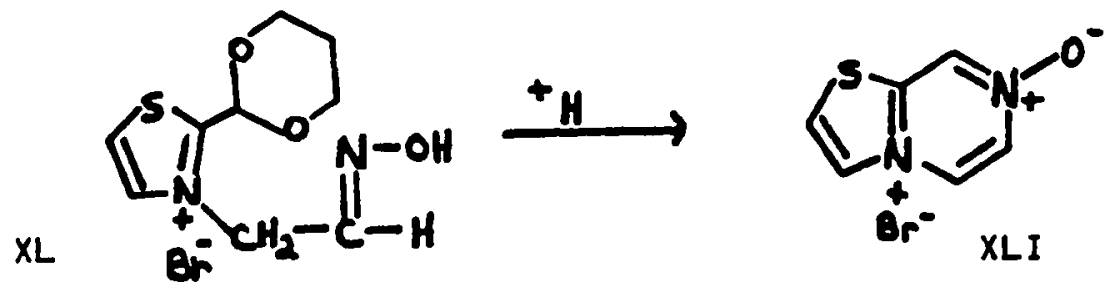

In 1970, Tisler and coworkers were able to oxidize the parent 1,2,4-triazolo[4,3b]pyridazine (XLII) with $90 \%$ hydrogen peraxide in polyphosphoric acid to produce $\underline{x} \underline{x} \underline{x} \underline{V} \underline{I} \underline{I} \underline{I}$ 
(35). This oxidation was also successful in converting imidazo[1,2b]pyridazine(XLIII) to the corresponding $\mathrm{N}$ oxide $(X L I X)$. Tisler and coworkers suggested that the role of the polyphosphoric acid might involve the uptake of water. rather than act as a proton donor or a Lewis acid.

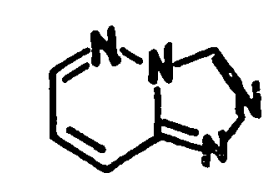

XLII<smiles></smiles>

XLI I I
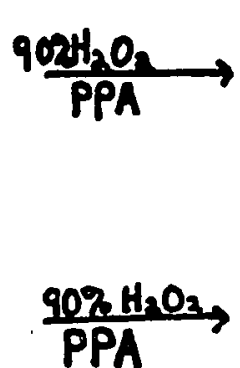<smiles>CO[C@H]1CC=Cc2nncn21</smiles>

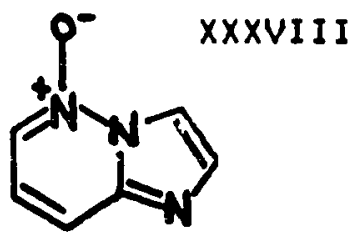

XLIV

The same workers demonstrated that several b-substituted polyazaindenes (XLV), when oxidized with $90 \%$ hydrogen peroxide in polyphosphoric acid produce the 6-substituted3-nitro-pyridazine-1-oxides (XLVI) (35).

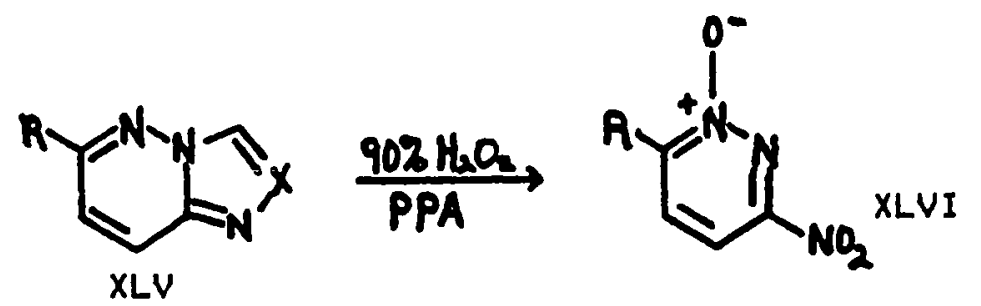

In 1973, Abushanab and coworkers reported the successful oxidation of imidazo[1,5a]pyrazine(XLVII) with meta-chloroperbenzoic acid in chloroform to give the imidazo[1,5c]pyrazine-7-oxide(XLVIII) (36). 


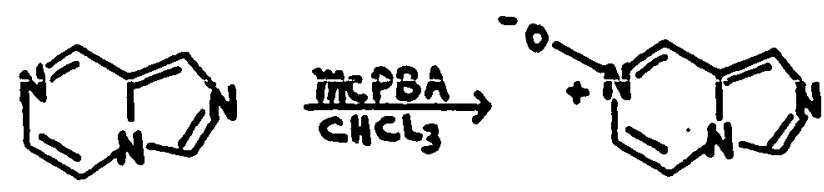

XLVIII

XLVI I

Attempts by Koshel and coworkers to prepare the $\mathrm{N}$ oxides of $1,2,4-$, and $1,2,3,4-a z$ oloquinoxalines $(X L I X)$ with hydrogen peroxide in acetic acid, alkaline potassium permanganate, or acidic chromic anhydride resulted in an unusual oxidation of C-4 rather than $\mathrm{N}$-oxidation. (37) Successful syntheses of these heteroaromatic $\mathrm{N}$-oxides were achieved by Cue and coworkers using the N-oxide<smiles>c1ccc2c(c1)ncc1nnnn12</smiles>

[0]

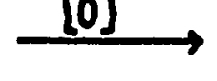

XLIX

precursors (3B). Cue and coworkers cyclized 3hydrazinoquinoxaline-1-oxide(L) with ethyl orthoformate to yield 1,2,4-triazolo[4,3c]quinoxal ine-5-oxide(LI, $x=C H)$. The S-hydrazino compound (L) was converted to the tetraazolo[1,5a]quinoxaline-5-oxide( $I, x=N)$ by a diazotiza-<smiles></smiles>

L<smiles></smiles> 
tion reaction in aqueous acetic acid (38). Cue and coworkers also synthesized the 1,2,3-triazolo[1,5a]quinoxal ine-5oxide by the treatment of LII with $e^{-}$ toluenesulfonylhydrazine in methanol to yield the tosylhydrazone(LIII). The reaction of LIII with sodium methylate in methanol gave 1,2,3triazol o[1,5a]quinoral ine (LIV) (38).<smiles>O=C(O)c1nc2ccccc2[n+]([O-])c1P</smiles>

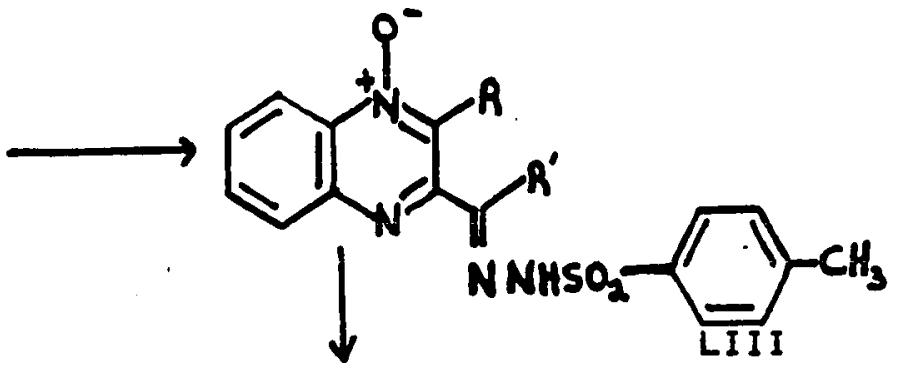

LI I<smiles>[R]c1nnn2c1c([2H])nn2-c1ccccc1[N+](=O)[O-]</smiles>

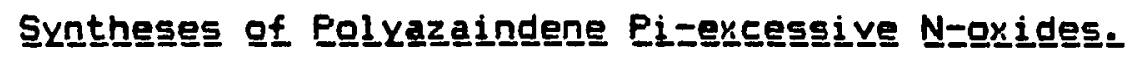

Rees and coworkers in 1974 were first to prepare. 2iexcessive polyazaindene $N$-oxides (39). They found that pyrido-and pyrimidino-5s-dimethyl sulphimides (LV) react with e-toluonitrile to give the $2-e-t o l y 1-1,2,4-t r i z o l o-$ [1,5a]pyridine-3-oxide (LVIa) and the 2-e-tolyl-1,2,4trizolo[1,5a]pyrimidine-3-oxide (LVIb), respectively (39). Fees and coworkers synthesized the 2-0-tolyl-1,2,4-triazolo- 
[1,5a]pyridine (LVIa) via a different method as an independent structure proof (39). This is shown in scheme 1.

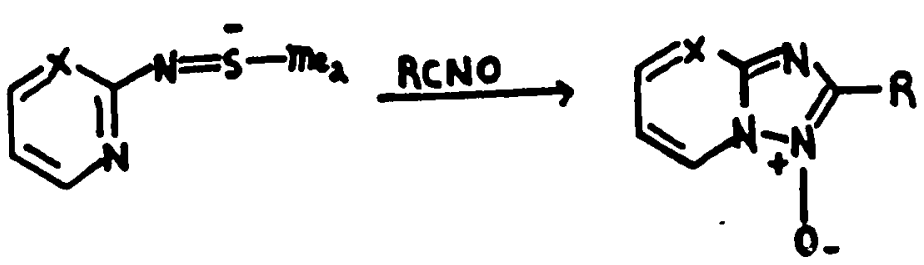
LVIa $(x=C H)$ $b(x=N)$

$\operatorname{LVa}(x=C H)$

$b(x=N)$

LVII

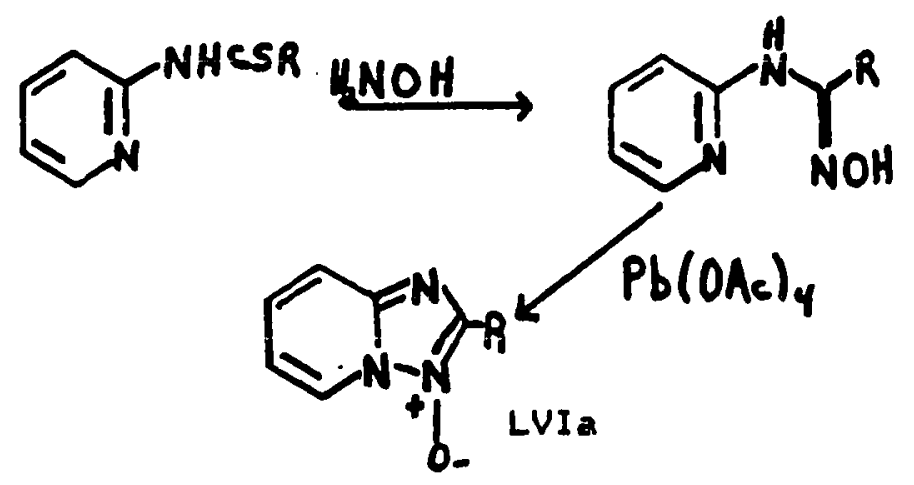

Scheme 1

Later. Rees expanded the reactions of the sulphimides to pyrazin-2-ylsulphimide (LVII) to produce 1,2,4-triazolo[1,5a]pyrazine-3-oxide(LIX) (40). The thermal stability of<smiles>[R14]C=C(CC)c1nc2cnccn2n1</smiles>

LVII 
eeri-substituted triazolopyridine-3-oxides was greatly reduced relative to the parent $\mathrm{N}$-oxides. Thus, when the triazolopyridine-3-oxides were heated under reflux in toluene, deoxygenation occurred after 7 to 8 hours (scheme 2) $(39,40)$. Temperature dependence was noted in the thermal treatment of 5,7-dimethyl-1,2,4-triazol o[1,5a]pyrimidine-5oxide. In this case the compound rearranges to "shift" methyl groups (scheme 3) (40).

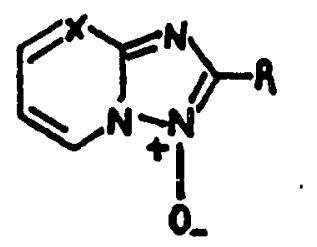<smiles>[R]c1nc2[Y4]cccn2n1</smiles>

Scheme 2

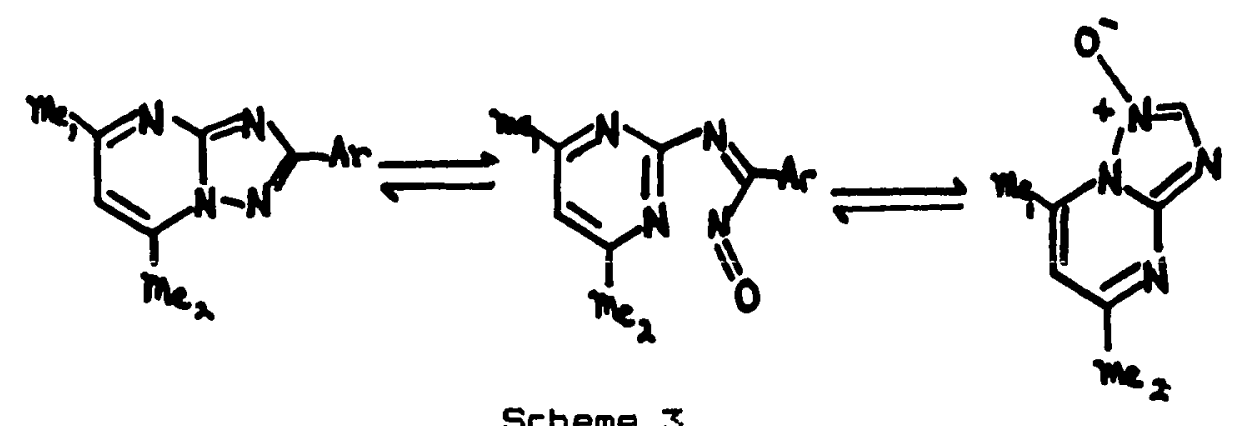

Tisler and coworkers found that when 6-chloro-3hydroxyiminomethyleneaminopyridazine(LXI) reacted with bromine in acetic acid buffered solution 6-chloro-1,2,4triazolo[1,5b]pyridazine-3-oxide(LX) was produced in high yield $(71 \%)(41)$. The oxidation of $L \underline{X} \underline{I}$ was also accomplished using an electrochemical method (42). 


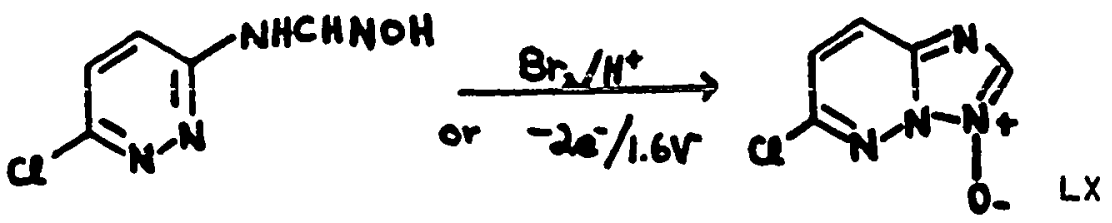

LXI

In 1978, Faudler and Hand produced 2phenyl imidazo[1,2a]pyridine-1-oxide(LXIII) from 2-bromo-1phenacylpyridinium bromide (LXII) and hydroxyamine hydrochloride (43). They noted that the ground state resonance contributing structure was not altered greatly by the presence of the $\mathrm{N}$-oxide function (see scheme 4).

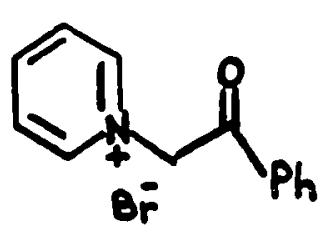

$\stackrel{\text { HNOH.HEL }}{\longrightarrow}$

LXII
LXIII

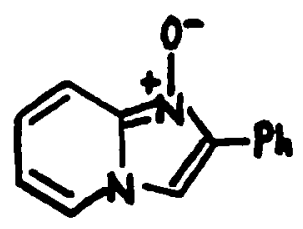

The presence of the $N$-axide function does not alter the reactivity of the imidazo[1,2a]pyridine system (see scheme 5) (43).<smiles>Oc1nc2ccccn2c1O</smiles><smiles></smiles> 


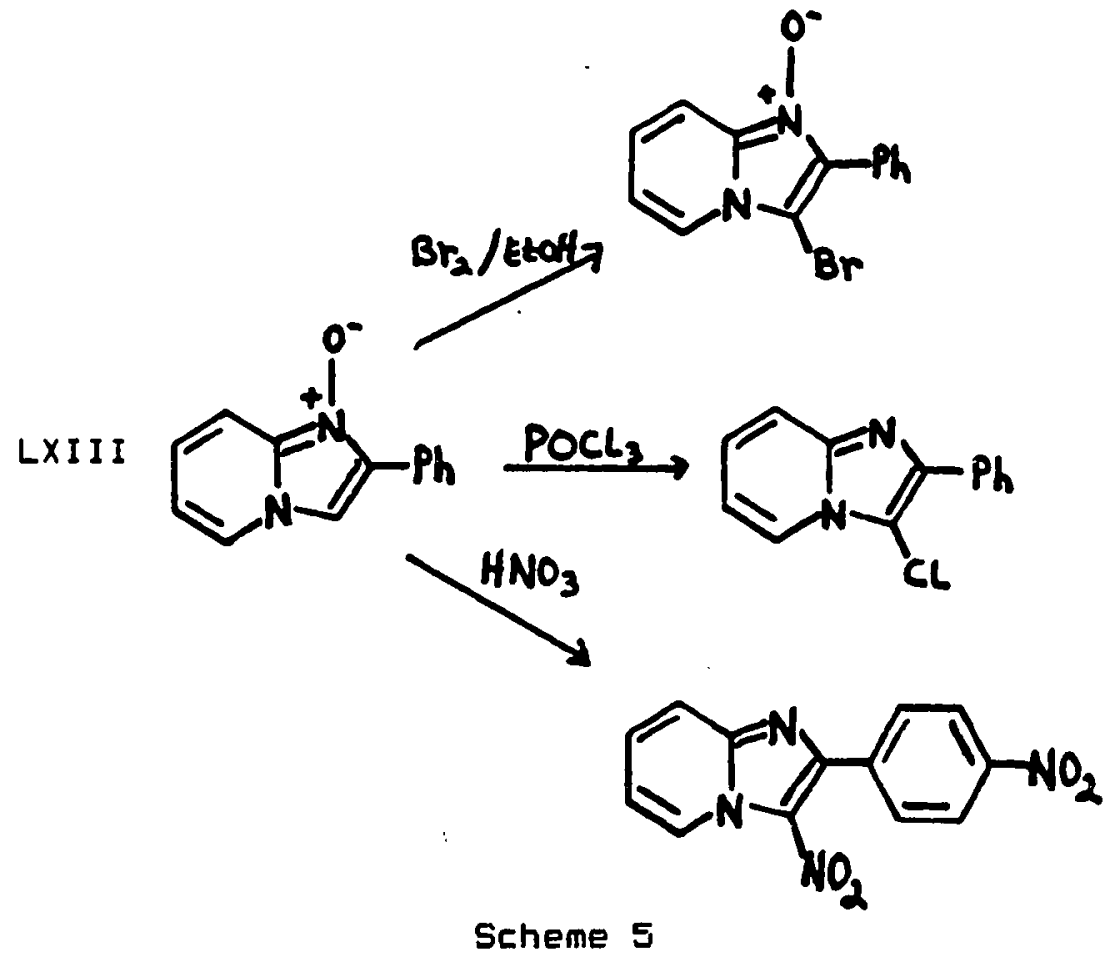

Miyasaka and coworkers prepared imidazo [1,2b]pyridazine-1-oxide (LXV) by reacting oxazolo[3,2b]Pyridazinium perchloroates (LXIV) with hydroxylamine (44).

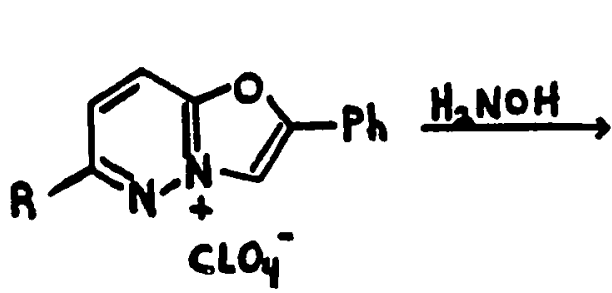

LXIV<smiles></smiles>

LXV

Miyasaka and coworkers examined the electrophilic substitution reactions of LXV and noted that these substitition reactions at position 3 were also not effected by the $\mathrm{N}$-oxide group (45). 
III. DISCUSSION

Faudler and coworkers have made numerous contributions to the field of polyazaindene chemistry. The ring systems that have been studied to date include imidazo[1,2,a]pyridine(LXVI), imidazo[1,5a]pyridine(LXVII), pyrazol o[ 1, 2a]pyridine (LXVIII), pyrrolo[1, 2a]pyrazine (LXIX), imidazo[1,2a]pyrazine (LXX), imidazo[1,2a]pyrimidine(LXXI), imidazo[1, Sa]pyrimidine (LXXII), $\quad$ s-triazolo[1,2]pyridine (LXXIII), s-triazolo[4,3a]pyrimidine(LXXIV), s-triazolo[1,5a]pyrimidine (LXXV), imidazo[1,2b]-as-triazine (LXXVI), and Imidazo[2, 1]-as-triazine (LXVII).

The chemistry of these polyazaindene systems has<smiles>c1ccn2ccnc2c1</smiles>

LXVI<smiles></smiles>

LXIX<smiles>c1cnc2cncn2c1</smiles>

LXXII<smiles>c1ccn2cncc2c1</smiles>

LXVII<smiles>c1cn2ccnc2cn1</smiles>

LXX<smiles>c1ccn2cnnc2c1</smiles>

LXXIII<smiles>c1ccn2nccc2c1</smiles>

LXVIII<smiles>c1cnc2nccn2c1</smiles><smiles>c1cnc2nncn2c1</smiles>

LXIV 
<smiles>c1cnc2ncnn2c1</smiles>

LXXV<smiles>c1cnn2ccnc2n1</smiles>

LXXVI<smiles>c1cn2ccnc2nn1</smiles>

LXXVII

been studied in detail. These studies include: syntheses, electrophilic reactions, protonation and methylation reactions, hyorogen-deuterium exchange, nuclear magnetic resonance, mass spectral work, and correlation of molecular orbital calculations with the experimental results.

The present research was begun for the purpose of gaining a basic understanding of the chemistry of the poorly understood polyazaindene $\mathrm{N}$-oxide series.

This investigation consists of the following research areas: (a) synthesis of the parent s-triazolo[3,4c]-asstriazine-7-oxide, s-triazolo[3,4c]pyrazine-7-oxide and $\mathbf{s}_{-}$ triazolo[3,2c]pyrazine-7-oxide (b) reactions of 3-hydrazinoas-triazine-1-oxide and 3-hydrazinopyrazine-1-oxide with different cyclization reagents (c) reaction of striazolo[3,4c]-as=triazine-7-oxide and s-triazolo[3,4c]pyrazine-7-oxide (d) synthesis and reactions of imidazo[1,2c]-pyrazine-7-oxide, (e) spectral information (NMR and Mass Spectra) of s-triazolo[3,4c]-as-triazine-7oxide, s-triazolo[3,4c]pyrazine-7-oxide, s-triazolo[3,2]pyrazine-7-oxide and imidazo[2,16]pyrazine-7-oxide. 
A second important purpose deals with the possible biological activity in these systems. Testing and evaluation will be done in subsequent studies by other workers. What follows represents efforts to accomplish these above goals.

Syntheses and Struuㅡtuuㅡㄹ Determination of the Fiarent s=

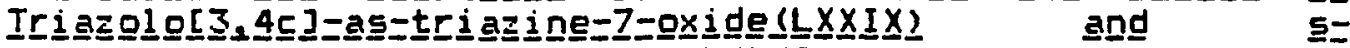

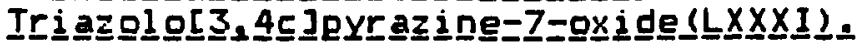

Synthesis of the s-triazolo[3,4c]-as-triazine-7oxide(LXXIX) was done by thermal cyclization of 3-hydrazinoas-triazine-1-oxide(LXXVIII) with diethoxymethyl acetate. The effect of the $\mathrm{N}$-oxide upon cyclization was not known prior to this work. Cyclization of 3-hydrazino-as-triazines is always to the $\mathrm{N}-2$ nitrogen. The only known synthesis for s-triazolo[3,4c]-as-triazine (LXXXIII) is cyclization of a substituted azole ring to form the azine ring (46).<smiles>NNc1nc[nH]n1</smiles><smiles>Cc1cn2cnnc2nn1</smiles>

LXXXIII

Several possibilities exist for preparing the cyclized product of 3-hydrazino-as-triazine-1oxide(LXXVIII). Cyclization of LXㅡㅁIII could occur at either N-2 or N-4 producing two different isomers. The potential 
exists that either of these compounds may undergo Dimroth<smiles>[R14][X]</smiles>

rearrangement of give s-triazolo[3,2c]-ass-triazine-7-

oxide $(L X X X I X)$ or s-triazolo[2,3b]-as-triazine-7-oxide (LXXXII). The only known cyclization of a 3-substituted-astriazine into the 4-position is that found for 2-methyl-3azido-as-triazine (LXXXV) (47). In all other reported cases cyclization has occurred at the $\mathrm{N}-2$ position.

The reaction of diethoxymethyl acetate with $3-$ hydrazino-as-triazine-1-oxide(LXXVIII) produces only one product in high vield. The elemental and mass spectral analysis showed the molecular formula to be CHND. The mass spectrum shows a parent peak of $137 \mathrm{~m} / \mathrm{e}$ and the facile 1055 of 16 mass units, the $\mathrm{N}$-oxide oxygen. This result points to the probable presence of the $\mathrm{N}$-oxide (51).

Comparison of the proton NMR spectrum with known structures was successful in determining the structure of this compound. Table 2 gives the proton NMFi data of several polyazaindenes and their $\mathrm{N}$-oxides, while table 3 gives the 
differences in the resonance positions for the s-triazoloand imidazo-compounds.

The normal deshielding of Eeri-hydrogens relative to the $\mathrm{N}$-oxides is approximately $0.5 \mathrm{ppm}$. This deshielding was first noted in the 1,8-naphthridine-1-oxide by Paudler and coworkers (48), and later by Tisler and coworkers (35). The effect on the chemical shift of the nç=Reri hydrogen by the $\mathrm{N}$-oxide is very small $(<0.1 \mathrm{ppm})$ and can occur in either direction. This latter small proton chemical shift is observed in the cyclization of the 3-hydrazino-as-triazine1-oxide (LXXVIII) (51). Consequently, eyclization in the reaction of 3-hydrazino-ag-triazine-1-oxide with diethoxymethyl acetate occured at the N-4 nitrogen (51).

Table 3 lists H-NMR chemical shifts of non-rearranged polyazaindene versus the Dimroth rearranged polyazaindene. The rearranged product has a typical proton chemical shift upfield by approximately of 0.5 to $1.2 \mathrm{ppm}$ for the azole hydrogen. In general the ngn-rearranged pol yazaindenes have typical azole proton chemical shifts of 9.25 ppm while the Dimroth rearranged product have a typical azole proton chemical shifts of 8.2 to 8.75 ppm. By comparison, the cyclized product from the reaction of 3-hydrazino-astriazine-1-oxide(LXXVIII) with diethoxymethyl acetate, has a azole proton chemical shift of. 9.28 ppm. This clearly establishes that the Dimroth rearrangement did not occur.

Final structure elucidation of the s-triazolo[3,4c]- 
as-triazine-7-oxide( $L X X I X)$ was accomplished by the preparation of a second polyazaindene $\mathrm{N}$-oxide. The reaction of 3-hydrazinopyrazine-1-oxide $(L X X X)$ with diethoxymethyl<smiles>NNc1c[n+]([O-])ccn1</smiles>
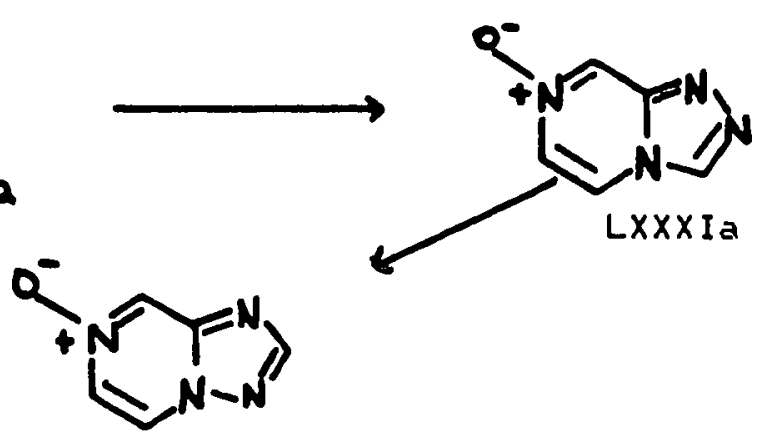

LXXXIB

acetate can produce either the s-triazolo[3,4c]pyrazine-7oxide(LXXXIa) or the s-triazolo[1,5e]pyrazine-7oxide(LXXXIIb) by the Dimroth rearrangement. The product obtained has the correct empirical formula, C H N O based on elemental analyses. The mass.spectrum as anticipated for a N-oxide shows a M-16 ion (the loss of axygen). The mass spectrum has a base peak due to the parent ion. The proton nuclear magnetic resonance spectrum contains a singlet at $9.21 \mathrm{ppm}$ and an $\mathrm{ABX}$ pattern at $7.79 \mathrm{ppm}, 8.74 \mathrm{ppm}$ and $9.14 \mathrm{ppm}$. The proton chemical shift of the singlet is in agreement with g-triazolo[3,4ᄃ]pyrazine-7-oxide (LXXXIa), rather than the s-triazolo[1,5c]pyrazine-7-oKide (LXXXIb). These chemical shifts are in agreement with the structure assigned to the product formed by the eyclization of 3hydrazino-as-triazine-1-oxide(LXXVIII) with diethoxymethyl acetate $(51)$. 
Additionai information was obtained when the $\underline{s}-$ triazolo[3,4c]pyrazine-7-oxide(LXXXIa) was treated with aqueous hydrochloric acid. On treatment with 1 normal hydrochloric acid in ethanol, the triazolopyrazine-N-oxide<smiles>[O-][n+]1ccn2cnnc2c1</smiles>

LXXXI
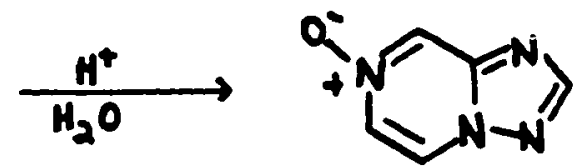

LXXXII

undergoes the Dimroth rearrangement to the striazolo[3,2c]pyrazine-7-oxide(LXXXIb). The proton NMR spectrum of this compound contains a singlet at $8.62 \mathrm{ppm}$ and exhibited an ABX pattern at $9.06 \mathrm{ppm}, 8.03 \mathrm{ppm}$ and $9.11 \mathrm{ppm}$ (51). Hence these $\mathrm{H}-3$ proton shifts are in excellent agreement with the predicted resonance position (see table 2).

Qther Fegactions of 3-Hydrazing=as=Triazinge=1=oxide and Exrazinge=1=gxiㅁㅁㅡ.

The reaction of 3-hydrazino-as-triazine-1oxide(LXXVIII) with formic acid yields 3-formylhydrazino-astriazine-1-oxide(LXXXVIa). This cyclization may be hindered by the protonation of the $\mathrm{N}-4$ nitrogen in an acidic reaction medium. Similar results are obtained with formic acid and $\mathbf{3}-$ hydrazinopyrazine-1-oxide $(L X X X)$. However, the cyclization can be completed by heating with 3-formylhydrazinopyrazine1-oxide(LXXXVIb). The product obtained has an identical retention time when applied to a thin layer chromatographic 
<smiles>C[N+]1([O-])CC=NC(NN)=N1</smiles>
LXXVI I I

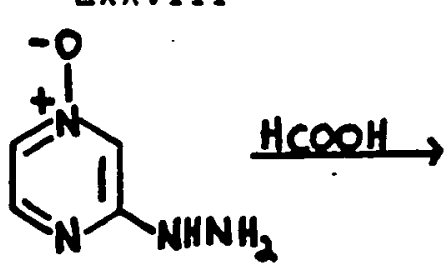

$\operatorname{LXXX}$
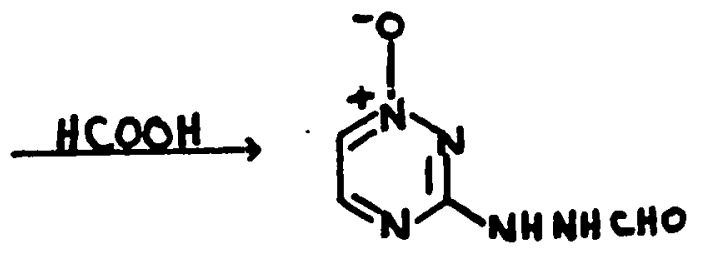

LXXXVIa<smiles>COCc1cnc(C)cc1OC</smiles>

LXXXVIb

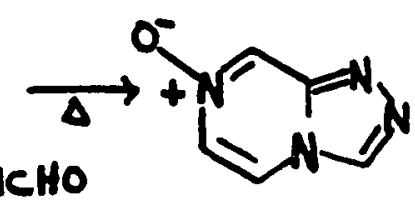

LXXXIa

plate as a known sample of s-triazolo[3,4c]pyrazine-7oxide (LXXXI).

The reaction of 3-hydrazino-gs-triazine-1oxide(LXXVIII) with benzaldehyde in acetic acid affords 3benzylidenohydrazino-as-triazine-1-oxide(LXXXVII). This benzylidene product was treated with lead tetraacetate in an unsuccessful attempt to complete the cyclization. It returned the benzylidino compound unchanged! A similar, attempted cyclization of the 3-benzylideno compound with

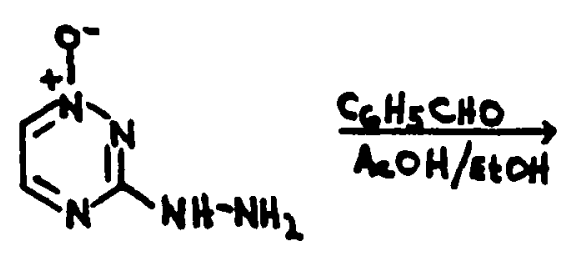

LXXVIII

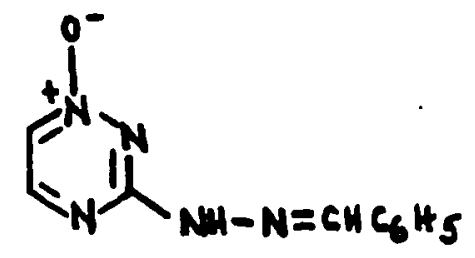

LXXXVII

bromine in acetic acid and sodiun acetate also failed. The reaction of 3-hydrazinopyrazine-1-oxide(LXXX) with 
benzaldehyde produces 3-benzylidenohydrazinopyrazine-1oxide(LXXXVIII). Cyclization to the corresponding bicyclic compound was not achieved by using iead tetraacetate or bromine in acetic acid.

The reaction of 3-hydrazino-as-triazine-1oxide(LXXVIII) with acetaldehyde did not produce the expected methyl ideno compound but instead produces the 2,3dihydro-3-methyl-g-tri azol o[3, 4c]-as-triazine-7-oxide $(L X X X I X)$. There are two features of the NMR spectrum that show this cyclization occurs without aromatization. The first is the proton ehemical shifts of 3-benzylideno(LXXXVIII), 3-formy1-(LXXXVIb) pyrazine-1-oxide, 3benzylideno-(LXXXVII) and 3-formyl-(LXXXVIa) -as-triazine1-oxide (see table 4). The proton resonance positions of the formyl and benzylideno protons are about $8.50 \mathrm{ppm}$, whereas the proton chemical shift of the product formed from acetaldehyde with 3-hydrazino-as-triazine-1-oxide (LXXVIII) is at $7.60 \mathrm{ppm}$. This indicates that the chemical environment

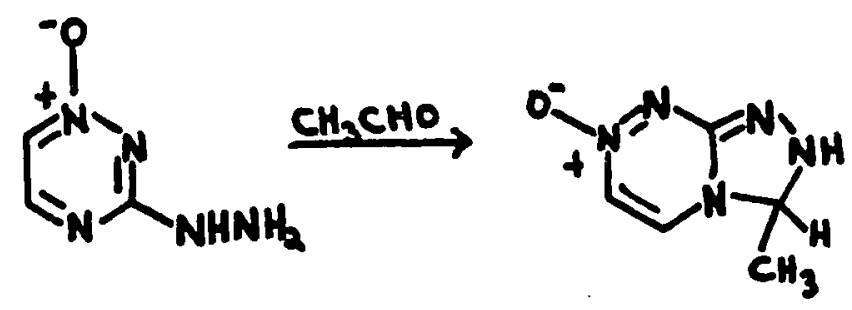

LXXVII

LXXXIX

is different for the normally observed proton chemical shifts for the derivatives of 3-hydrazino-as-triazine-1oxide. The second is the proton resonance positions of the 
ring protons and the differences between these chemical shifts are given below (see table 4). With the 3-hydrazinoas-triazine-1-axide derivatives there is a difference in the proton chemical shifts of $0.5 \mathrm{ppm}$ for the aromatic protons, $(H-5)-(H-6)$. The chemical shifts for $\mathrm{H}-5$ and $\mathrm{H}-6$ of the methylideno compound are 7.63 and 8.30 , respectively. The difference, $(\mathrm{H}-5)-(\mathrm{H}-6)$, is $-0.67 \mathrm{ppm}$, which is greater than expected, represents an upfield shift (increased shielding). This shielding effect is due to the change or $105 s$ of the azine ring aromaticity. These results rule out that the compound is the methylideno derivative.

The reaction, of 3-hydrazino-pyrazine-1-oxide(LXXX) and -as-triazine-1-oxide(LXXVIII) with phenyl isothiocyanate produces the expected 3-(4-phenylthiosemicarbizide)pyrazine-1-oxide(XCa) and as-triazine-1-oxide(XCb). This is

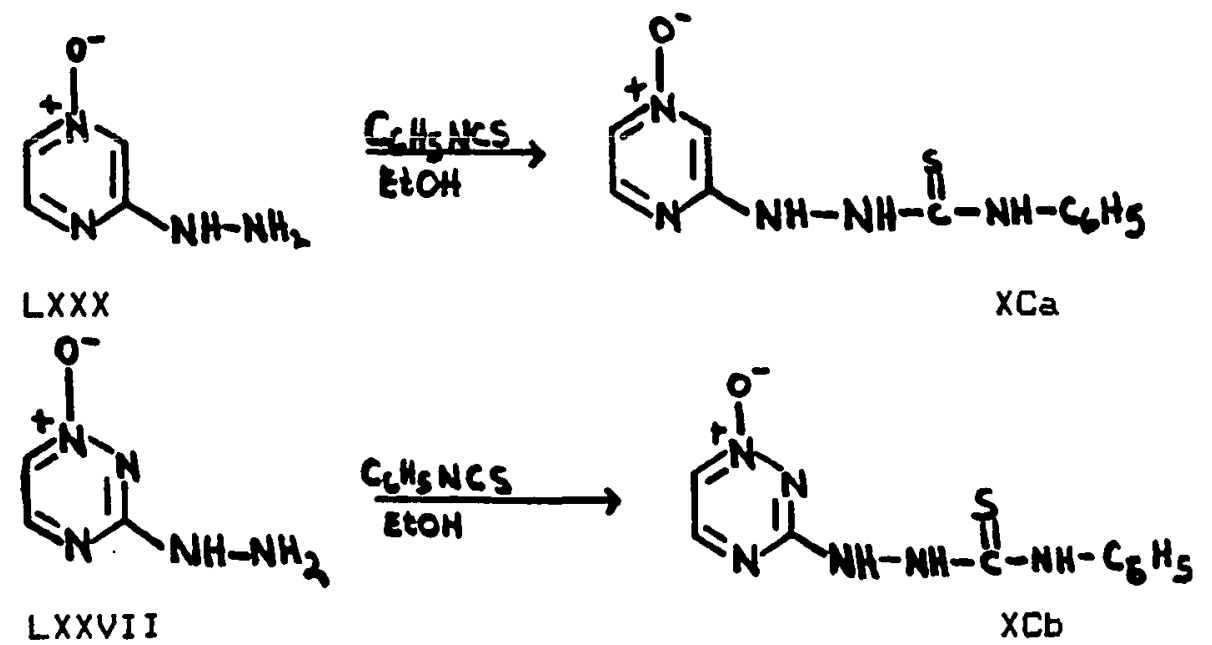

shown in Table 4. The thermal decomposition of these compounds did not produce either of the expected cyclized 
products. These reactions need to be examined further!

The reaction of cyanogen bromide or carbon disulfide in the presence of base with 3-hydrazino-pyrazine-1oxide $(L X X X)$ or ass-triazine-1-oxide(LXXVIII) failed to produce the 3-amino or the 3-mercapto derivatives, respectively.

The reaction of the 3-hydrazino-5-phenyl-as-triazine1-axide(XCI) with diethoxymethyl acetate produces 2,3dihydro-3-ethoxy-5-phenyl-s-tri azol o[3,4c]-ass-tri az ine-7oxide(XCII); cyclization without aromatization in this case

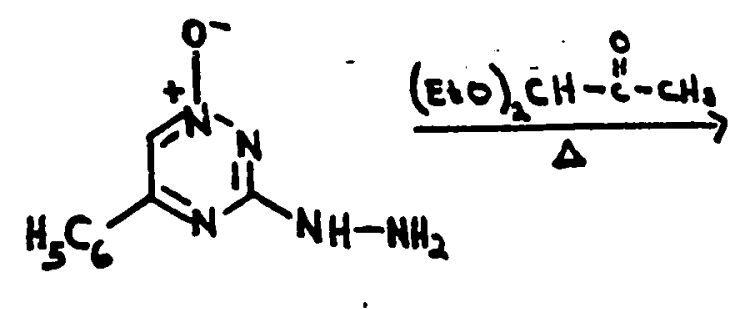

$X C I$

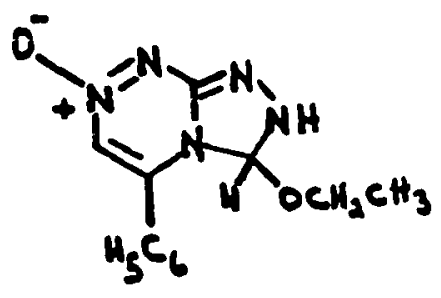

XCI I<smiles>COc1cnnc2nnc(OC)n12</smiles>

XCI I I<smiles></smiles>

XCIV

may be a result that the $\mathrm{N}$-oxide group can not participate in the removal of the ethoxy group without opening the triazole ring. Attempts to aromatize the azole ring with $10 \%$ palladium on carbon were successful but at the expense of the $N$-axide. The loss of the $N$-axide is the result of the failed aromatization allowing deoxygenation by the $10 \%$ 
palladium on carbon. The resulting products are 3-ethoxy-5phenyl-s-triazolo[3,4c]-as-triazine(XCIII) and $2,3-$ dihydro-3-ethoxy-5-phenyl-s-triazolo[3, 4c]-astriazine (XCIV).

The formation of the 3-acetylhydrazino-ass-triazine-1oxide (XCV) and 3-acetylhydrazino-5-phenyl-as-triazine-1-<smiles></smilesLXXVIII<smiles></smiles>

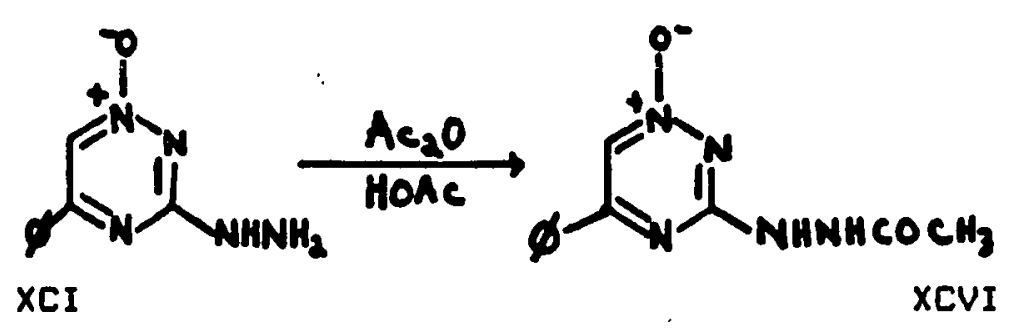

oxide(XCVI) occurs via the reaction of acetic anhydride in triethyl orthoformate with 3-hydrazino-as-triazine-1-oxide or in ecetic acid with the 5-phenyl deriyative, respectively. Further attempts to cyclize the acetyl derivative failed causing decomposition.

REACIIQNS OF S-TEIAZQLQ[3,4C]FYRAZINE=7=QXIDE AND S=

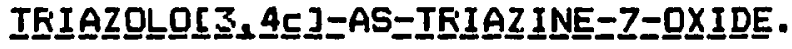

A variety of reactions was studied using triazolopyrazine-N-oxide and triazolotriazine-N-oxide. Unfortunately, the expected product was not obtained. A few of the reactions will be mentioned and all will be listed in the experimental section. 
The deuterium exchange of the $\mathrm{H}-3$ proton has been well documented by Faudler's research group (49). The attempted exchange of the triazolopyrazine-N-oxide and the triazolotriazine-N-oxide results in the uniform disappearance of all chemical shifts in the proton NMR spectrum. The disappearance of the proton chemical shifts can be explained in two ways. The first way suggests that all protons are exchanging at an equal rate. Secondly, the bicyclic compounds may be decomposing.

The latter process is correct since the bicyclic compounds could not be isolated from the reaction vessel after the "exchange" experiment.

All attempts to study the reaction of triazalopyrazine N-oxide or triazolotriazine $N$-oxide with electrophilic reagents failed and resulted in product decomposition. The most probable cause for the decomposition was that most electrophilic agents were generated in water or water was employed during the reaction workup. This water usage, under basic conditions, may start the Dimroth rearrangement which may lead to sample decamposition in either products or reactants. It has been observed that the addition of base to hydrazino compounds produced a red color when the $\mathrm{pH}$ of the system exceeded 6. Attempts to recover any organic material from the basic solution failed. Spectral evidence showed the loss of bicyclic system ( NMR and mass spectrum) and 
replacement with some type of amino or imino compound (infrared spectrum).

Attempts to deoxygenate the $\underline{s}$-triazolo[3,4c]-agstriazine-7-oxide(LXXIX) with triethyl phosphite or many other deoxygenation reagent (see experimental section) failed to produce the non-oxide derivative. One possible explanation is that a very strong $N-O$ bond (a 1 arge amount of backbonding) exists in these compounds.

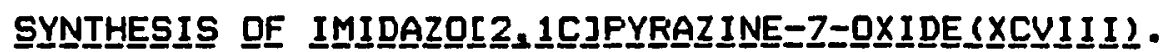

The direct oxidation of the imidazo[2,1c]pyrazine with meta-chloroperbenzoic acid in chloroform is successful. This type of reaction is unusual because most attempts to oxidize the bicyclic rings of 'indolazine-like" or "indene-1ike" structures result in the cleavage of the azole ring (29). Only two other cases of this direct type of oxidation have been reported (see Historical Section).<smiles>c1cn2ccnc2cn1</smiles>

XCVII

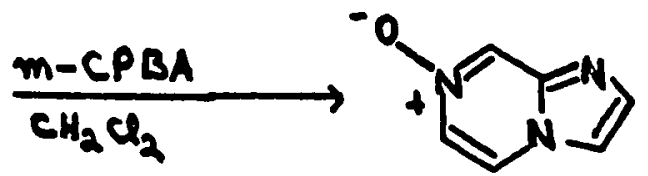

XCVIII

FEACIIQNSS OF IMIDAZQL 2, 1C]PYEAZINE=7=QXIIDE.

As with s-triazolo[3,4]- pyrazine-7-oxide(LXXXI) and -as-triazine-7-oxide $(L X X I X)$, the attempted electrophilic substitution of imidazo[2,1C]pyrazine-7-oxide(XCVII) resulted in sample decomposition. This behavior is 
consistent with the three other polyazaindene-N-Oxides discussed earlier and suggests that the $N-O$ bond facilitates the decomposition of the polyazaindene $N$-oxides.

Attempts to deoxygenate the imidazo[2,10]pyrazine-7oxide were unsuccessful and resulted in the decomposition of the bicyclic ring system.

NUCLEAF MAGNETIC FESONANCE AND MASS SFECTRA INFORMATION QN

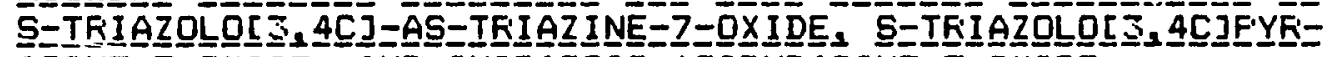

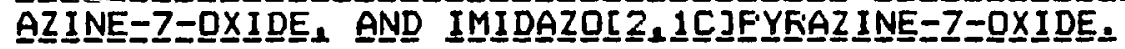

MASS SFECTRAL INFORMATION.

The mass spectra of all polyazaindene have one fragmentation pattern in common, the base peak (100\%) is the molecular ion peak $(M+)$. The large $M+$ peak may well reflect the stability caused by the aromatic properties of the bicyclic ring system. In the case of the parent systems of triazolopyrazine and triazolotriazine, the base peaks are at $136 \mathrm{amu}$ and $137 \mathrm{amu}$, respectively. This is followed by

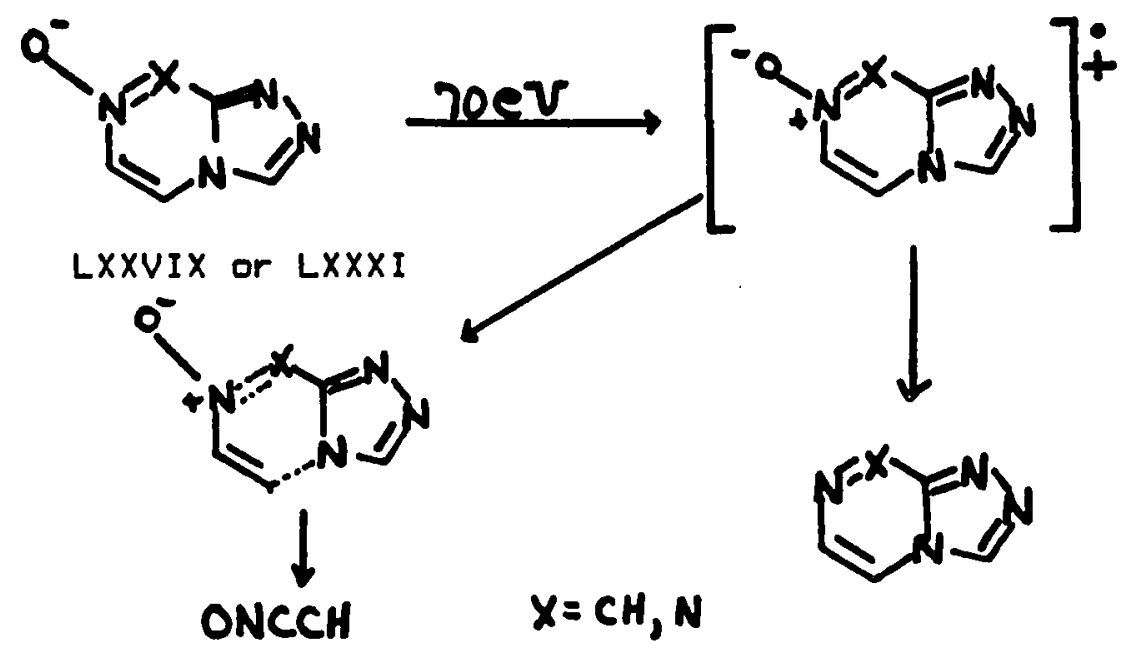


the loss of 16 amu which is the cleavage of the $N-O$ bond. Neither the triazolopyrazine N-oxide nor the triazolotriazine $N$-oxije have a large M-16 peak $112.7 \%$ and $20.9 \%$, respectively).

The major pathway for cleavage of triazolo- Fyrazine$\mathrm{N}$-oxide and triazine $\mathrm{N}$-oxide is through the azine ring. Eoth the triazolopyrazine and triazolotriazine $\mathrm{N}$-oxides have a M-5s 10s5. This loss represents the cleavage of the 7-8 bond ( glgha to the $N-\square$ bond ) and the splitting of the 4-5 bond (gammma to the $\mathrm{N}-\mathrm{O}$ bond which is alpha to the bridging nitrogen at position 4 ). This results in the loss of the HCCNO fragment which "leaves" only the azolo ring system.

The remaining fragments are caused by the decomposition of the azole ring system and are not identified.

NUCLEAR MAGNETIC RESONANCE SFECTRAL INFOFMATION

The proton nuclear magnetic resonance spectra of seven polyazaindenes $\mathrm{N}$-oxides have been determined by this study and compared in part with the results obtained by other workers. These proton NMR data are compiled in table 4.

An interesting change that occurs between the parent compound versus the $\mathrm{N}-$-oxide is the characteristic shielding effect of the $N$-axide on the grtho protons. This effect has been examined and described by Paudler and coworkers for a number of b-membered heteroaromatic compounds (50). The typical shielding of $0.23-0.50 \mathrm{ppm}$ for the H-B proton is 
also seen in the polyazaindene structures. A similar shielding effect ( 0.04 to $0.65 \mathrm{ppm})$ is found for the $\mathrm{H}-6$ proton. These shielding effects are within the range of shifts proposed by Paudler and coworkers for the six membered heteroaromatic systems (50). These chemical shift differences suggest that these compounds have similar degrees of $\mathrm{N}$-oxide backbonding.

The proton meta in these $\mathrm{N}$-oxides is deshielded by 0.5 to $0.76 \mathrm{ppm}$. This shift is not seen in the proton chemical shifts in azines, but is observed in Carbon-1: chemical shift values ( 50 ). This deshielding effect observed here may be in part due to electonegative induction from the bridging ortho nitrogen.

The proton NMF chemical shifts of the azole ring of the polyazaindenes shows a small deshielding effect for the $\mathrm{N}$-oxidation of the azine ring. The $\mathrm{H}-2$ chemical shift differences are larger than the $\mathrm{H}-3$ shifts $\mathrm{H} H-2,0.12$ to $0.25 \mathrm{ppm} ; \mathrm{H}-3,0.00$ to $0.15 \mathrm{ppm})$. This is unexpected since a reasonable resonance form can be drawn that places a negative charge on the carbon at position $3(\mathrm{H}-3$ is the
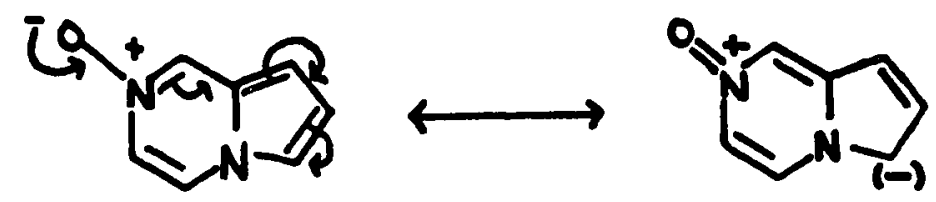

position that is substituted by electophilic reagent in the polyazaindene series). The deshielding effect observed here 
does not cause failure of the electrophilic substitution but indicates a decreased reactivity.

The H-2 proton resonance position deshielding effect may be due to a long range inductive effect caused by the N-axide function.

This study has produced shielding and deshielding parameters for polyazaindene system after $\mathrm{N}$-oxidation. These shifts are tabulated in table 4 and are as follows:

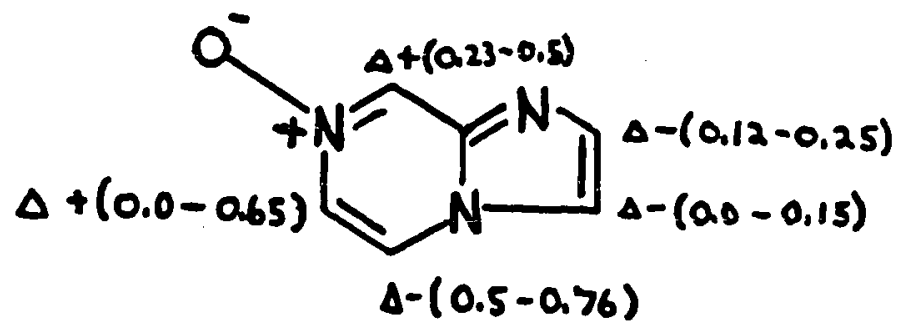


IV. EXFEFIMENTAL

Melting points were taken with a Thomas Hoover capiliary apparatus and are uncorrected. H-NMF specta were recorded with a Varian HA-10O spectrometer. Mass spectra were obtained with a Hitachi Perkin-Elmer FMU-GM instrument equipped with a solid-sample injector and employing an ionizing voltage of $70 \mathrm{eV}$. Elemental analyses were determined by The Analytical Services Laboratory of the University of Alabama, Chemistry Department.

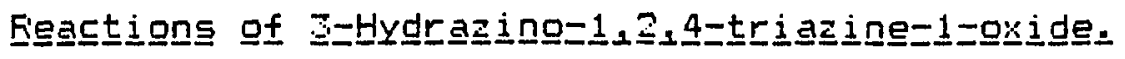

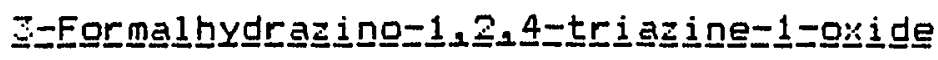

A solution of 0.202g $(0.0016$ mol.) J-hydrazino-1,2,4triazine-1-oxide in formic acid was heated for two hours on a steam bath. The yellow solution was allowed to cool to room temperature and the excess formic acid was removed under vacuum to dryness. The remaining dark yellow oil was dissolved in water and the solution was neutralized with sodium carbonate. The water solution was then continuously extracted with methylene chloride for 72 hours to yield a light yellow solid (m.p. 176-178 C, 82\% yield)

Anal. CHN: found C $30.95 \% ; H 3.37 \%$ N $46.7 \%$;

calculated for C H N D : C $30.98 \%$ H $3.22 \% ; N 45.15 \%$. 4552

Mass spectral data: parent, $\mathrm{m} / \mathrm{e} 155 ; \mathrm{m} / \mathrm{e} 127(-28)$

loss of $\mathrm{CO}$; $\mathrm{m} / \mathrm{e} 112(-44)$ loss of HNCHO; $\mathrm{m} / \mathrm{e} 97(-59)$ loss of $\mathrm{NH}-\mathrm{NH}-\mathrm{CHO}$.

$$
\text { H-NMF : } 8.78 \text { ppm(doublet), } 8.47 \text { ppm(singlet), } 8.27
$$
ppm(doublet). 


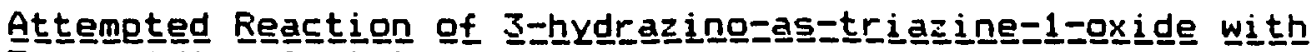

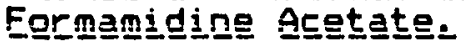

Formamidine acetate $0.163 \mathrm{~g}(0.00157 \mathrm{~mol})$ was added to

$0.200 \mathrm{~g}(0.00157 \mathrm{~mol})$ of 3-hydrazino-as-triazine-1-oxide in $25 \mathrm{~mL}$ of distilled water. The resulting solution was refluxed over a steam bath for 48 hours. The remaining water was removed under vacuum and the remaining yellow solid was collected by vacuum filtration. This material was placed in a sublimation apparatus at $60 \mathrm{C} / 0.5 \mathrm{~mm} \mathrm{Hg}$. The sublimate when analyzed by mass spectroscopy and NMFi proved to be the starting material with trace amounts of 3 formyl hydrazino-1, 2, 4-triazine-1-oxide.

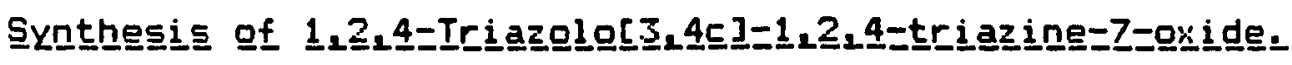

To $0.7 \mathrm{~mL}(0.004 \mathrm{~mol})$ of diethoxymethyl acetate was added $0.200 \mathrm{~g}(0.00157 \mathrm{~mol})$ of 3-hydrazino-1,2,4-triazine-1oxide. This solution was heated on a steam bath for 10 minutes and cooled to room temperature. The crystals which separated were collected by vacuum filtration and washed with absolute ethanol and air dried lyield 193mg, $90 \%$, m.p. 190-191 C (decomp)).

Anal. found: carbon $35.02 \%$ ihydrogen $2.31 \%$ initrogen $50.33 \%$ calculated for CHN D: carbon 35.03\%; hydrogen 435

$2.18 \%$; nitrogen $51.09 \%$.

Mass spectral data: $m / e-137 \mathrm{M}+\mathrm{m} / \mathrm{e}-121(-16) 1055$ of oxygen.

H-NMFi.Spectral data: 8.1 ppm. (doublet), 9.1 ppm. 
(doublet), 9.2 ppm. (singlet).

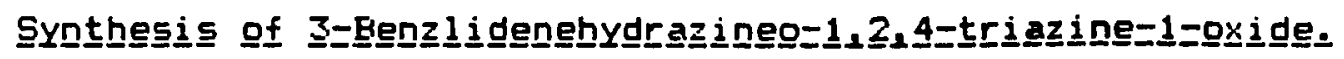

3-Hydrazino-as-triazine-1-oxide, $0.127 \mathrm{~g}(0.001 \mathrm{~mol})$,

was suspended in $30 \mathrm{~mL}$ of absolute ethanol. To this suspension was added $5 \mathrm{~mL}$ acetic acid. The resulting clear

solution was then heated on a steam bath. To the hot solution was added $0.120 \mathrm{~g}(0.001 \mathrm{~mol})$ of benzylaldehyde in 5 $\mathrm{mL}$ of ethanol. The solution was lightly refluxed over a steam bath for 10 minutes, and evaporated to dryness under vacuum. The light yellow solid was collected by vacuum filtration ( m.p. 209-210 C, yield 65\%).

Anal. : CHN: found icarbon 56.02; hydrogen 4.26; nitrogen 32.78 ; calculated calculated for C H N O: carbon 55.81; hydrogen 4.18; nitrogen 32.56 .

Mass Spectral data: $m / e-215(M+), m / e-138(M-77) 1055$ of phenyl, $m / e-112(M-130)$ loss of phenylcyanide.

H-NMF Spectrum: 8.27 ppm (doublet), 8.53 ppm (broad singlet), 8.80 ppm (doublet), 8.00 and 7.75 ppm (phenyl).

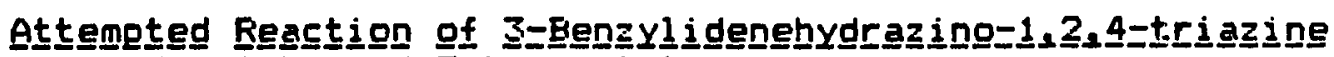

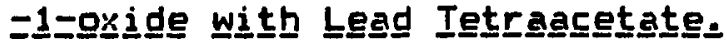

3-Benzyl i denehydrazino-1,2,4-triazine-1-oxide, $0.450 \mathrm{~g}$ $(0.002 \mathrm{~mol})$, was placed in $35 \mathrm{~mL}$ of glacial acetic acid. To this suspension was added $0.886 \mathrm{~g}(0.002 \mathrm{~mol})$ lead tetraacetate and placed in the dark for 30 minutes. To the suspension $B O \mathrm{~mL}$ of water was added and the $\mathrm{pH}$ was adjusted 
to 7 using sodium bicarbonate. The solution was placed in the dark for 4 hours and the black precipitate was removed by vacuum filtration. The remaining yellow solution was extracted with $4 \times 50 \mathrm{~mL}$ portions of chloroform. The chloroform extract was washed with $50 \mathrm{~mL}$ of a saturated solution of sodium carbonate and then dried over anhydrous sodium carbonate. The chloroform solution was reduced in volume under vacuum and the precipitate that formed was collected by vacuum filration. Mass Spectral and H-NMR data showed only the presence of starting material. MS: $m / e-215 ; m / e-112$.

Attempted Reaction of 3-Eenzl idenehydrazine=1_2_4-triazinge=1=

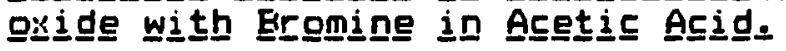

$$
\text { 3-Eenzyl i denehydrazine-1,2,4-triazine-1-oxide, } 0.2009
$$
$(0.0009 \mathrm{~mol})$, was suspened in $3 \mathrm{~mL}$ of glacial acetic acid. To this suspension $0.8 \mathrm{~mL}(0.015 \mathrm{~mol})$ bromine in glacial acetic acid was added over a 30 minute time period. The suspension was filtered by vacuum filration and the precipitate was analyzed by mass spectrum and showed only starting material, $0.1749(88 \%)$ recovered.

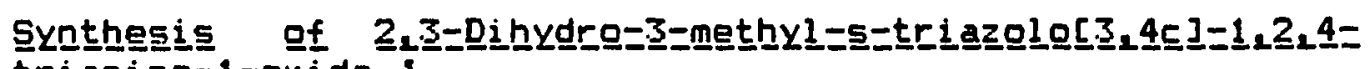

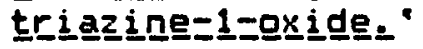

$$
\text { 3-Hydrazino-1,2,4-triazine-1-oxide, } 0.1279 \quad 10.001
$$
mol), was suspended in $30 \mathrm{~mL}$ of absolute ethanol and $5 \mathrm{~mL}$ of acetic acid. This solution was heated over a steam bath until it turned elear. To this hot solution was added 0.1960 .0022 
mol) acetaldehyde in $5 \mathrm{~mL}$ absolute ethanol which was refluxed over a steam bath for 15 minutes. The 1 ight yellow solution was evaporated to dryness under vacuum and the yellow solid was collected by vacuum filtration. The yellow solid was recrystallized from 50\% chloroform/ 50\% hexane mixture to yield a very light yellow solid that darkened with exposure to air. The yellow solid was dissolved in absolute ethanol and applied to a thick layer Tlc plate of silica grade 3 (neutral) and eluted with $94 \%$ ethyl acetate, $5 \%$ ethanol (absolute), and $1 \%$ ammonium hydroxide. Two products were collected from the plate, \#1 the 3rd up the plate yielded 0.039 which was 2,3-dihydro-3-methyl-5triazolo[3,4c]-as-triazine-7-oxide. Melting point 133-134 C. Anal. CHN : found; carbon $39.13 \%$, hydrogen $4.67 \%$, nitrogen 43.06\%; calculated for C H N D: carbon $39.21 \%$, hydrogen $4.57 \%$, nitrogen $45.75 \%$. 595

Mass spectral data: $m / e-153(M+), m / e-138(-15) 1055$ of methyl, m/e-112 (-41) loss of acetonitrile.

H-NMFi Spectral data: 2.06 ppm (doublet), 7.60 ppm (singlet), 7.63 ppm (doublet), 8.28 ppm (doublet), 9.75 ppm (broad singlet).

The second compound identified (the Sth up the plate) was 3-(1-methyl i dene-2-vinyl-hydrazino)-1, 2,4-tri azine-1-oxide (yield $10 \mathrm{mgs}$. ).

CHN : found: carbon $46.77 \%$, hydrogen $5.06 \%$, nitrogen 40.61\%; calculated for CHN O: carbon 46.93\%, hydrogen 795 
$5.03 \%$ nitrogen $39.10 \%$

H-NMF Spectrum: 6.22 ppm (multiplet), 1.87 ppm (doublet), $7.63 \mathrm{ppm}$ (doublet), $7.83 \mathrm{ppm}$ (doublet), $8.28 \mathrm{ppm}$ (doublet).

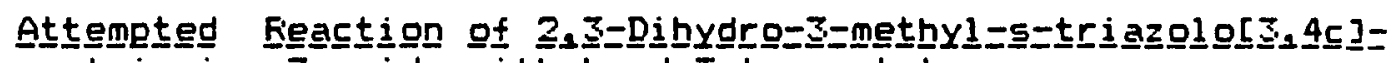

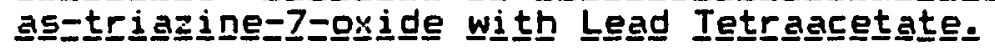

To $0.3009(0.00196 \mathrm{~mol})$ of 2.3-Dihydro-3-methyl-5triazolo[3,4c]-ass-triazine-7-oxide suspended in $30 \mathrm{~mL}$ of 91 acial acetic acid was added $0.886 \mathrm{~g}(0.002 \mathrm{~mol})$ of 1 ead tetraacetate with stirring. This suspension was placed in the dark for 30 minutes then the dark precipitate was filtered by vacuum filtration. The light yellow solution was extracted with 4-50 $\mathrm{mL}$ portions of chloroform. The chloroform extract was washed with saturated sodium carbonate solution and dried over anhydrous sodium carbonate. The solution was evaporated to dryness under vacuum. Mass Spectral information showed only starting material. $m / e-153$ and $m / e-138$.

Attegmpted Kegaction of 2,3 믄

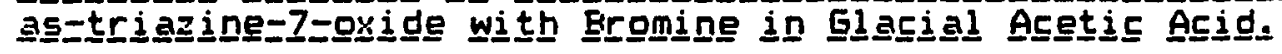

To $0.154 \mathrm{~g}(0.001 \mathrm{~mol})$ of 2.3-dihydro-3-methyl-5triazolo[3,4[]-ass-triazine-7-oxide suspended in $5 \mathrm{~mL}$ of glacial acetic acid was added dropwise $0.8 \mathrm{~mL}(0.015 \mathrm{~mol})$ bromine in $8 \mathrm{~mL}$ of glacial acetic acid over a 30 minute time period. The suspension was stirred for 1.5 hours then evaporated to dryness under vacuum. The yellow solid was 
collected and mass spectral analysis snowed recovered starting material $(92 \%$ recovery).

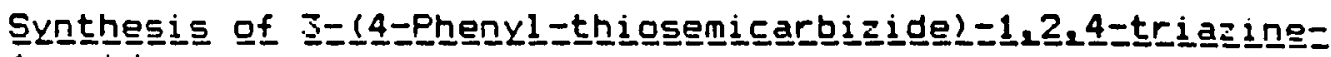
$\underline{1}=\underline{\underline{0} \times \underline{i} \text { de }}$.

To a suspension of $0.200 \mathrm{~g}(0.00157 \mathrm{~mol})$ s-hydrazino1,2,4-triazine-1-oxide in $12 \mathrm{~mL}$ of chloroform was added 0.4 $\mathrm{mL}(0.0033 \mathrm{~mol})$ phenyl isothiocynate. This suspension was refluxed over a steam bath of 30 minutes. Analysis by thin layer chromatograhy utilizing ultraviolet light detection showed the major component of this solution was the $3-$ hydrazino-as-triazine-1-oxide. An additional $0.5 \mathrm{~mL}$ of phenyl isothiocynate was added and the solution was reflused for 3 hours. The solution was evaporated to dryness under vacuum and the white solid was collected by vacuum filtration $(0.291 \mathrm{~g}, 77 \%$ yield: melting point 171-172 C).

Anal. CHN: found; carbon 45.90\%, hydrogen $3.55 \%$, nitrogen 31.63\% : calculated for C H N OS; carbon 45.97\%, hydrogen $3.83 \%$, nitrogen $32.18 \%$.

Mass Spectral data: $\mathrm{m} / \mathrm{e}-261(M+), \mathrm{m} / \mathrm{e}-135(-127) 1055$ of 3-hydrazino-1,2,4-triazine-1-oxide, m/e-127 (-1.35) loss of phenyl isothiocyanate relative to the parent ion $(M+)$.

ب-NMR Spectral data; $8.29 \mathrm{ppm}$ (doublet), $8.6 .5 \mathrm{ppm}$ (phenyl), B.79 ppm (doublet), 10.21 ppm (broad singlet contains 3 protons). 


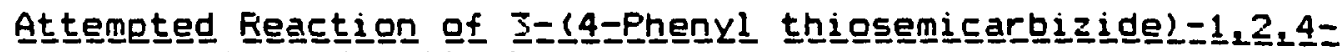

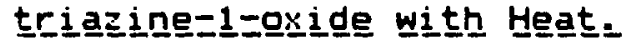

$$
\text { A suspension of } 0.147 \mathrm{~g}(0.00055 \mathrm{~mol}) \text { of 3-(4-phenyl- }
$$
thiosemicarbizide)-1,2,4-triazine-1-oxide was heated to a reflux in $25 \mathrm{~mL}$ of toluene for $30 \mathrm{minutes}$ in the dark. The solution was cooled to room temperature and the suspension was filtered by vacuum filtration. $0.100 \mathrm{~g}$ of a yellow solid was collected. NMR and mass spectral analysis showed only starting material. The toluene solution was evaporated to dryness under vacuum and showed by mass spectral analysis only decomposed material ( no mass units above 112 amu).

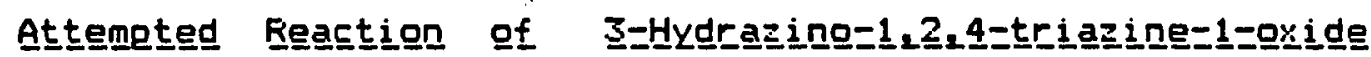
with Carbon Disulfíide in Base.

To a hot refluxing suspension of $0.2009(0.00157 \mathrm{~mol})$ 3-hydrazino-1,2,4-triazine-1-oxide in $15 \mathrm{~mL}$ of absolute ethanol and $3 \mathrm{~mL}$ of base $($ triethylamine or $0.1 \mathrm{~N} \mathrm{NaOH}$ ) was added $2 \mathrm{~mL}$ of carbon disulfide. The solution at this point was blood red in color. The solution was refluxed for 30 minutes allowed to cool to room temperature. The solution was evaporated to dryness under vacuum. The resulting dark brown solid did not have a melting pointe $>350$ C). Mass spectral analysis did not produce a fragmentation pattern. H-NMR spectral analysis produced no peak: in the spectrum. Infrared spectrum did not show an aromatic ring system. 


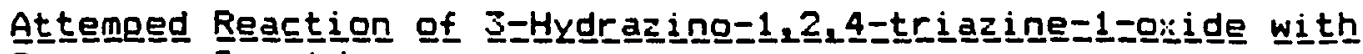
Cvangogen Bromide.

To a suspension of $0.200 \mathrm{~g}(0.00157 \mathrm{~mol})$ of 3-hydrazino1,2,4-triazine-1-axide in $10 \mathrm{~mL}$ of absolute ethanol was added $0.17 \mathrm{~g}(0.0016 \mathrm{~mol})$ cyanogen bromide. This solution was heated over a steam bath for 1 hour and to this solution was added $1 \mathrm{~mL}$ triethylamine. The solid suspended in the solution was collect by vacuum filtration. Mass Spectral analysis showed only the starting 3-hydrazino-1,2,4-triazine1-oxide present. Retention times of thin layer chromatography analysis with an authentic sample of 3hydrazino-as-triazine-1-oxide was identical to the solid collected by filtation.

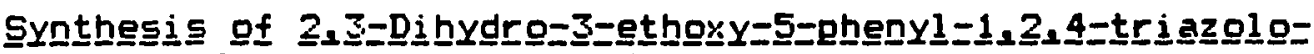

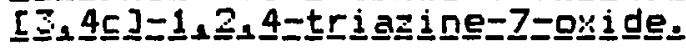

To $0.4 \mathrm{~mL}$ of diethoxymethyl acetate was added $0.080 \mathrm{~g}$ (0.00039 mol) of 3-hydrazino-5-phenyl-1,2,4-triazine-1oxide. This solution was heated over a steam bath for 10 minutes. During this time a light yellow crystal formed in the reaction vessel. This crystal was collected by vaculum filtration then air dried $(0.100 \mathrm{~g}(0.00038 \mathrm{~mol})$, yield $97 \%)$.

Anal. CHN.: found; carbon 55.75\%, hydrogen $5.13 \%$, nitrogen 26.83\%; calculated for C H N O ; carbon 55.59\%, hydrogen $5.02 \%$, nitrogen $27.02 \%$.

Mass Spectral data; $m / e-259(M+), m / e-215(-44) 1055$ of acetaldehyde fragment. 


$\begin{array}{lll}\text { H-NMR } & \text { Spectral data: } 10.37 \text { ppm(singlet), } & 8.88 \\ \text { ppm(singlet), } & 8.46 \text { ppm(phenyl), } 7.89 \text { ppm(phenyl), } 7.35 \\ \text { ppm(singlet), } 4.53 \text { ppm(quartet), } 1.66 \text { ppm(triplet). } & \end{array}$

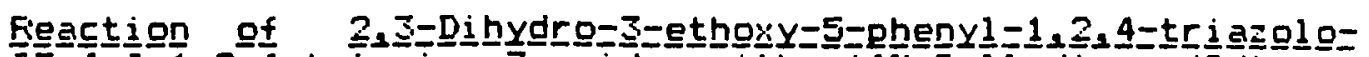

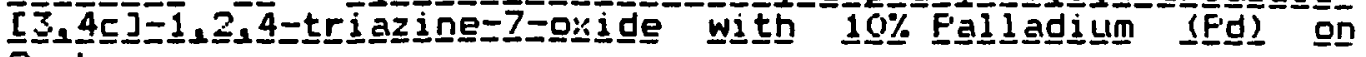
Caㅡ므므.

To $30 \mathrm{~mL}$ of p-xylene with $0.100 \mathrm{~g}$ of $10 \%$ Fd on carbon was added $0.100 \mathrm{~g}(0.00034 \mathrm{~mol})$ of 2,3-dihydro-3-etho:v-5phenyl-1,2,4-triazolo[3,4c]-1,2,4-triazine-7-oxide. This suspension was refluxed for 22 hours then allowed to cool to room temperature. The solution was filtered by vacuum filtration and the black carbon was air dried $(0.102 \mathrm{~g}$ recovered).

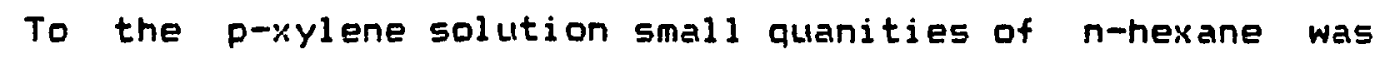
added until a precipitate formed (solid $A, 0.0239$ ) and was collected by vacuum filtration. Additional he\%ane was added to the p-xylene solution and another precipitate formed which was collected by vacuum filtration ( solid E, 0.019 ). The p-xylene solution was evaporated to dryness under vacuum to yield a brown solid. This solid material did not have a mass spectral fragmentation pattern or produce a H-NMR spectrum.

$$
\text { Solid } A \text { was redissolved in chloroform and }
$$
recrystallized by slow evaporation under nitrogen, yield 20 mos. Thin layer chromatographic analysis showed only one compound present. Mass spectral analysis idenyified this compound to be 2,3-dihydro-3-ethoxy-5-phenyl-1,2,4- 
triazolo[3,4c]-1,2,4-triazine.

Solid E mass spectrum showed a molecular weight of 243. This compound was identified as 3-ethoxy-5-phenyl$1,2,4-\operatorname{tr} i a z 010[\Xi, 4 \subset]-1,2,4-t r i a z i n e$.

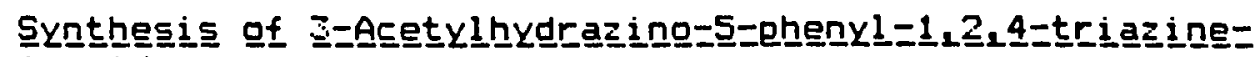
1=oㅛㅁㅁㅡ.

A solution of $1.0 \mathrm{~mL}$ of ethyl orthoformate and $0.56 \mathrm{~mL}$ of acetic anhydride was freshly prepared. Of this solution $0.4 \mathrm{~mL}$ was added to $0.080 \mathrm{~g}(0.00039 \mathrm{~mol})$ of 3-hydrazino-5phenyl-1,2,4-triazine-1-oxide and heated over a steam bath for 1 minute. The precipitate was collected by vacuum filtration and washed with methylene chloride and hexane (0.095g, 100\% yield: m.p. 242-243 C). Mass Spectra showed a molecular weight $\mathrm{m} / \mathrm{e}$ of 245 , and $\mathrm{m}-28 \mathrm{~m} / \mathrm{e}-217$.

Anal. CHN: found; carbon $53.66 \%$, hydrogen $4.51 \%$,

nitrogen 29.01\%: calculated for C H N O icarbon 53.87\%, hydrogen $4.489 \%$, nitrogen $28.57 \%$.

Mass Spectral data: $m / e-245(M+), m / e-217(M-28,1055$ of nitrogen)

H-NMFi Spectral data: 10.33 ppm(singlet), 10.01 ppm(singlet), 8.97 ppm(singlet), 8.53 ppm(phenyl), 7.97 ppm (phenyl). 


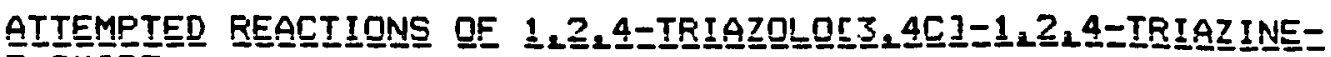
7므므믙

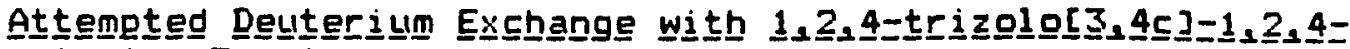

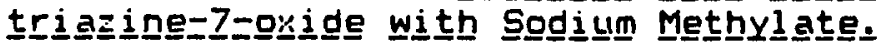

To a solution of $0.04 \mathrm{~g}(0.0003 \mathrm{~mol}) 1,2,4-t r i a z 010-$ $[3,4[]-1,2,4-t r i a z i n e-7-0 x i d e$ in $0.4 \mathrm{~mL}$ dimethyl sulfoxide with one drop of deuterium oxide was added a trace amount of sodium methylate. This solution was placed in a NMR tube and the spectrum was taken every five minutes for one hour. All NMR signals disappeared at a progressive rate. The sample was extracted with ether and the remaining solid was applied to a thin layer chromatography plate and eluted with ethyl acetate-90\% / ethanol-10\%. The retention times of the appearing spots were unique when compared with the starting material.

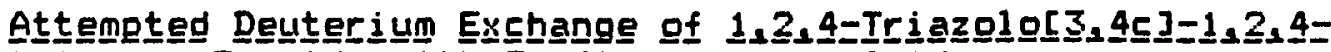

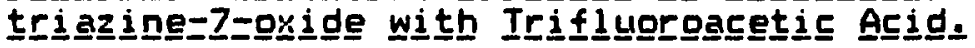

To a solution of $0.0329(0.00023 \mathrm{~mol}) 1,2,4-t r i a z 010-$ $[3,4 \subset]-1,2,4-t r i a z i n e-7-a x i d e$ in $0.4 \mathrm{~mL}$ dimethyl sulfaxide with one drop of deuterium oxide was added 2 drops trifluoroacetic acid. This solution was placed in a NMF tube and the spectrum was taken every 5 minutes for one hour. All NMF signals disappeared at an equally progessive rate. The sample was extracted with ethier to remove the dimethyl sulfaxide which left a browm solid. This solid was dissolved in $90 \%$ ethyl acetate / $10 \%$ ethanol and applied to a thin 
layer chromatography plate and eluted with the same solvent. The retention times of the spots that appeared, when compared with the authentic sample, were distinctly unique.

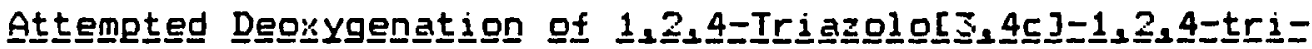

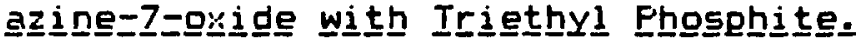

$$
1,2,4-\operatorname{Tr} i a z 010[3,4[]-1,2,4-\operatorname{tr} \text { iazine-7-okide, } 0.160 \mathrm{~g}
$$

(0.0017 moll), was heated to reflux with $5 \mathrm{~mL}$ triethyl phosphite under nitrogen for 3 hours. The triethyl phosphite was removed under vacuum leaving a light yellow solid. The yellow solid was dissolved in $90 \%$ ethyl acetate $110 \%$ ethanol and applied to a thin layer chromatography(TLC) plate and eluted with the same solvent. The retention time of the detected spot was identical to the starting material. H-NMF spectral analysis was identical to the starting material.

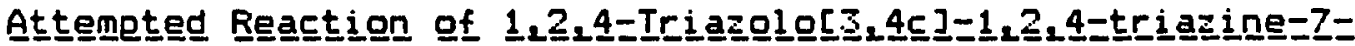

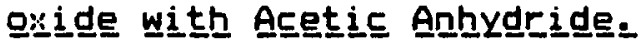

$$
\text { S-Triazolo[3,4[]-ąs-triazine-7-0\%ide } 0.100 \mathrm{~g}, \quad 10.0007
$$

mol), in $1 \mathrm{~mL}(0.01 \mathrm{~mol})$ of acetic anhydride was heated over a steam bath of 1 hour. The solid material in the reaction vessel was filtered under vacuum and air dried. The solid material was applied and elute on a TLC plate and the detected spots were identical to the starting material.

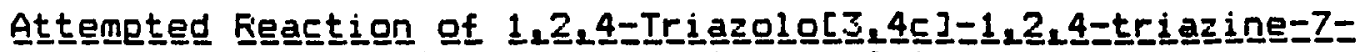

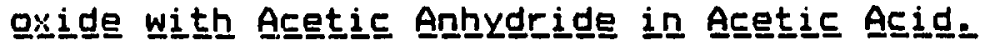

$1,2,4-T r i a z o l o[3,4 c]-1,2,4-t r i a z i n e-7-o x i d e, 0.0709$

$(0.0005 \mathrm{~mol})$, was dissolved in $5 \mathrm{~mL}$ of hot acetic acid, 
$0.8 \mathrm{~mL}$ of acetic anhydride was added and then the solution was heated over a steam bath for 45 minutes. At this time the solution was evaporated to dryness under vacuum to yield an oily brown solid. TLC, H-NMFi and mass spectral analyses showed starting material and acetic acid.

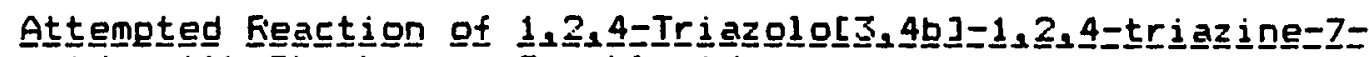

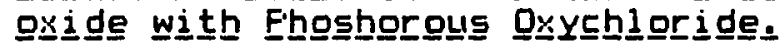

Fhosphorous oxychloride, $0.9 \mathrm{~mL}(0.0096 \mathrm{~mol})$, was added to $0.0509(.00036 \mathrm{~mol})$ of $1,2,4-\operatorname{tri} a=010[3.4 c]-1,2,4-$ triazine-7-oxide then heated over a steam bath for 30 minutes. The solution was evaporated to dryness under vacuum to yield a yellow solid, H-NMFi and mass spectral analyses showed only starting material.

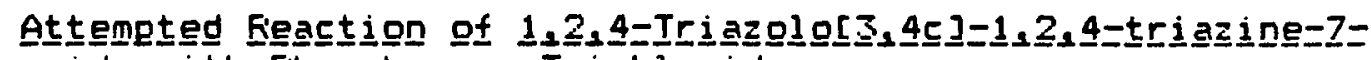

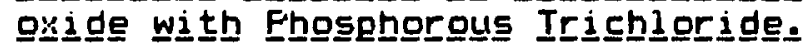

To $2 \mathrm{~mL}$ of phosphorous trichloride was added $0.126 \mathrm{~g}$ (0.0009 mol) of 1,2,4-triazolo[3,4[]-1,2,4-triazine-7-oxide. This mixture was heated over a steam bath for 24 hours. The phosphorous trichloride was removed by reduced pressure leaving a needle like crystal. H-NMR spectrum showed only the starting material which was confirmed by the melting point of 191-194 C.

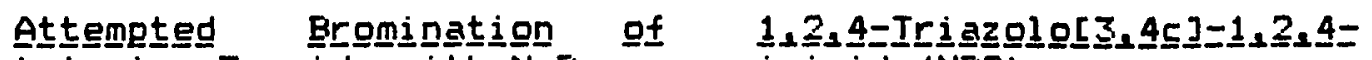

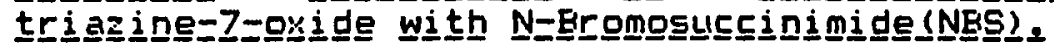

$$
\text { 1,2,4-Triazolo[3,4[]-1,2,4-triazine-7-oxide, } 0.1309
$$
$10.00095 \mathrm{~mol})$, was dissolved in hot acetic acid. To this 
solution $1.689(0.0094 \mathrm{~mol})$ of NBS was added as a slurry in $13 \mathrm{~mL}$ of acetic acid. This solution was heated over a steam bath for 1 hour and was then allowed to cool to room temperature. The solution was evaporated to dryness under vacuum to yield a yellow solid. Thin layer chromatographic analysis detected three spots, the first was 1,2,4triazolo[3,4ᄃ]1,2,4-triazine-7-oxide, the second was succinimide and the third was NES.

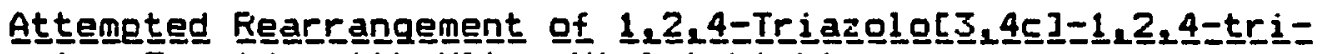

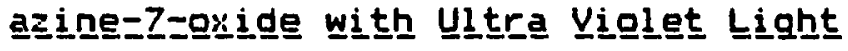

$$
\text { 1,2,4-Triazol o[3,4c]-1,2,4-triazine-7-oxide, } \quad 0.060 \mathrm{~g}
$$

(0.00044 mol), was dissolved in $125 \mathrm{~mL}$ of dioxane and irradiated with 600 watts of $254 \mathrm{~nm}$ ultra violet light for 16 hours. At $2,4,6,8,10,12$, and 16 hours thin layer chromatography was performed and the results showed the loss of starting material with replacement with numerous new compounds. The solution was evaporated to dryness under vacuum to yield a brown oil. Mass Spectrum and H-NMR spectrum analyses showed the loss of aromatic protons and a general decomposition of the sample into unknown fragments. 


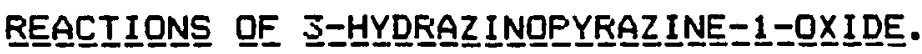

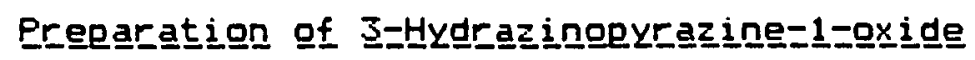

3-Chloropyrazine-1-oxide, 0.615g (0.0047 mol), was

dissolved in $10 \mathrm{~mL}$ of freshly distilled dry tetrahydrofuran. To this solution with stirring was added $0.3 \mathrm{~mL}(0.0094 \mathrm{~mol})$ of 95+ \% hydrazine. Immediately upon addition anhydrous methanol was added to dissolve the hydrazine. This solution was allowed to stand at room temperature for 48 hours in the dark. A white precipitate was formed and was collected by vacuum filtration and washed with methylene chloride $886.8 \%$ yield, m.p. 200-200.5 C (decomp)).

Anal. CHN: found; carbon $37.94 \%$, hydrogen $4.53 \%$, nitrogen 43.87\%: calculated for C H N O; carbon $38.11 \%$, hydrogen $4.76 \%$, nitrogen $44.43 \%$.

H-NMR Spectral data: B.01 Ppm(doublet), 7.58 ppm(doublet of doublets), 7.83 ppm(singlet)

Synthessis of 1,2,4=Ir

3-Hydrazinopyrazine-1-0xide, $100 \mathrm{~g}(0.0008 \mathrm{~mol})$, was added to $0.5 \mathrm{~mL}$ of diethoxymethyl acetate. The solution immediately turned yellow and produced heat. The solution was warmed over a steam bath for 3 minutes and then cooled to room temperature. The solution was evaporated under vacuum to yield a dark brown oil. The oil was recrystallized from absolute ethanol and Norite to yield a white solid 
(0.036g, 36\% yield, m.p. 204-205 C (decomposition)).

Anal. CHN: found; carbon $44.26 \%$, hydrogen $2.61 \%$,

nitrogen $41.16 \%$ : calculated for C H N O: carbon $44.14 \%$, hydrogen $2.94 \%$, nitrogen $41.16 \%$.

Mass Spectral data: $\mathrm{m} / \mathrm{e}-136(M+), \mathrm{m} / \mathrm{e}-135(M-1), \mathrm{m} / \mathrm{e}-$ $120(M-16)$.

H-NMFi Spectral data: 9.21 ppm(singlet), 9.14 ppm (singlet), 8.74 ppm(doublet), $7.79 \mathrm{ppm}$ (doublet of doublets).

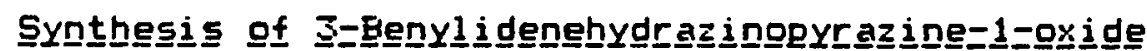

To a stirring soution of $0.510 \mathrm{~g}(0.0047 \mathrm{~mol})$ of $3-$ hydrazinopyrazine-1-oxide in $50 \mathrm{~mL}$ of ethanol and $12 \mathrm{~mL}$ of acetic acid at $B O C$ was added $0.5 \mathrm{~mL}$ of benzaldehyde. This solution was heated over a steam bath for 25 minutes and was evaporated under vacuum to yield a yellow solid. The product was washed with ethanol and chloroform and recrystallized from benzenel m.p. 194 C (decompostion), $0.1969,56 \%$ yieid).

H-NMR Spectral data: 8.96 ppm(multiplet), 8.74 ppm (multiplet), $8.53 \mathrm{ppm}(\mathrm{multiplet})$

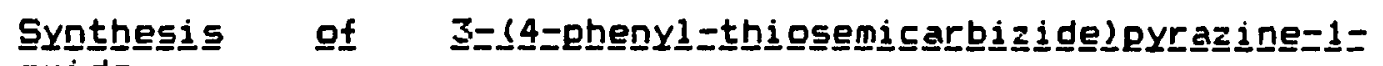
Q쁨므.

3-Hydrazinopyrazine-1-okide, $0.200 \mathrm{~g}(0.0016 \mathrm{~mol})$, was suspended in $12 \mathrm{~mL}$ of chloroform and heated to $80 \mathrm{C}$. To this hot solution $0.4 \mathrm{~mL}$ of phenyl isothiocyanate was added and maintained at $80 \mathrm{C}$ for 4 hours. The solution was allowed 
to cool to room temperature and the white crystals were collected by vaculum filtrations m.p. 153-154 c, yield $0.3009,73 \%$.$) .$

The Fol

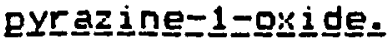

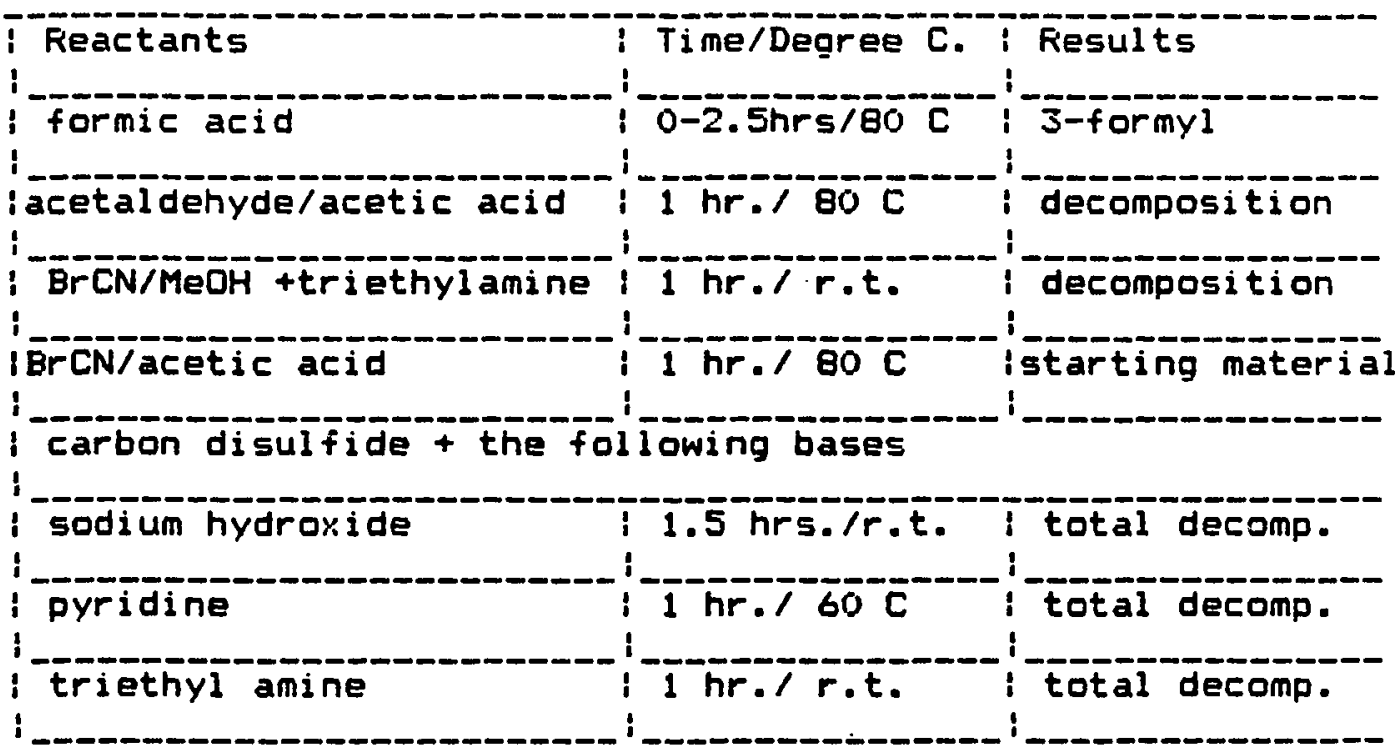

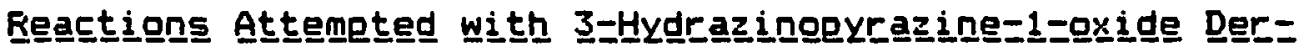

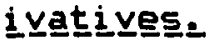

$\begin{array}{l:l}\text { i Reactants } & \text { Conditions/TimetTemp. } \\ \text { benzylidene } & \text { bromine/acetic acid } \\ \text { phenyl thio } & \text { he.l r.t. } \\ \text { semicarbize } & \end{array}$




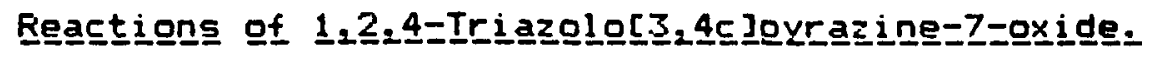

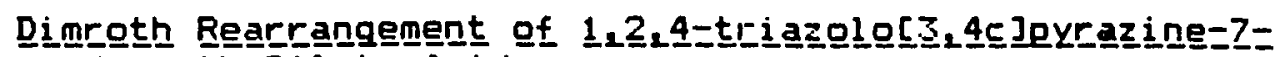

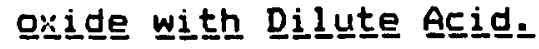

$$
\text { 1,2,4-Triazolo[3,4c]pyrazine-7-oxide, } \quad 0.300 \quad 10.0022
$$

mol), was dissolved in $0.4 \mathrm{~mL}$ of perdeutero-dimethyl sulfoxide. To this solution 50 microliters of trifluoroacetic acid was added. The sample was placed in a NMFi spectrometer and the resulting spectra were taken every 15 minutes over a six hour period. H-NMR spectral analysis showed a new singlet at $8.62 \mathrm{ppm}$. After several hours of observation $H-8$ now is spilt into two new peaks at 9.14 and 9.06 with a ratio of 60 to 40 . The later new shift of 9.06 was due to the 1,2,4-triazolo[3,2c]pyrazine-7-oxide. NMFi: 9.11 (doublet), 9.06 (singlet), 8.62 (singlet): 8.03 (doublet of doublets)

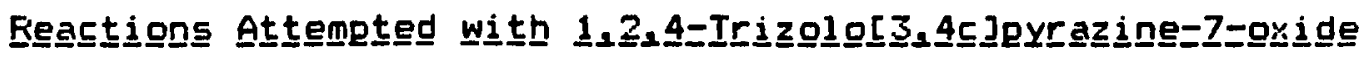

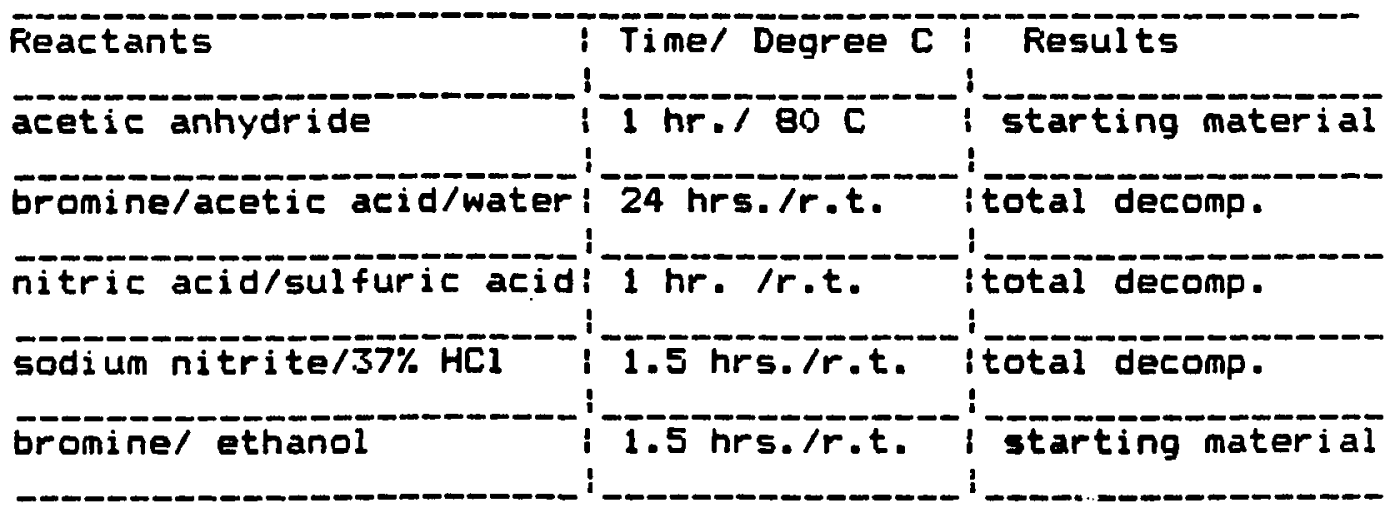


SYNIHESIS AND REACIIONS OF IMIDAZOQL2 21C]EYRAZINE-7ZQXXIDE.

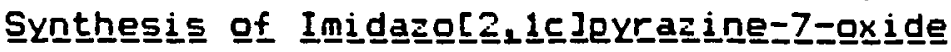

Imidazo[1,2a]pyrazine, $1.019(0.00848$ mol), was dissolved in $22 \mathrm{~mL}$ of chloroform at $60 \mathrm{C}$. To this solution $2.9 \mathrm{~g}(0.017 \mathrm{~mol})$ of metéa-chloroperbenzoic acid in $40 \mathrm{~mL}$ chloroform was added dropwise over a ten minute period. The solution was maintained at $60 \mathrm{C}$ for 20 minutes and then the solution was evaporated to yield a light yellow solid. This solid was added to $25 \mathrm{~mL}$ of saturated sodium carbonate solution and was continually extracted with chloroform for 64 hours. The extract was dried over sodium carbonate and evaporated to dyrness under vacuum to yield a light yellow solid. This solid was recrystallized for absolute ethanol to give white needles (m.p. 167 C (decomp), $0.3926 .2 \%$ yield).

H-NMR Spectral data : 8.83(singlet), 8.81(doublet), 8.05 (singlet), 7.78 (doublet of doublets), 7.76 (singlet).

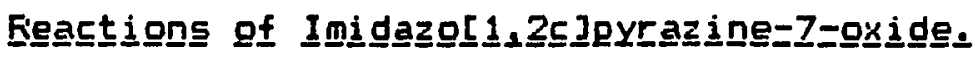

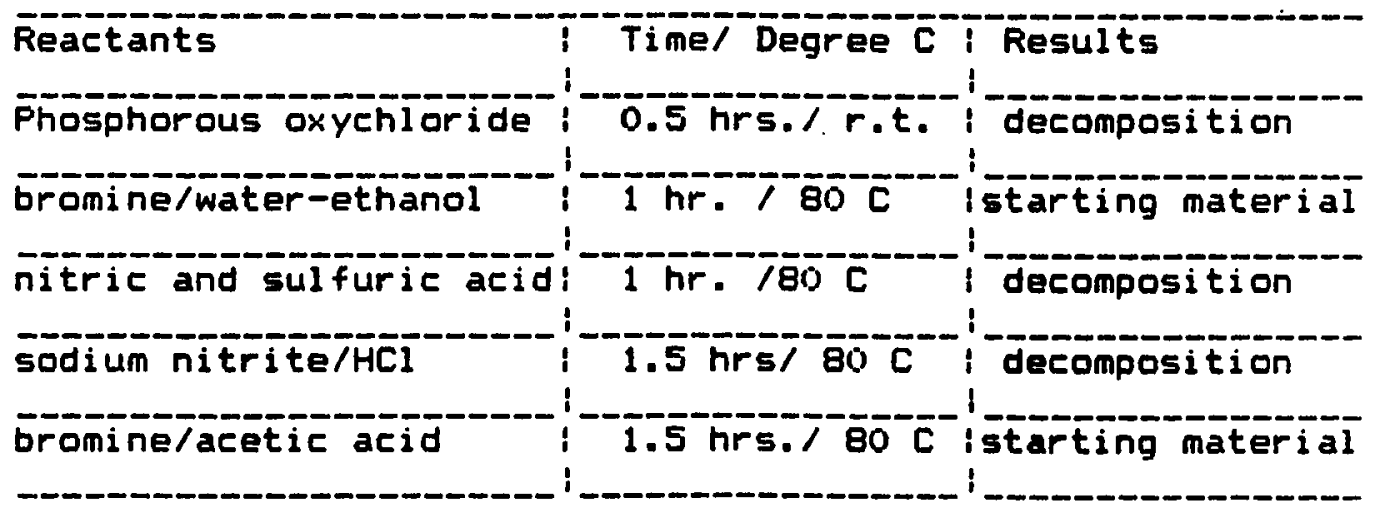


V. References

1. E.T. Eorrows and D.0. Holl and. Chnen. Ëev. 1948, 42. 611 .

2. F.Yoneda, T. Ohtaka and Y. Nitta,Chem. Fharm

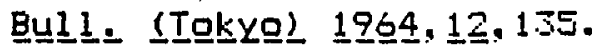

3. L.M. Webel and M.L. Zamora. J. Hetegrocyc‥ Chen. 19으로, 2., 287.

4. S.C. Bell 1 and W.T. Caldwel $1, \underline{J}$. Am. Chem. Sogc. 1966요요, 1467 .

5. S. Inoue, S. Sugiura, H. Kokoi and T. Goto, Ietrrahegdron Let․‥ 19969, 1609.

6. T. Goto, S. Inoue and S. Sugiura, Ietrahhedron 느르느. 1 으으르. 3873 .

7 (a). F. Euerret, Fi. Jacquier and G. Maury, J. Hetero= 도도. 드료. 197ㄴ. 1,643 .

(b). W.W. Faudler and J.E. Kuder, J. Drg. Chem. 1966. 31.809.

(c). N.F'. Buu-Hoi and M. Dat Xuong, 드토. Acagd. Sci.

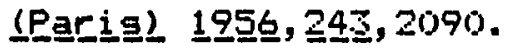

8(a). T. F'yl and W. Eaufeld, Ann. Chem. 1966의,699,112.

(b). F. Guerret, F. Jacquier, and G. Maury, Eulㅣㄹㅗ Sgc.

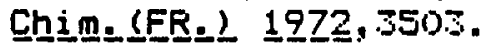

9. Fi. Fusco and S.Fossi, Fiend, Ist. Lombardo Sci.

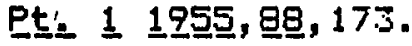

10. E.Loev and M.M. Goodman, Ietrahgedron Lettt. 19668, 789.

11. J.M. Barton, Fh.D. Thesis, University of ohio, Athens, Ohio, 1966.

12. J. Daunis, Fi. Jacquier, and F.Viallefont, Bull 1 . Sogc. Chinim. (FR.) 19을, 2492.

13. J. Kobe, E. Stanovnik, and $M$. Tisler, Tetrahehgoron $19 \underline{70}, 2 \underline{\underline{6}}, 3557$.

14(a). C.F.H. Allen, H.F. Beilfuss, D.M. Eurness, G.A. Reynolds, J.F. Tinker, and J.A. Van Allen.J.

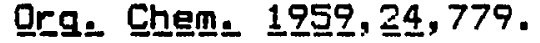

(b). C. Temple, R.L. Mac Kee and J.A. Montgomery.J.

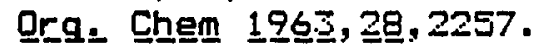


(c). W.W. Paudler and L.S. Helmick, I. Hetererosyc‥ Cheng. 19응. …269.

15. F.J. Nelson and K.T. Fotts. J. Org. Cheng. 196ㄹ. 2.7. 3243 .

16. A. Follak, E. Stanovnik and M. Tisler. J. Hetegro=

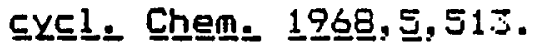

17 (a).C. Temple, B.H. Smith and J.A. Montgomery, J.

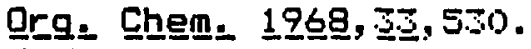

(b) .G.W. Milier and F.L. Fose. J. Chem. Soc. 196.5. 5642 .

18. A. Dornow, W. Abele and $H$. Menzel, Chenem. Ber. 1으는, 므, 2179 .

19. J.Maguire, D. Faton, and F.L. Fose, J. Chem. Soc. (드) 1으의, 159․․

20. W. Eroadbent, G.W. Miller, and F.L. Fose, I.

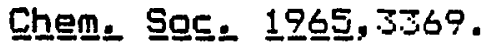

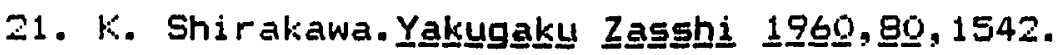

22(a). C.F.H. Allen, H.F.. Beifluss, D.M.Burness, G.A. Reynolds, J.F. Tinker and J.A. Van Allen, J. Qrg. 드료. 19959. 24. 787 .

(b). Fi.G.W. Spickett and S.H.E. Wright, J. Chem. Soc. (C) 1 은ㄱ, 498 .

(c). A.H. Beckett, F.G.W. Spickett and S.H.B. Wright,

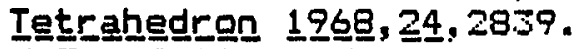

(d). K.T. Fotts, H.F. Eurton and S.K. Fioy, J. Org.

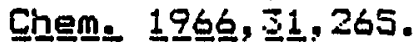

23(a). N.K. Hart, S.R. Johns, and J.A. Lambertson, and R. I. Willing, Ausstr. J. Chem. 1970, 23, 1670.

(b). F. KhuongHuu, J.P. Leforestier, G Maillard, and

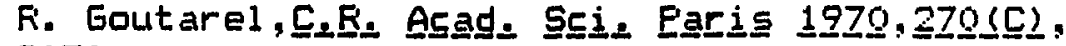
2070.

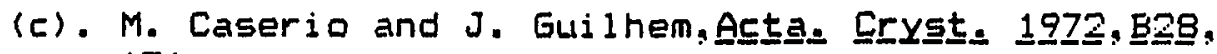
151.

24. W. Schuett and H. Fiapoport, I. Am. Chem. Soc. 1 으르, 84,2266 .

25. J.F. Dyer, C.K. Kellogg, F.F. Nassar and W.E.

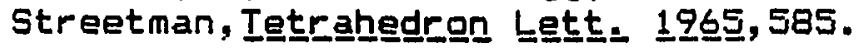

26(a). Y. Makisumi, Japanese Patent $1.3640(1963)$ 
(b). A. Takamizawa and 5. Hayashi, Japanese Patent $2546(1964)$.

27. Communications 52-56, A.C.5. National Meeting, Medicinal Chemistry, New York, 1972.

28(a). T. Okabayashi, Chem. Fharm. Bull 1. (Tokyo) 1960․ $8,162$.

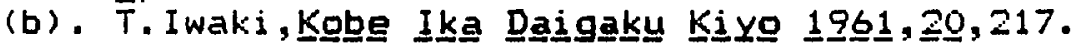

29(a). K.T. Fotts, H.F. Burton and S.K. Fioy, J. Drg.

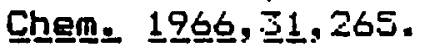

(b). J.D. Eower and G.Fi. Fiamage. J. Chem. Soc. 1957. 4500 .

J0(a). E.T. Borrows, D.O. Holland, and J. Kenyon, J. 드르. S므드. 1으능, 1069 .

(b). ibid, 1075 .

(c). ibid, 1077 .

(d). D. Deils and R. Mayer,Ann, Cheng: 51 1 , 129.

\$1. E. Lieber, T.S. Chad, and C.N.F. Fao. J. Org. Chenem. 195ㄱ, 22,654.

S2(a). G. Tennant, I. Chem. Soc. (C) $1966,2290$.

(b). G. Tennant, J. Chem. Soc. (드) 1967,1279.

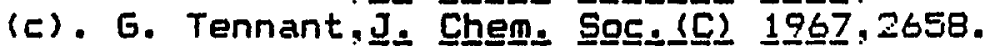

33. A. Follak, E. Stanovnik, M. Tisler, J.

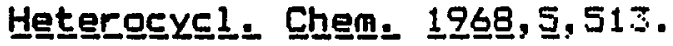

34. J. Adamson, E.C. Campbel1, E.E. Glover, J. Chen. S으드.드) 1으으. 2270.

35. S. Follak, B. Stanovnik, M. Tisler, J. Org. Chem. 19금, 퐁, 2478 .

36. E. Abushanab, A.F. Bindra, L. Goodman, and $H$.

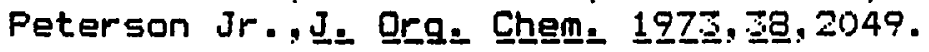

37. N.G. Koshel, E.G. Kovalev and I.Y. Postovskii,

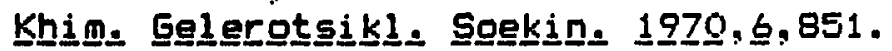

38. B.W. Cue Jr., L.J. Czuba, J.D. Dirlam, J. Qrg. Chㅡㄹㅛ. 19278, 43. 4125 .

39. T.L. Gilehrist, C.J. Harris, C.J. Moody, and C.W. Rees, J. Chem. Sogc. Chem. Comm. 19744,486.

40. T.L. Gilchrist, C.J. Harris, D.G. Hawkins, C.J.

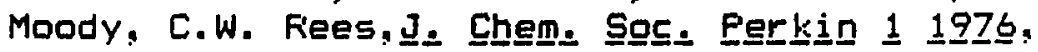
2166. 
41. J. Bratoz-Stres, S Fol ane, B. Stanovnil, $M$.

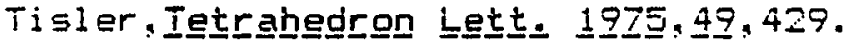

42. I. Tabakovie', M. Trkovnik and D. Gali jas", Is

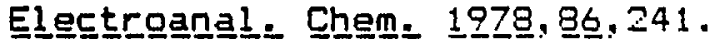

43. W.W. Paudler and E.S. Hand, ․ㅡ Qrg. Chene. 1978. 4 S. 658 .

44. K. Satoh, T. Miyasaka, K. Arakawa, Chem, Lett. $19 \underline{7} \underline{7}, 1501$.

45. K. Satoh and T. Mi yasaka,Hetergeycles 197ㅇ., 10, 269.

46. J. Daunis, H.Lopez, and G. Maury, J. Org. Chem. 1으그, 42 , 1081 .

47. M.M. Goodman and W.W. Faudler.J. Heterocycl. Chene. 1977., 14,1221.

48. W.W. Faudler, D.J. Fokorny, and S.J. Cornrich, J.

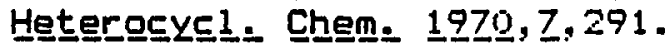

49. W.W. Paudler and L.S. Helmick. Chem. Comm. 19697. 377.

50. Fi.J. Fiadel, E.T. Keen, C. Wong and W.W. Faudler, J. Org. Chhen. 19근, 42,546.

51. W.W. Faudler and F.M. Sheets, J. Org. Chem. 1980, 45, 5421 . 
TABLE I

Application of Several Fused Folyazaindenes.

\begin{tabular}{|c|c|}
\hline Farent compound & Application \\
\hline 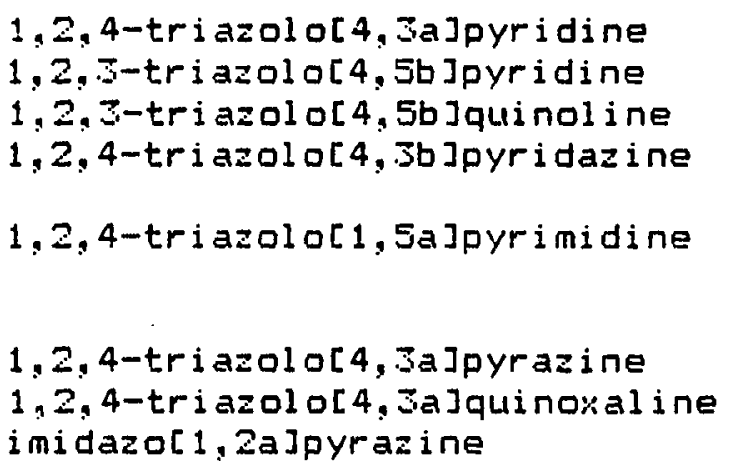 & $\begin{array}{l}\text { Photography } \\
\text { Pesticide } \\
\text { Antiallergic } \\
\text { Vasodilator } \\
\text { Fhotography } \\
\text { Photography } \\
\text { Herbicide } \\
\text { Enetic } \\
\text { Bronchodilator } \\
\text { Fice growth control } \\
\text { Bioluminescent }\end{array}$ \\
\hline
\end{tabular}


TABLE II

FFOTON NUCLEAFi MAGNETIC FESONANCE CHEMICAL SHIFTS OF SOME POLYAZAINDENES AND THEIR N-OXIDES. (a)

\begin{tabular}{|c|c|c|c|c|c|c|c|}
\hline $\begin{array}{l}\text { S-TRIAZOLOL } 1,2 a] \text { FYRIDINE } \\
\text { (b) }\end{array}$ & --- & --- & 9.16 & 8.47 & 6.92 & $7 . .2$ & 7.80 \\
\hline $\begin{array}{l}\text { S-TFIIAZOLD } 1 \text { 1, 5A]FYRIDINE } \\
\text { (b) }\end{array}$ & -- & 8.35 & --- & 7.82 & 7.52 & 7.04 & 8.62 \\
\hline $\begin{array}{c}\text { S-TFIIAZOLOL } 4, \text {;a]- } \\
\text { PYRIMIDINE(c) }\end{array}$ & -- & -- & 9.28 & 9.02 & 7.15 & 8.77 & -- \\
\hline $\begin{array}{l}\text { S-TRIAZOLO[1, } 5 a]- \\
\text { PYRIMIDINE(c) }\end{array}$ & --- & 8.76 & --- & 9.52 & 7.46 & 8.89 & -- \\
\hline $\begin{array}{l}\text { 5-TFI I AZOLOL } 3,4 C]- \\
\text { PYRAZINE-7-OXIDE }\end{array}$ & $-\infty$ & -- & 9.21 & 8.74 & 7.79 & ---9. & .14 \\
\hline $\begin{array}{l}\text { S-TFIAZOLOL } 1,5[]- \\
\text { PYRAZINE-7-OXIDE }\end{array}$ & --- & 8.62 & -- & 9.11 & 8.03 & --- & 9.06 \\
\hline $\begin{array}{l}\text { S-TRIAZDLO } 1, \text { sa }]- \\
\text { PYRAZINE (d) }\end{array}$ & $-\infty$ & 8.50 & --- & 8.58 & 8.19 & $\longrightarrow$ & 9.37 \\
\hline $\begin{array}{l}\text { S-TFIIAZOLO[3, 4C]- } \\
1,2,4-T R I A Z \text { INE-7-OXIDE }\end{array}$ & --- & -- & 9.28 & 9.07 & 8.10 & -- & --- \\
\hline $\begin{array}{l}\text { IMIDAZO[1, 5a]FYFAZ INE- } \\
\text { 7-OXIDE (e) }\end{array}$ & 7.65 & -- & 8.25 & 7.97 & 7.38 & $--\infty$ & 3.56 \\
\hline IMIDAZO[1, 5a]FYRAZINE (e) & 7.83 & -- & 8.28 & 7.58 & 7.91 & -- & 9.05 \\
\hline $\begin{array}{l}\text { S-TRIAZOLO[4, 3b]- } \\
\text { FYRIDAZINE-7-OXIDE (f) }\end{array}$ & - & 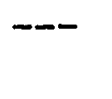 & 9.74 & -- & 8.35 & 8.35 & 8.04 \\
\hline $\begin{array}{l}\text { S-TFIAZOLOL } 4,3 \text { B]- } \\
\text { PYRIDAZINE (d) }\end{array}$ & 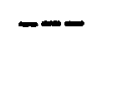 & $-\infty$ & 9.15 & --- & 8.40 & 7.17 & 8.20 \\
\hline
\end{tabular}


TABLE II CONTINUED

COMFOUND
H-1

(a) all chemical shifts are recorded in parts per million and are down field from TMS.

(b)

(c) W.W. Faudler and L.S. Helmick. J. Hetergocyl. Chem.. $1966,3.269$.

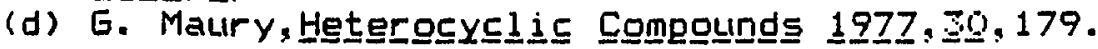

(e) see reference number $\$ 6$.

(f) see reference number 3.5 . 
TABLE II I

CHANGES IN CHEMICAL SHIFTS OF DIMFIOTH FIEAFIFANGED AND NON REARRANGED COMPOUNDS.

\begin{tabular}{|c|c|c|c|c|c|c|}
\hline COMFOUND & $(H-3)$ & $(H-2)$ & $H-5$ & $H-6$ & $\mathrm{H}-7$ & $H-Q$ \\
\hline TRIAZOLOFYRIDINE & 9.16 & 8.35 & $\begin{array}{l}8.47 \\
7.82\end{array}$ & $\begin{array}{l}0.92 \\
7.52\end{array}$ & $\begin{array}{l}7.32 \\
7.04\end{array}$ & $\begin{array}{l}7.80 \\
7.62\end{array}$ \\
\hline TRIAZOLOFYRIMIDINE & 9.28 & 8.76 & $\begin{array}{l}9.02 \\
9.00\end{array}$ & $\begin{array}{l}7.15 \\
7.19\end{array}$ & $\begin{array}{l}8.77 \\
8.77\end{array}$ & $\ddot{--}$ \\
\hline $\begin{array}{c}\text { TRIAZOLOPYRAZINE } \\
\text { 7-OXIDE }\end{array}$ & 9.21 & 8.6 .5 & $\begin{array}{l}8.74 \\
9.11\end{array}$ & $\begin{array}{l}7.79 \\
8.05\end{array}$ & $-\infty$ & $\begin{array}{l}9.14 \\
9.06\end{array}$ \\
\hline TFI I AZOLOFYFIDAZ INE & 9.15 & 8.35 & $\begin{array}{l}-- \\
---\end{array}$ & $\begin{array}{l}8.40 \\
8.44\end{array}$ & $\begin{array}{l}7.17 \\
7.42\end{array}$ & $\begin{array}{l}3.20 \\
8.08\end{array}$ \\
\hline TRI AZOLO-ASTTKIAZINE & 9.13 & 8.59 & -- & $\begin{array}{l}8.61 \\
\text { Me } \\
2.791\end{array}$ & $\begin{array}{l}8.45 \\
8.67\end{array}$ & -- \\
\hline TRI I AZOLOPYFAZ INE & 9.38 & 8.50 & $\begin{array}{l}7.90 \\
8.19\end{array}$ & $\begin{array}{l}8.59 \\
8.58\end{array}$ & -- & $\begin{array}{l}9.40 \\
9.57\end{array}$ \\
\hline
\end{tabular}


TABLE IV

CHEMICAL SHIFTS OF S-HYDFAZINO-AS-TFIAZINE-1-OXIDES. DIFFERENCES BETWEEN $\mathrm{H}-\mathrm{S}-\mathrm{H}-6$

COMPOUND

$\underline{H}=\underline{5}-\underline{H}=\underline{E}=d i f f$ erence OTHEF FFIOTONS (PPm)

3-HYDRAZINE-AS-TRIAZINE-1-OXIDE

$8.68-8.10=0.58 \quad$ NONE

3-(4-FHENYL-THIOSEMICAREIZIDE ) HYDRAZ IND-AS-TFIAZINE-1-QXIDE

$8.77-8.26=0.51 \quad$ NONE

3-EENZYLIDENEHYDFAZIND-AS-TFI AZ INE-1-OXIDE

$8.80-8.28=0.52$ benylideno proton 8.50

S-FORMYLHYDRAZ INO-AS-TRIAZINE-1-OXIDE

$8.88-8.32=0.56$ formyl proton 8.50

3-METHYLIDENEHYDRAZ INO-AS-TR I AZ INE-1-OXIDE

(expected)

$8.80-8.30=0.50$ methylideno proton 8.50

(found)

$7.60-8.30=-0.70 \quad$ methyl ideno proton 7.60 
TABLE $V$

DIFFEFENCES BETWEEN FARENT AND N-OXIDE FFIOTON CHEMICAL SHIFTS OF SOME POLYAZAINDENES.

IMI DAZO[ 1, 2a]PYRAZ INE

$\begin{array}{llll}\text { EQSIIION } & \text { FARENT } & \text { N-OXIDE } & \text { DIFEEFENCE } \\ H-2 & 7.80 & 9.05 & -0.25 \\ H-3 & 7.80 & 7.76 & +0.04 \\ H-5 & 8.07 & 8.71 & -0.65 \\ H-6 & 7.82 & 7.78 & +0.04 \\ H-8 & 9.06 & 8.83 & +0.23\end{array}$

TRIAZOLO[3, 4C]1.2,4-TRIAZINE

\begin{tabular}{llll}
\multicolumn{5}{c}{ - METHYL } \\
$H-3$ & 9.1 .3 & 9.28 & -0.15 \\
$H-5$ & 8.80 & 9.07 & -0.27 \\
$H-6$ & -- & 8.10 & ---
\end{tabular}

TRI IAZOLOLF, 4C JFYFAZINE

$\begin{array}{cccc}\text { 8-CHLORO } & \\ H-5 & 9.25 & 9.21 & +0.02 \\ H-5 & 7.90 & 8.74 & -0.76 \\ H-6 & 7.36 & 7.79 & +0.45 \\ H-8 & - & 9.14 & -\end{array}$

TRI AZOLOL 1, SA JFYYRAZINE

$\begin{array}{llll}H-2 & 8.50 & 8.62 & -0.12 \\ H-5 & 8.58 & 9.11 & -0.55 \\ H-6 & 8.19 & 8.03 & +0.16 \\ H-8 & 9.57 & 9.06 & +0.51\end{array}$

IMIDAZO[1, Sa]PYRAZ INE

$\begin{array}{llll}H-1 & 7.83 & 7.63 & +0.20 \\ H-3 & 8.28 & 8.25 & +0.03 \\ H-5 & 7.58 & 7.97 & -0.41 \\ H-6 & 7.91 & 7.38 & +0.5 .3 \\ H-8 & 9.03 & 8.56 & +0.47\end{array}$


TABLE $\vee$ CONT INUED

\section{5-TRI AZOLOLE, 4b ]PYR I DAZ INE}

$\begin{array}{llll}\text { FQSIIIQN } & \text { FARENT } & \text { N-OXIDE } & \text { DIFEEFENCE } \\ H-5 & 9.15 & 9.74 & =0.59 \\ H-6 & 8.40 & 9.35 & +0.05 \\ H-7 & 7.17 & 7.46 & -0.29 \\ H-8 & 8.20 & 8.04 & +0.16\end{array}$

IMIDAZO[ 1, 2b ]FYFIDAZINE

$\begin{array}{llll}\mathrm{H}-\mathrm{Z} & 7.76 & 7.56 & +0.10 \\ \mathrm{H}-\mathrm{S} & 7.99 & 8.80 & =0.81 \\ \mathrm{H}-6 & 8.30 & 7.82 & +0.48 \\ \mathrm{H}-7 & 7.00 & 7.00 & 0.00 \\ \mathrm{H}-8 & 7.95 & 7.58 & +0.38\end{array}$


PART 2 
I. HISTORY OF NITROGEN-15 NUCLEAR MAGNETIC RESONANCE (NMR).

\begin{abstract}
Since Nitrogen-14 and Nitrogen-15 nuclei have non-zero spin quantum numbers they lend themselves to nuclear magnetic resonance spectroscopic studies. In 1957, Fiay and Dgg examined the nitrogen-14 spectra of several compounds to aid in structure determination studies (1). Continued studies of nitrogen nuclear magnetic resonance spectra provided the necessary background information for others to expand its use $(2-6)$.

Nitrogen-14 is present to the extent of $99.64 \%$, with a spin quantum number of 1 , and consequently a very large quadrupole moment. The spin-lattice relaxation time, T1 lsee equation 2), is large causing an increase in the T2'term. Inclusion of the T2'value into equation 1 increases the, $I(H)$, causing this line broadening. This line broadening in nitrogen-14 can be up to $1000 \mathrm{hz}$.
\end{abstract}

$$
\begin{array}{cl}
I(H)=T 2^{\prime} / P i \text { EXP }\left[\{-(H-H M) \text { EXP } 2)\left(T 2^{\prime} \text { EXP2)/pi }\right]\right. & \text { eq. } 1 \\
1 / T 2^{*}=1 / T 1+1 / T 2 & \text { eq. } 2
\end{array}
$$

This 1 ine-broadening problem is not present in the nitrogen15 isotope with the spin quantum number of $1 / 2$. The biggest drawback in using the nitrogen-15 isotope is that it has a very low natural abundance and a rather low sensitivity. 
Converison from nitrogen-14 chemical shifts to nitrogen-15 chemical shifts can be done by multiplying by the ratio of the magnetogyric ratios with the nitrogen-14 chemical shifts ( see equation 3 ).

$$
\begin{array}{r}
N-15 \text { chemical shifts }=(\gamma N-15 / \gamma N-14) * N-14 \text { shifts } \\
\text { eq. }
\end{array}
$$

The chemical shift of nitrogen nuclei can be expressed in terms of the semiempirical formula (eqaution 4) as developed for carbon-13 nuclear magnetic resonance spectroscopy. This qualitative treatment of the nitrogen chemical shift is hindered by the electrons which greatly.

$$
\sigma \text { total }=\sigma \text { dloc }+\sigma \text { ploc }+\sigma \text { other eq. } 4
$$

affect chemical shifts. The term $\sigma$ dloc is the local diamagnetic screening of the nucleus and comes from the magnetically induced local electron circulation about the nucleus ffor example proton chemical shifts are dominated by this term, which is closely related to electron density). The local paramagnetic term, oploc, is a measure of the spherical symmetry of electron distribution and is negative. The greater it becomes the more the electrons are in orbitals of nonzero angular momemtum.

The $\sigma$ other term in equation 4 expresses the influences on the chemical shift by causes other than the nitrogen nucleus. The "other" sources include anisotropic 
field and solvent effects, along with a number of other minor ones.

The major influences on the nitrogen chemical shifts arise from the diamagnetic and paramagnetic terms in equation 4. The "other" influences on the nitrogen chemical shifts are considered very small and are not treated in this qualitative analysis.

The paramagnetic term in equation 4 can be represented by three structurally related subterms. 1 see equation 5)

$\sigma$ ploc $=1 / E *[1 /(r$ expz $)] * \operatorname{sum} \theta \quad$ eq. 5

The $E$ subterm from equation $\mathbf{S}$ is related to the electronic excitation energy between the ground-state and the weighted excited-states of nitrogen. This subterm is the measure of accessibility of low-lying excited states of the nucleus.

The subterm [1/r exp3] in equation 5 is the inverse cube of the non-s orbital radius. This subterm is a direct measure of the amount of "s" character in the nucleus.

The subterm (sumQ) in equation 5 is a measure of the charge-density and bond-order and is related to the hybridization of the nucleus.

Equation 5 allows some general deshielding components to be identified and they are the following: 
1. a smaller transitional energy of the low-lying states is involved when deshielding occurs.

2. a smaller radius or orbitals with greater "s" character cause deshielding.

3. changes in bond length or changes in hybridization of the nucleus ( multiple bonding) cause deshielding.

EONDING EFFECTS ON NITROGEN-15 CHEMICAL SHIFTS

Two types of nitrogen generally exit in different heteroaromatic systems. Type I is referred to as "pyrrolelike'. These 'pyrrole-like' nitrogens have an unshared pair of electrons incorporated into the $\mathrm{E} i$ system of the heteroaromatic system. These 'pyrrole-like' nitrogen chemical shifts are similar to those found in the nitrogen in anilines.

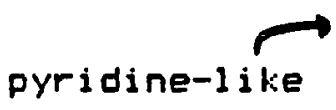

pyridine-like

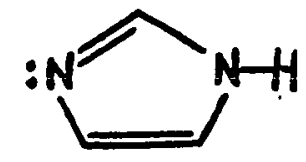

Type II nitrogen is labeled 'pyridine-like'. This type of nitrogen is sp-2 hybridized and its geometry places its unshared pair of electrons orthhogonal to the Qi system. The 'pyridine-like' nitrogens have an additional n - pi* transition which deshields them considerably more than the 'pyrrole-like' nitrogens.

Froton tautomerism is possible when both nitrogens are present in the same heteroaromatic system (as in imidazole above). This type of tautomerism causes, in many 
instances, the observation of only one absorption peal: in the nitrogen NMR spectrum. This tautomeric exchange averaging causes some $l$ ine broadening and is most evident in the nitrogen-15 spectra.

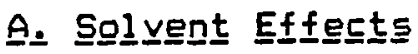

Litchman and coworl:ers measured the effects of solvent dilution on ammonia nitrogen-15 chemical shifts $(7,8)$ and proposed a linear combination of six interaction parameters, each of which makes a contribution to the nitrogen-15 chemical shifts at infinite dilution (9).

$$
\begin{aligned}
& \text { A-OH hydrogen bonding between the } N-15 \text { lone } \\
& \text { pair and a solvent } \mathrm{DH} \text { proton } \\
& \text { A-NH hydrogen bonding between the } \mathrm{N}-15 \text { lone } \\
& \text { pair and a solvent NH proton } \\
& \text { A-Me interaction between the } N-15 \text { lone pair } \\
& \text { and a solvent methyl group } \\
& \text { A-Et interaction between the } \mathrm{N}-15 \text { lone pair } \\
& \text { and a solvent ethyl group } \\
& \text { Bo hydrogen bonding between solvent oxygen } \\
& \text { lone pair and the } \mathrm{N}-15 \text { protons } \\
& \text { En hydrogen bonding between solvent nitrogen } \\
& \text { lone pair and } \mathrm{N}-15 \text { protons }
\end{aligned}
$$

On the basis of this model and a number of assumptions the infinite dilution shifts for ammonia in EtOH as a solvent are:

$$
\text { shift EtOH }=1 / 2 \mathrm{~A}-\mathrm{Et}+1 / 2 \mathrm{~A}-\mathrm{OH}+50 \text { eq. } 6
$$


Foberts and others have established various relationships for the nitrogen chemical shifts of pyridine in different solvents (10). The correlation with Kosower's $Z$ values and $\mathrm{N}-15$ chemical shifts affords a coefficient of correlation $(r)$ of 0.944 (10a) and a relationship between the $n$ to pi* transitions and the nitrogen chemical shift seems indicated. Similar studies of solvent dependences were done on pyrroles, indoles, pyrazoles and imidazoles (11).

The theoretical validity of these types of correlations were shown by Kato, Kato and Yonezawa (12).

Kolling used the Kamlet, Taft and Addoud method of computing the hydrogen-bonding and acceptor effects ( alleha terms) versus the nitrogen-15 chemical shifts and obtained a useful relationship(14). This correlation yielded a multiple linear regression equation of:

$$
\begin{aligned}
& S=5.92(\mathrm{Qi} \underline{\underline{*}}+3.3 \underline{\mathrm{a}} \mathrm{g} \mathrm{gha})+1.5 \\
& \text { correlation coefficient }=0.993
\end{aligned}
$$

eq. 7

Kolling proposed that this equation is valid not only for the weaker hydrogen-bonding donors and acceptors but also for the non-hydrogen-bonding solvents. The dominant mechanism for the medium effects on chemical shifts is the probe-solvent dipolar interactions (14).

Many of these solvent dependent chemical shifts have been recorded and tabluated, and, in general, a typical shift of 10 to $20 \mathrm{ppm}$ is common $(13,15)$. 
B. Prototonatition of Nítrogen

In 1964, Herbison-Evans and Fichards described the effects of protonation on pyridine (4) and reported a shielding of $120 \mathrm{ppm}$ for the pyridinium ion relative to pyridine. This was rationalized as the result of removing the nonbonding electrons of the nitrogen by protonation and causing changes in the local paramagnetic term of the $n-p i *$ transition to the greater sigma- pi* transition.

Foberts and others have shown that the protonated shifts of azoles and azines are similar to those of the azines but the magnitude is not as great $(10,11)$. These workers concluded that the solvent was not only changing the ion-pair distance but also the counterion influence on the nitrogen chemical shifts as well (10a).

Methylation of azine nitrogens has the same effect as protonation and the products show considerably less sensitivity to solyent influences. The nitrogen chemical shifts of methylated compounds are minimally influenced by changes in the counter anion (10a).

In general, protonation and methylation shields the nitrogens by about 100 Ppm $(13,15)$.

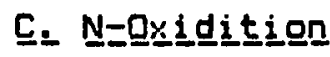

N-oxidition produces shielding of the nitrogen chemical shift, but the magnitude of displacement is much smaller than the shift upon protonation $(4,16)$. One possible 
reason for this smaller effect is that, although the azinium ion stabilizes the non-bonding electrons, the two n-pi* transitions in oxygen decrease the overall magnitude of the chemical shift contribution (4). An interesting trend can be seen for the number of $n$ to $p i *$ transitions and the chemical shifts:

FYFIDINE

FYRIDINE-N-OXIDE N-HYDFDXYFYFIDINE FYRIDINIUM ION
320 FFM DOWNFIELD

280 PPM DOWNFIELD 2 (N TO PI*)

230 FFM DOWNFIELD 1 (N TO FI*)

200 PFM DOWNFIELD 0 (N TO PI*)

The upfield shift of the pyridine-N-oxide nitrogen relative to the pyridine nitrogen is consistent with the removal of the lone pair of electrons (16a) which suggests that the smaller overall shift is due to the increased electronegativity of the oxygen (16a). Lichter also noted that the nitrogen chemical shift of pyridine-N-oxide, relative to that in the pyridinium ion is of 88.7 ppm (16a). This is more than twice the difference of the 2 nucleus (39.6 pPm) between $\mathrm{C}-1$ of the phenoxide ion and benzene (16a). This shift might well be a reflection of the higher $\mathrm{Q}$ i bond character in the $N-\mathrm{Q}$ bond compared to the $\mathrm{C}-\mathrm{D}$ bond (16a). Foberts and Yavari made a similar proposal to account for differences between the $\mathrm{N}-15$ chemical shifts in Pyridine-N-oxide and the pyridinium ion(16b). Foberts also reasoned that another fundamental difference between pyridine-N-oxide and the pyridinium ion nitrogen-15 chemical 
shifts is that a resonance form for the pyridinium ion could not be drawn (16b).

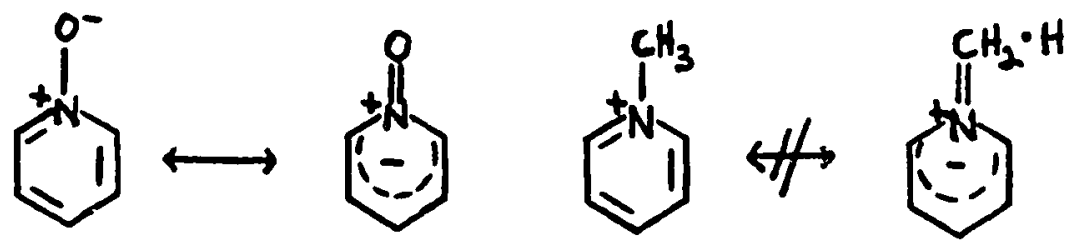

LINEAR CORFELATIONS

Herbison-Evans and Richards have shown that there exists a relationship between the ultraviolet spectra and nitrogen-14 chemical shifts of a number of substituted pyridines (4). This crude correlation suggests contributions of the $n$ to pi* transitions to the chemical shifts (4).

In 1972 , Webb and coworkers plotted the nitrogen chemical shift versus the ei-charge density and the mobile bond orders and obtained a linear correlation for the azoles and the benzazoles (17a). Earlier, Webb and coworkers used this type of correlations in the azine and the substituted pyridine series (17e). The INDO molecular orbital calculations were used to abtain the gi-charge densities of several simple azines which were plotted against the nitrogen chemical shifts of these azines (17c). These plots gave a very good linear correlations but, were insensitive to any geometric changes (17d).

Stefaniak compared the chemical shifts of monoazines and azines versus their $\mathrm{N}$-oxides and noted that the shifts, 
within the two groups, are parallel to each other (18). A linear equation for the diazines and monoazines $\underline{\text { s }}$ their $\mathrm{N}$ Qxides was calculated and is: (18)

for diazines:

$$
\begin{array}{ll}
y(N-a \times i d e)=0.3117 \times(N)+62.0 & \text { eq. } 8 \\
y(N)=2.984 \times(N-0 \times i d e)-182.9 & \text { eq. } 9 \\
\text { correl ation coefficient }=0.9645 &
\end{array}
$$

for monoazines:

$$
\begin{aligned}
& y(N-0 \times i d e)=0.7646 \times(N)+37.48 \\
& y(N)=1.2969 \times(N-0 \times i d e)=47.93 \\
& \text { correlation coefficient }=0.9956
\end{aligned}
$$

Similar linear correlations exist between the $\mathrm{N}$-oxides and the pi charge densities calculated by the Pariser-Parr-Pople method (18). The corresponding equations are: for diazines:

$$
\begin{aligned}
& y(N-\text { oxide })=353.4 \times(q)-328.8 \\
& y(q)=0.002642 \times(N-0 \times i d e)+0.9434 \\
& \text { correl ation coefficient }=0.9663
\end{aligned}
$$

for monoazines:

$$
\begin{array}{ll}
y(N-o \times i d e)=6071.5 \times(q)-7029.5 & \text { eq. } 14 \\
y(q)=0.0001 .3878 \times(N-q \times i d e)+1.160 & \text { eq. } 15 \\
\text { correlation coefficient }=0.9179 &
\end{array}
$$

In 1980, von Philipsborn and coworkers reported the beta, gama, and delta-subsitutuent effects of the amino and alkyl groups of pyrimidines (19). A linear correlation was observed between the amino substituents on the ring nitrogen chemical shifts (N-15) in aminopyridines and the corresponding carbon-13 chemical shifts in aminobenzenes. Similarly, a relationship between the nitrogen-15 chemical 
shifts of aminopyrimidines and the carbon-13 chemical shifts of aminopyridines exist (19).

for aminopyridine:

difference of shift $(N$ shift $)=3.73 * d i f f e r e n c e$ of shift shift (C-13 Shift) -4.62

correlation coefficient $=0.9985$

eq. 16

for aminopyrimidine:

difference of shift $(N$ shift $)=2.78 * d i f f e r e n c e$ of shift $(C-13$ shift $)-3.38$

correlation coefficient $=0.9904$

eq. 17

Webb, Witanowski and Stefaniak expanded Stefaniak's earlier work (18) to include several additional azine $\mathrm{N}$ oxides (20). Webb's correlation of the nitrogen chemical shifts of azines and the average excitation energy calculated local paramagnetic term times the average excitation energy (20). The correlation coefficient was 0.9963.

The substituent correlations of pyridine were latar expanded by von Philipsborn and coworkers to include most of the available substituents and a new correlation equation was derived (21). A similar substitution correlation was also derived for pyrimidines (21).

for pyridine:

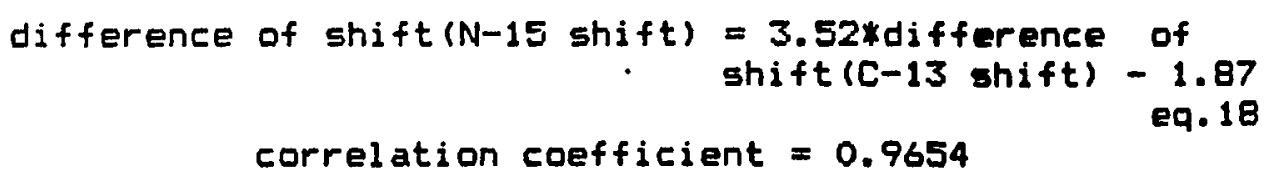
shift $(C-13$ shift) -1.87 eq. 18 correlation coefficient $=0.9654$ 
for pyrimidine:

$$
\begin{aligned}
\text { difference of shift }(\mathrm{N}-15 \text { shift }) & =2.89 * \text { difference of } \\
& \text { shift(C-13 shift })-0.47 \\
\text { correlation coefficient } & =0.9789
\end{aligned}
$$

The substitutuent effects of pyrazine were described in 1980 by Gunther and coworkers (22) in the same way as had been done by von Fhilipsborn and coworkers (21). A linear correlation with $\mathrm{N}-2$ gave the following equation:

for pyrazine:

$$
\begin{aligned}
& \text { difference of shift }(\mathrm{N}-15 \text { shift })=3.05 * d i f f e r e n c e \text { of } \\
& \text { shift }(C-13 \text { shift })-9.68 \\
& \text { correlation coefficient }=0.9744 \\
& \text { eq. } 20
\end{aligned}
$$

Attempted correlations with $\mathrm{N}-4$ did not yield satisfactory results.

In 1983, Yanez and coworkers described the linear correlation with charge density and the amino-substituted pyridines and pyrimidines (23) similar to the results of von Philipsborn and coworkers (19).

\section{NITROGEN-15 CHEMICAL SHIFTS}

The chemical shift standard reference for nitrogen-14 and -15 is anhydrous ammmonia at $25 \mathrm{c}$. The chemical shift behavior of ammonia as a liquid and a gas has been studied extensively, (7-9) and its resonance position is easily established and is readily reproduced.

An excellent secondary reference is nitromethane. 
Although the nitrogen chemical shift of nitromethane is influenced by solvents, its strong resonance signal is easily detected. Another advantage is that the nitromethane nitrogen lies at the low-field end of the "normal" spectrum. The nitrogen nuclei of heteroaromatic compound absorb in this region. Nitromethane can be used as a combination of reference and lock signal ( if the niti-ogen isotope enriched nitromethane in perdeuterio nitromethane is used). This combination, when used as an external reference, is the one of choice.

AZOLE CHEMICAL SHIFTS.

The nitrogen-14 and -15 chemical shifts of some of the azoles are listed in table 2 .

In the five membered heteroaromatics, both the 'pyrrole-like' and the 'pyridine-like' nitrogens can be present, and if they are a proton exchange can occur. The proton exchange phenomenon produces one spectral line in the NMFi time scale, unless the resonance positions are widely separated (105).

Pyrrole, the simplest of all the azoles, has a nitrogen-14 chemical shift of $148.8 \mathrm{ppm}$ down field for ammonia (10c). Methylation of the pyrrole nitrogen results in a small shielding effect on the nitrogen of 5 to $8 \mathrm{ppm}$.

Fyrazole has nitrogens at positions 1 and 2 and both 'pyridine- and pyrrole-like' nitrogens present. The 


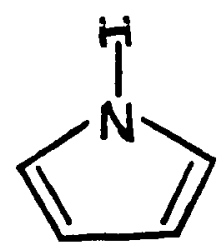

pyrrole

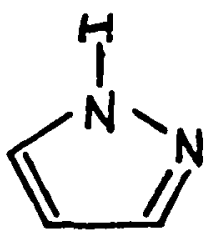

pyrazole

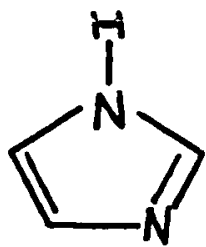

imidazole

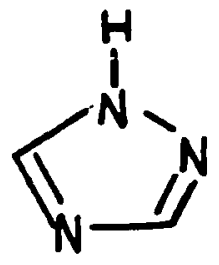

$1,2,4-t r i a z a l e$

resonance position of both nitrogens is 251 ppm (10c). Methylation produces two nitrogen chemical shifts of $\mathbf{2 0 6 . 2}$ ppm for the methylated nitrogen and $308 \mathrm{ppm}$ for the nonmethylated nitrogen (10c).

Imidazole nitrogens at positions 1 and 3 , behaves similarly to those in pyrazole (106,11b).

The 1,2,4-triazole, nitrogens at positions 1,2 and 4, produce only one chemical shift (245 ppm) in acetone. This is due to rapid proton exchange which averages these chemical shifts (10c). Methylation of 1,2,4-triazole produces 3 unique resonances of 228.2 (n-methyl), $261(N-2)$ and $329(\mathrm{~N}-4)$ (IOC). These resonances are different than those reported in Table 2 for 1-methyl-1,2,4-triazole.

Additive chemical shift rules for 'pyrrole-like" nitrogens are reported by Webb and coworkers $(14 b, 17 a, 24)$ and are dependent on several algebraic summations. Their contributions are as follows:

1. $-50+1.5 \mathrm{ppm}$ for each pyridine like nitrogen in positions 2 or 5.

2. $-30+4 \mathrm{ppm}$ for each pyridine like nitrogen at position 3

3. $-12+2 \mathrm{ppm}$ additionally for each pyridine like 
nitrogen which is next to a nitrogen at position 2 or 5

4. $+7+2.5 \mathrm{ppm}$ additionally for each pyridine 1 ike nitrogen which is next to position 3 or 4.

The nitrogen chemical shifts in the oxazoles were found to be very similar to the chemical shifts found in the azole series. (24) The similarities between the adjacent nitrogen or oxygen on nitrogen-15 chemical shifts has been determined. (24)

The oxazoles, thiazoles, n-methylazoles and indolizines have been examined by Stefaniak in 1978 (25). The additive rules used by Webb and coworkers were extended for azoles to account for the introdution of sulfur (25).

B. CHEMICAL SHIFTS OF AZINES.

In 1964, Fichards and coworkers reported the nitrogen-14 chemical shifts of pyridine and several substituted pyridines (4). They showed the existence of strong solvent effects in seyeral 2-substituted pyridines and in the 2-,3- and 4-picoline-N-oxides (4).

In 1965, an attempt was made to correlate hyperconjugation, conjugation and charge-transfer interactions in substituted-pyridine and pyridine $\mathrm{N}$ owide (5). The authors found that any electron/bonding change with the lone pair of electrons leads to the reduction of the paramagnetic term in equations 4 and 5 . This effect is seen by the greater shielding of pyridinium 
ions and in pyridine-N-oxide. The 2-,3- and 4-amino pyridines have been studied (5). This study is important, because of the possible tautomeric and resonance forms that can exist in the 2 and 4 isomers where electron flow from the orttho and/or Raraa substituted compounds (see example below for aminopyridine) (5). The resonance stabilization would result in the shielding of the ring nitrogen and deshielding of the animo nitrogen (5).
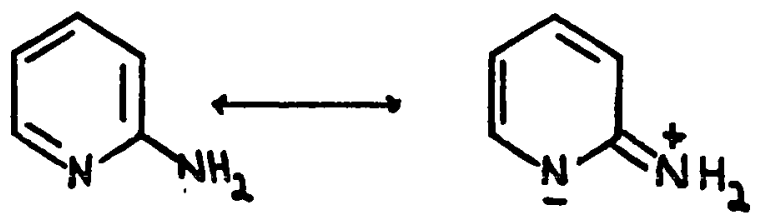

Substituent effects on pyridine were reported in more detail by Webb and coworkers (26). The substituent effects were divided into two groups; group I li.e. nitro, cyano, formyl and acetyl) which represented the electronwithdrawing effect via an inductive and/or conjugative mechanism, and group II (i.e. hydroxy, methoxy, amino, and methyl groups) represented the electron releasing effect by resonance contributions or hyperconjugation. The electron withdrawing substituents shifted the nitrogen-14 resonances downfield relative to the resonance position of pyridine (17b). Webb and coworkers noted that in two compounds, the 2-nitro and the 2-acetylpyridine, showed a higher than expected chemical shift by 15-18 ppm. This Interesting 
effect was probably due to forced non-coplanarity of the ring and/or substituent dipole-dipole replusions (17b).

For group II substituents, the amino and hydroxy groups can exist in a tautomeric forms (see below). Webb and coworkers determined that the pyridone form of the 2and 4-hydroxy pyridine were favored by the higher chemical shifts observed (26). Similarly the 2- and 4- aminopyridine structures are favored by the lower chemical shifts (26). The substitution at the meta position produced the<smiles></smiles><smiles>O=c1cc[nH]cc1F</smiles>

smallest resonance shifts, and substitution at the ortho position causes some steric effects (26). The Rara substitution showed good agreement with the conjugative and inductive effects expected by both groups (26). In 1974, Webb and coworkers reported the chemical shifts of several parent heterocycles (17c) which were correlated against the calculated paramagnetic terms in equation 5 . Webb and coworkers in another article reported the chemical shifts of the azines (17a).

$\begin{array}{ll}\text { 1,3,5-triazine } & 282 \mathrm{ppm} \\ \text { pyrimidine } & 298 \mathrm{ppm} \\ \text { pyridine } & 322 \mathrm{ppm} \\ \text { pyrazine } & 338 \mathrm{ppm} \\ 1,2,4,5-t e t r a z i n e & 385 \mathrm{ppm} \\ \text { pyridazine } & 400 \mathrm{ppm}\end{array}$


Stefaniak, in 1976, reported the chemical shifts of several azine-N-oxides and these are reported in table 3 (18). Stefaniak noted that a trend existed between the mono-N-oxides nitrogen chemical shift and the addition of conjugated aromatic rings (18). Stefaniak developed a additive scheme to calculate these trends (18).

Webb and coworkers, in 1978, reported the chemical shifts of 1,2,4-triazine and benzo-1,2,4-triazine (25). These chemical shifts were calculated by additive rules developed by Webb earlier (17). In general they found the following trends: (1) the $(\mathrm{N}-1)-(\mathrm{N}-2)$ one bond interaction was predicted to have a large deshielding effect; (2) the $(N-2)-(N-4)$ two bond interaction is predicted to cause a moderate shielding effect, (3) and the $(N-1)-(N-4)$ three bond interaction was predicted the has a moderate deshielding effect. The actual and predicted nitrogen chemical shifts are shown below:

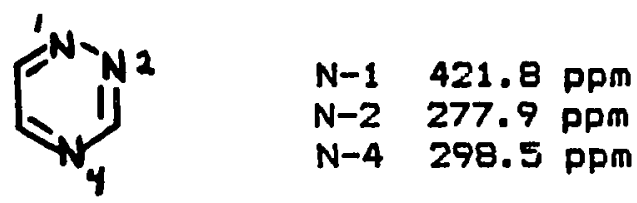<smiles></smiles>

$\mathrm{N}-1 \quad 458.1 \mathrm{ppm}$ $\mathrm{N}-2 \quad 406.3 \mathrm{ppm}$ $\mathrm{N}-4 \quad 281.7 \mathrm{pPm}$

calculated values of 1,2,4-triazine $\mathrm{N}-1469 \pm 8 \mathrm{ppm}$ $\mathrm{N}-2428 \pm 8 \mathrm{ppm}$ $\mathrm{N}-4388 \pm 8 \mathrm{ppm}$ 
The 1,5-, 1,6-, 1,8-naphthyridines nitrogen-14 chemical shifts are very similar to those of quinoline and isoquinoline. In addition the nitrogen in the adjacent aromatic ring has little effect on either nitrogen-14 chemical shifts (26). In 1,8-naphthyridine, the geriposition nitrogen has very little effect on the adjacent nitrogen-14 chemical shift (26).

$\begin{array}{ll}\text { 1, 8-naphthyridine } & 293 \mathrm{ppm} \\ \text { 1,6-naphthyridine } & 316 \mathrm{ppm} \\ \text { 1,5-naphthyridine } & 308 \mathrm{ppm} \\ \text { quinoline } & 309 \mathrm{ppm} \\ \text { isoquinoline } & 312 \mathrm{ppm} \\ \text { quinazoline } & 290 \mathrm{ppm}\end{array}$

Lichter and coworkers in 1978 examined the nitrogen-15 chemical shifts of alkylpyridines and picolinium, lutidinium ions as well as the picoline $\mathrm{N}$-oxides (15a). They noted that orthho and/or parga substitution induced small upfield shifts while the meta substitution produces essentially no change in the nitrogen-15 chemical shift relative to pyridine (15a). The authors noted that the pyridine-N-oxide nitrogen resonance is upfield relative to pyridine and was consistent with the loss of the lone pair of electrons on nitrogen. The magnitude of this 1055 for pyridine-N-oxide was less than that found for the pyridinium ion. This result was thought to be a reflection of higher pi bond character in the $\mathrm{N}-\mathrm{O}$ bond (see below). Roberts confirmed these results (15b). 


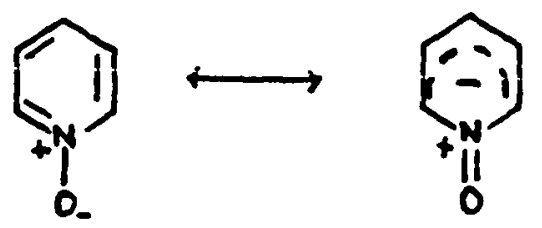

Foberts and coworkers found that the small nitrogen-15 chemical shifts observed in pyridine are very sensitive to the type and the position of the substituents (15b). For example, chemical shift changes of 4-methoxypyridine-Noxide was 33 ppm higher field than that of 4-nitropyridine-

N-oxide (15b). This result was attributable to the highly electronegative effect of the 4-nitro group and the very strong electron releasing effect of the 4-methoxy group influencing the resonance structures of pyridine-Noxide (15b). These effects are illustrated below:

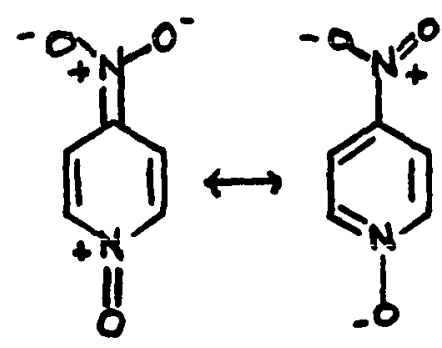<smiles>COc1cc[n+](OC)cc1</smiles>

Several azine-N-oxides nitrogen chemical shifts were calculated by additive rules developed earlier by Webb $(20)$. It is of interest that the calculated nitrogen-15 chemical shifts of several azine-N-oxides agreed closely with their experimental values (20).

The substituent effect on pyridine, pyrimidine and pyrazine have been reported (21-22). The linear correlation 
have been discussed earlier in this text, the chemical shifts of these substituted compounds are described in the following paragraph.

Von Fhilipsborn and coworkers predicted the nitrogen15 chemical shifts of the amino substituents on pyrimidine and pyridine (19). The ring nitrogen of pyridine, pyrimidine and pyridazine (relative to the ortho amino group) experiences substantial shielding (19). The shielding shifts in general (parent azine minus substituted azine) for the ortho, meta, and para positions were $-50.8,-0.9$ and -40.7 ppm respectively (19). A similar trend can be seen for the amino pyrimidines, however, the magnitude of the nitrogen-15 chemical shift was approximately half of what was expected. Von Philipsborn and coworkers suggested that a more effective conjugation was present in the pyrimidine system (19), see conjugated resonance form following:

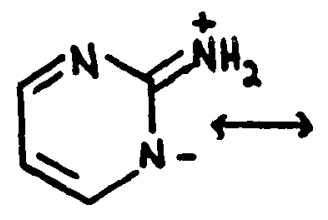<smiles>Nc1ncccn1</smiles><smiles></smiles>

\section{NITROGEN CHEMICAL SHIFTS OF POLYAZAINDENES}

The polyazaindenes systems have only recently been examined by nitrogen-15 NMR. Webb and coworkers in 1979 examined seven polyazaindene systems (17d). The chemical shift assignments were determined by the AEE calculationa. (See table 4 for the chemical shifts.) 
One of the major purposes of this work was to examine the polyazaindene systems. Correlation of the ground-state resonance contributing structure was calculated. The results of this study follows (page 91-95). In addition substitution parameter for pyridine, pyrimidine, pyrazine and 1,2,4triazine has been studied. The pyrazine- and 1,2,4triazine- N-oxides contribution to the nitrogen-15 chemical shifts is preposed. The results of this study follows (page 95-99). 
II I. DISCUSSION

A. N-15 Chemical Shifts of a Number of Folyazaindenes: Correlation with Charge Separated Resonance Contributing Structures

$$
\text { Studies by the Faudler research group have focused on }
$$

the existence of several different ground-state resonance forms in these systems $(27,28)$. In 1977, Faudler and coworkers proposed structures $A$ and $B$, based on the low-<smiles>C[Y](C)(C)N1C(=O)c2nc3ccccc3n21</smiles>

A

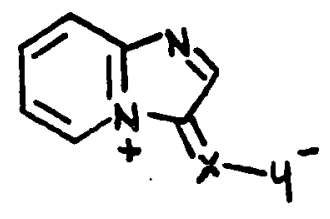

B

frequency proton nuclear magnetic resonance spectrum and on the infrared carbonyl absorption in the compounds bearing an aldehyde or dichloroacetyl groups (27). In 1980 this research group again examined the imidazo[1,2a]pyridine structuras (A and $\underline{B})$ by nuclear magnetic resonance spectroscopy (28). This time the uniform field theories of Buckingham's were employed to show that the same charge separated structural effects are indeed valid (28).

Table 5 shows the $\mathrm{N}-15$ chemical shifts obtained in this study, as well as those reported in ref 170 . Among all of the polyazaindenes the bridgehead-atom, $\mathrm{N}-4$, is always the most shielded nitrogen, except in some instances where it is directly bonded to another nitrogen atom $(\underline{q}, \underline{q}, \underline{1})$. The contribution of the resonance contributing structures such 


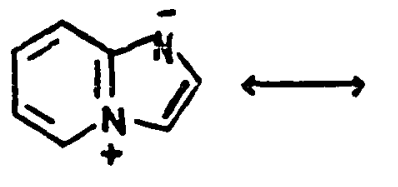

C<smiles>CCn1cc2cccc[n+]2c1</smiles>

D<smiles>c1ccn2ccnc2c1</smiles>

$\mathbf{E}$<smiles>c1ccn2cncc2c1</smiles>

$\mathbf{F}$

as $\subseteq$ and $D$ elearly places a partial positive charge on the bridge nitrogen and a partial negative charge on $\mathrm{N}-1$ or $\mathrm{N}-2$ respectively.

When pyridine $[\mathrm{N}-15$ shift $=317(\mathrm{ppm})]$ is quaternized, as in $\mathrm{N}$-methylpyridinium iodide, the nitrogen becomes more shielded by $123 \mathrm{ppm}$ (16b). Thus, if resonance structure $\underline{c}$ in Imidazo[1,2a]pyridine is the 'sole' resonance contribution structure to the ground state, the $\mathrm{N}-4$ nitrogen-15 chemical shift would be similar to that in N-alkylpyridinium ions. Conversely, the more deshielded the bridging nitrogen, $\mathrm{N}-4$, is with respect to the other polyazaindenes, the less this resonance structure contributes to the ground state of the compound. Among the structures listed in Table 5 , the polyazaindenes can be divided into two classes. (1): Compounds with $\mathrm{N}-4$ chemical shifts in the range 180-202 ppm, 
<smiles>c1ccn2ccnc2c1</smiles>

I: $N-X=n i l$

IV: $N-X=N-7$

V: $N-X=N-8$

VI: $N-X=N-2$<smiles>c1ccn2cncc2c1</smiles>

II

and (2) Polyazaindenes with $\mathrm{N}-4$ chemical shifts in the range 221-318 ppm.<smiles>c1ccn2nccc2c1</smiles>

III: $\mathrm{N}-\mathrm{X}=\mathrm{N}-2$

VII: $N-X=N-1, N-2$

$X: \quad N-X=n \dot{1}$

IX: $\quad N-X=N-1, N-8$

XI: $\quad N-X=N-1$<smiles>c1cnn2ccnc2n1</smiles>

VIII

Clearly, $N-4$ in those polyazaindenes with an $N-N$ bond involving the bridge nitrogen is invariably more deshielded than the nitrogens in those compounds without this structural feature.

If one considers these polyazaindenes as arising from the modification of a given pi-deficient ring systen. by fusion to a s-membered ring, the changeg in the chemical shift between the monocyclic nitrogen and the chemical shift of this now bridge-nitrogen in the polyazaindene will reflect the contribution of resonance contributing structures involving a positive charge on N-4. A plot of the difference in nitrogen-15 chemical shift between the 
bridgehead-nitrogen of the corresponding polyazaindene and the nitrogen-15 chemical shift of the 'parent' 6-membered ring heterocycle against the nitrogen-15 chemical shifts of the bridgehead nitrogen should be linear. The slope of this line will reflect the shieleding caused by the 5-membered ring. Among all of these compounds, the only ones which do not fulfill this linearity requirement are those where the nitrogen is orthog or Rara to the bridge nitrogen in the 6member ring (IX and VIII) ( see figure 1). The remaining nine polyazaindenes fall on the correlation line with Equation 21 (see figure 1 ).

\section{Equation 21}

CN-15 chemical shift (N-4 of polyazaindene)

- N-15 chemical shift (parent 6-membered heterocycle)]

$=0.93[\mathrm{~N}-15$ chemical shift $(\mathrm{N}-4$ of polyazaindene $)]+$ 203

When the chemical shift difference between the $\mathrm{N}$ methyl pyridinium ion and pyridine (deltza $=123 \mathrm{ppm}$ ) and the N-methyipyridinium ion chemical shift $(\mathrm{N}-15$ chemical shift $=179 \mathrm{ppm})$ is added to the graph shown in Fig. 1, they also fall on the correlation line. Thus, the relative contribution of resonance contributing structures such as $\underline{\underline{C}}$ and D is given by this correlation. In other words, compounds $\Sigma, \underline{\underline{2}} \underline{2}$ and 1 , exist to an extent greater than $70 \%$ in the resonance forms $\underline{C}$ and $\underline{D}$, respectively. Those polyazaindenes where the bridgehead nitrogens are directly bonded to another nitrogen (either at position 3 or 5) 
(compounds $\underline{9}, \underline{10}, \underline{1} \underline{1}, \underline{7}, \underline{3}$ and $\underline{8}$ ) exist largely (greater than 70\%) in the non-charge separated forms 1 such as in general structure E ). Two polyazaindenes, 1,4,7-triaza derivative 4 , and, the $1,4,5,8$-tetraaza derivative 8 , do not fall on the correlation line, nevertheless compound $\underline{4}$ can be judged as existing largely in the charge separated form (C), while the latter does not.

B. Nitrogen-15 Chemical Shifts of Some Pyrazines, 1,2,4Triazines and Their $\mathrm{N}$-0xides Correlation with Carbon 13 Chemical shifts and Substitution Parameters.

The existence of the linear relationships found by $w$. Stadeli and W. von Philipsborn and others suggests that a similar pattern should exist among the various parent heterocyclic systems and the des-monoaza analogs. In other words, the pyrazine nitrogen chemical shift should be related to the carbon-13 chemical shift of the gamma-carbon in pyridine. The pyridazine nitrogen chemical shift value should be related to the carbon-13 value fo the algha-carbon of pyridine and the pyrimidine nitrogen chemical shift should be related to the carbon-13 value of the beta-carbon of pyridine.

Figure 2 depicts the graph obtained when these considerations are applied to seven different nitrogens in $\mathbf{5}$ different heteroaromatic ring systems. The equation for this graph is: 
Equation 22

Nitrogen-15 Chemical Shift $=4.00 *$ Carbon-13 Chemical Shift -200

Clearly the corralation coefficient of $r=0.991$ is excellent. Table 8 compares the del stituted - parent) for pyridine (15a), pyrimidine (29), pyrazine (22) long with pyrazine and 1,2,4-triazine obtained is this study.

Comparison of one substituents effect among the four different ring systems is not consistent. For example, a 2methoxy group causes shielding differences of $-41,-49,-63$, and -60 , respectively, in the series: pyrimidine to pyridine to pyrazine to 1,2,4-triazine. Similar effects are noted for all of the other substituents, except for the fluoro instance (whether this is real or reflects some solventhydrogen bonding problem is a mute question for these analyses).

Linear correlation of delta-nitrogen-15 chemical shift verse deltä-carbon-13 chemical shift of the orthg substituted benzene in pyridine, pyrimidine and pyrazine follow the general equation of:

equation 23

[Nitrogen-15 chemical shift(substituted heteroaromatic - parent) ] = [ Carbon-13 chemical shifte ortho=carbogn substituted benzene - benzene] - $C$

These equations are tabulated in table 9. 
The Paudler research group has recently proposed a set of ei-deficiency parameters (pi-delta) for a number of heteraromatic compounds (30). These values, obtained from the carbon-13 chemical shift data, are:<smiles>c1ccncc1</smiles>

Ri-d므트로 $\quad 0.992$ intercept -14.13<smiles>c1ccncc1</smiles>

0.886 $-4.70$<smiles>c1cncnc1</smiles>

0.772

$+1.76$<smiles>c1cnncn1</smiles>

0.638 $[+11.65 \pm 0.5]$ est.

Thus, there is a gratifying interrelationship between the Ri_zdelta values of these heteroaromatic compounds 1 the smaller this value, the more pi-deficient is the ring system) and the nitrogen-15 chemical shifts(increasing intercept value correspond to increasing pi-deficiency). A linear correlation gives the following equation:

Equation 24

Nitrogen-15 Intercept $=\begin{array}{r}-72.03( \\ +57.93\end{array}$ Qí-deltia values

The correlation coefficient is 0.992 which is clearly excellent. When equation 24 used the intercepts of previously reported correlation the resulting correlation coefficient is lower $(r=0.918)$. This difference is not clearly understood.

Pyrazizine and 12224-Iriazine N-Qxides

These $\mathrm{N}$-oxides represent unique examples anong this type of heterocyclic $\mathrm{N}$-oxide because, backdonation of the 
lone-pair electrons of the $\mathrm{N}$-oxide oxygen leads to charge density increases on the ortho and para nitrogens with respect to the $\mathrm{N}$-oxide function shown by the following:

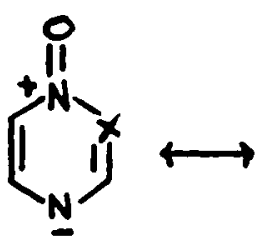

Table 10<smiles>[O-][n+]1[c-]cncn1</smiles>

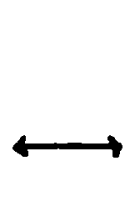<smiles></smiles>

experienced by the various nitrogens in some of the substituted pyrazines and 1,2,4-triazines when compared to their non-oxidized analogs.

Clearly, N-oxidation does not only cause shielding of the oxidized nitrogen (difference $=25-30 \mathrm{ppm}$ ) in pyrazines but also causes shielding (difference =18-30 ppm) of the non-oxidized nitrogen as well. The 3-methoxy- and the 3amino- pyrazine-1-oxides attenuate this effect due to their electron donating properties. Thus, the major ground state contributing structure for pyrazine-N-oxide is the following:<smiles>O=[N+]([O-])c1ccncc1</smiles>

The 1,2,4-triazine-1-oxide chemical shift change for $\mathrm{N}-1$ is -71 and $-87 \mathrm{ppm}$ for the 3-methoxy and 3-amino derivatives respectively. The shielding effect, as mentioned by Webb (20) for the parent compound, is clearly much larger than that observed in pyrazine-N-oxide. The $N-4$ shielding 
effect ( -27 ppm and $-21 \mathrm{ppm}$, respectively) is the same order of magnitude as that observed for the pyrazine-1oxide. The shielding (-39 ppm and -46 ppm, respectively experiemced by $\mathrm{N}-2$ ) is quite extensive and bespeaks a considerable contribution to the ground state structure.

In the 1,2,4-triazine-2-oxides, chemical shift changes for $\mathrm{N}-2$ is $-75 \mathrm{ppm}$ and $-69 \mathrm{ppm}$ for the 3-amino and 3-bromo derivatives, respectively. An amazingly large and equal shielding is observered for the $N-1$ 1-76 ppm and -73 ppm, respectively) in these compounds. Thus, it appears that a similar degree of backbonding exists in the 1- as well as the 2- oxides and, that in the former case charge dispersal occurs by $\mathrm{N}-2$ and $\mathrm{N}-4$, while in the latter case it is mainly "carried" by $\mathrm{N}-2$ ( $\mathrm{N}-4$ cannot be involved by rasonance). Therefore, the major resonance contributing structure must be the charge separated species.<smiles></smiles> 


\section{EXFERIMENTAL}

The N-15 spectra were obtained on a Nicolet NT-200 instrument operating at $20.27 \mathrm{MHz}$. Samples were placed in $20 \mathrm{~mm}$ 0.d. tubes. A typical sweep window of $2 \mathrm{KHz}$. Lusing $8 k$ words of memory was used to obtain the free induction decay data. N-15 decoupling was carried out with an inverse gated technique to suppress the NOE.

A co-axial $5 \mathrm{~mm}$ tube of $99 \%$ enriched nitromethane in deuterionitromethane served as a combination lock: and reference capillary, 0.05 M tris (acetylacetonate) chromium, Cr (acac) 3, was used to shorten the T-1 values. Normal operating conditions employed a 90 degree $f l i p$ angle and a pulse delay of 8 seconds.

Melting points were obtained on a Thomas Hoover capillary melting point apparatus and were not corrected. These proceedures were modified by the author and the physical properities are identical to the known samples

1. SYNTHESES OF SEVERAL FOLYAZAINDENDS FOR NITROGEN-15 SPECTROSCOPY

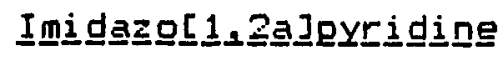

A solution of $39.4 \mathrm{~g}(0.20 \mathrm{~mol})$ allghä-bromoacetal dehyde diethyl acetal in $80 \mathrm{~mL}$ of diorane and $20 \mathrm{~mL}$ of water was warmed for $\Xi$ minutes. To this solution 5 drops of concentrated HCL was added, and the solution was refluxed until it turned clear ( 30 minutes). The solution was allowed to cool to room temperature and $19.2 \mathrm{~g}(0.20 \mathrm{~mol})$ of 2aminopyridine was added along with $17.0 \mathrm{~g}(0.20 \mathrm{~mol})$ of sodium bicarbonate. This solution was refluxed for 22 hours. The reaction mixture was made basic with $1 N$ sodium hydroxide and then extracted continuously with chloroform for 8 hours. The chloroform extract was dried over anhydrous sodium carbonate and reduced under vacuum to yield a dark oil. The oil was vacuum distilled at $0.05 \mathrm{mmHg}(6 . p .109-115$ C, yield $88.3 \%$ ). 


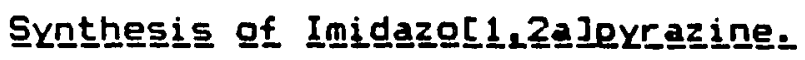

To a solution of $20 \mathrm{~mL}$ dioxane, $20 \mathrm{~mL}$ of water and

$9.99(0.05$ mol) 2lgha-bromoacetaldehyde diethyl acetal (97\%) was added 5 drops of concentrated hydrochloric acid. The solution was refluxed for 30 minutes until a clear solution was obtained. This solution was allowed to cool to room temperature and then $4.7 \mathrm{~g}(0.05 \mathrm{~mol})$ of 2-aminopyrazine was added. The solution was refluxed for 15 minutes and to the hot solution was added $5.3 \mathrm{~g}(0.062 \mathrm{~mol})$ of anhydrous sodium bicarbonate. This solution was refluxed for 15 hours and then was continuously extracted with methylene chloride for 72 hours. The extract was dried over sodium carbonate and reduced under vacuum to vield a dark solid compound. This solid was sublimed at $22 \mathrm{Cl} 0.05 \mathrm{~mm} \mathrm{Hg}$ (m.p. 83-84 C, 42\% yield).

Synthesis of Inidazg[1,2a]gyrimidinge.

The imidazoli, 2ajpyrimidine was prepared by condensing zlpha-bromoacetaldehyde diethyl acetate with 2-amino pyrimidine by the procedure used for the synthesis of imidazo[1,2]pyridine. The imidazo[1,2a]pyrimidine was purified by column ehromatography on grade 3 neutral woelm alumina using 50\% petrolum ether / 50\% ethyl acetate. The eluent was evaporated to dryness under vacuum to yield a white solid (m.p. 215-217 C, 58\% yield). 


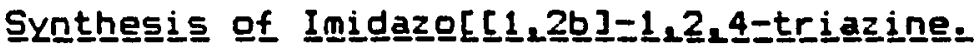

The imidazo[1,2b]-1,2,4-triazine was prepared by condensation of algha-bromoacetaldehyde diethyl acetal with 3-amino-1,2,4-triazine by the proceedure used for the preparation of imidazo[1,2ajpyridine. Purification of the imidazo[1,2b]-1,2,4-triazine was by sublimation at $25 \mathrm{c}$, $0.05 \mathrm{mmHg}$ vacuum to yield a light yellow solid ( $36 \%$ yield, m.P. 110-111 C).

Synthesis of Imidazo[ 2 SEa Jeyrazinge.

A mixture of $6.09(0.057$ mol) 2-aminomethylpyridine and $12 \mathrm{~mL}$ of formic acid were refluxed for 3 hours. Fractional distillation yielded $5.39(0.038 \mathrm{~mol}$, yield $86 \%)$ of 2-formamidomethyl pyridine.

The 2-formamidomethylpyridine was added to $12 \mathrm{~mL}$ of phosphorous oxychloride in $30 \mathrm{~mL}$ of benzene and refluxed for 3.5 hours. The excess phosphorous oxychloride and benzene were renoved under vacuum distillation. To the remaining residue, $50 \mathrm{~mL}$ of ice water basified with $15 \mathrm{~N}$ ammonium hydroxide was added and extracted with $4 \times 50 \mathrm{~mL}$ portions of chloroform. The chloroform extract was reduced under vacuum and the resulting oil was vacuum distilled. Imidazo[1,5a]pyridine was collected at 95-100 c/0.06 mm / m.p. 56-58 c, $62 \%$ yield). 


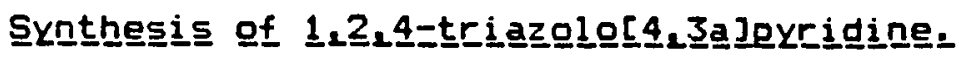

A solution of $5.0 \mathrm{~g}(0.045 \mathrm{~mol})$ 2-hydrazinopyridine in $20 \mathrm{~mL}$ of formic acid was refluxed for 6 hours. The solution was reduced under vacuum and the dark oil was applied to a grade 3 alumina (neutral) column and eluted with $50 \%$ benzene / $50 \%$ diethyl ether mixture to yield 1.39 $(0.011 \mathrm{~mol}$, yield $24.3 \%)$ of 1,2,4-triazolo[4,3a]pyridine.

SYnthes

A solution of $2.09 \cdot(0.0168$ mal $)$ 1,2,4triazolo[4,3a]pyridine in $50 \mathrm{~mL} 50 \%$ sodium hydraxide solution was refluxed for 48 hours. This solution was continuously extracted with methylene chloride for 105 hours and then evaporated under vacuum to yield a dark oil. The oil was dissolved in diethyl ether and slowly concentrated under a gentle stream of nitrogen to yield a white solid. The white solid was recrystallized in petroleum ether to yield 1.05g (52.5\% yield) of 1,2,4-triazolo[1,5a]pyridine.

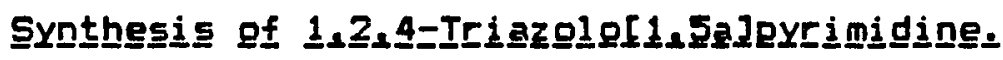

A solution of $20 \mathrm{~g}(0.24 \mathrm{~mol})$ of 3-amino-1,2,4-triazole and $80 \mathrm{~g}(0.36 \mathrm{~mol})$ of $1,1,3,3$-tetraethoxypropane in glacial acetic acid was warmed to $120 \mathrm{C}$ for 12 hours. The solution was evaporated to dryness under vacuum and the solid residue was sublimed at $130 \mathrm{C} / 0.05 \mathrm{~mm} \mathrm{Hg}$. The yield was $13 \mathrm{~g}$ (44.7\%), and the melting point was 140-142 C. 
2. SYNTHESES OF SUBSTITUTED PYRAZINES AND TRIAZINES AND THEIR N-OXIDES.

Syntheses of Substitututed Pyrazine N-Qxidges.

Synthesis of 2= and 3=Methyl Pyrazine=1=oxides.

To a room temperature solution of $24 \mathrm{~mL}(0.31 \mathrm{~mol})$ $30 \%$ hydrogen peroxide in $36 \mathrm{~mL}$ of acetic acid was added 13.8g (0.146 mol) of 2-methyl pyrazine. This solution was heated in a 80 degree oil bath for 17 hours. The resulting solution was evaporated to $1 / 3$ volume under vacuum which was then made basic with solid sodium carbonate and $100 \mathrm{~mL}$ water. The basic solution was extracted with $4 \times 50 \mathrm{~mL}$ portions of methylene.chloride. The extract was dried over sodium carbonate (anhydrous) then evaporated to dryness under vacuum. The remaining solid material was applied to a 2509 alumina grade II column and eluted with 50\% ether/ 50\% benzene to abtain 2.0g (12.5\%) of 2-methyl pyrazine-1oxide and $2.0 \mathrm{~g}(12.5 \%)$ of 3-methylpyrazine-1-oxide.

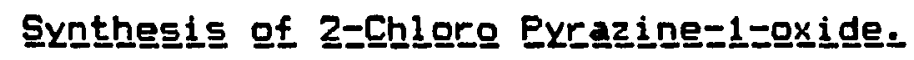

To a stirring solution of $11.4 \mathrm{~g}(0.1 \mathrm{~mol})$ of 2-chloro pyrazine in $100 \mathrm{~mL}$ of concentrated sulfuric acid at 10 degrees was carefully added $30 \mathrm{~g}(0.11 \mathrm{~mol})$ of potassium persulfate. The reaction mixture was allowed to stir at room temperature for 24 hours. The solution was then carefully poured over $300 \mathrm{~g}$ of ice and water. The aqueous solution was then extracted with $4 \times 100 \mathrm{~mL}$ portion of methylene chloride. The methylene chloride extract was washed with a 
saturated solution of sodium carbonate and water. This mixture was then dried over anhydrous sodium carbonate. The extract was evaporated to dryness under vacuum and the remaining solid material was sublimed at $75 \mathrm{C} / 0.04 \mathrm{~mm} \mathrm{Hg}$ to yield $2.8 \mathrm{~g}(21.5 \%)$ of 2-chloropyrazine-1-oxide.

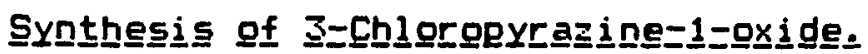

To a solution of $48 \mathrm{~mL} \quad(0.62 \mathrm{~mol}) \quad 30 \%$ hyorogen peroxide in $72 \mathrm{~mL}$ of acetic acid was added $27.6 \mathrm{~g} \quad 10.2115$ mol) of 2-chloropyrazine. The solution was then heated in a oil bath to $80 \mathrm{C}$ for 17 hours. The solution was then reduced to 1/3 volume and neutralized with a saturated solution of sodium carbonate. The basic solution was extracted with $4 \times 50$ $\mathrm{mL}$ portions of methylene chloride and the extract was dried over anhydrous sodium carbonate. The dried extract was evaporated to a white solid under vacuum. The solid material was sublimed to yield $13.8 \mathrm{~g}(50 \%)$ of 3-chloropyrazine-1oxide.

Synthests of 3-Methoxy Pyrazinge=1=oxide.

To a solution of $7.0 \mathrm{~g}(0.304 \mathrm{~mol})$ sodium metal in 200 $\mathrm{mL}$ of anhydrous methanol was added dropwise $3.84 \mathrm{~g} \quad 10.0294$ mol) of 3-chloro pyrazine-1-oxide in $150 \mathrm{~mL}$ of anhydrous methanol. This solution was allowed to stir for 48 hours and then the excess methanol was removed under vacuum to leave a yellow oil. This oil was added to $100 \mathrm{~mL}$ of saturated sodium carbonate solution and extracted with $5 \times 100 \mathrm{~mL}$ 
portions of methylene chloride. The extract was dried over sodium carbonate (anhydrous) then evaporated under vaculum to yield a yellow solid. A yield of 2.959 (79.6\%) of 3-methorypyrazine-1-oxide was obtained.

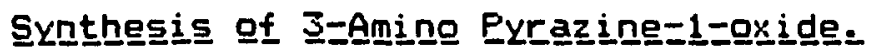

3-chloro pyrazine-1-oxide, $2 g(0.0153 \mathrm{~mol})$, was placed in $100 \mathrm{~mL}$ of methanolic ammonia and heated to $95 \mathrm{C}$ for 6 hours. The tube was allowed to coui and the solid precipitate was collected by vacuum filtration. The solid material was sublimed at $80 \mathrm{c} / 0.03 \mathrm{~mm} \mathrm{Hg}$ to yield $1.6 \mathrm{~g}$ (94.2\%) of 3-amino pyrazine-1-oxide.

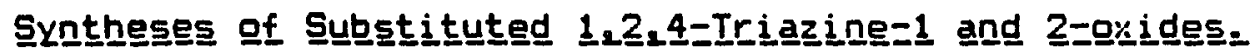

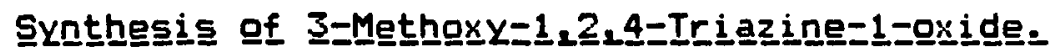
Meta-chloroperbenzoic acid, $7.0 \mathrm{~g}(0.034 \mathrm{~mol})$ in 60 $\mathrm{mL}$ of acetonitrile was added dropwise to $3.65 \mathrm{~g}(0.033 \mathrm{~mol})$ 3-methoxy-1,2,4-triazine in $120 \mathrm{~mL}$ of acetonitrile warmed to $60 \mathrm{C}$. After addition the solution was maintained at $65 \mathrm{C}$ for 16 hours. The acetonitrile was removed under vacuum to yield a yellow solid. To this, $40 \mathrm{~mL}$ of saturated sodium carbonate solution was added followed by extraction with $5 x$ $100 \mathrm{~mL}$ portions of chloroform. The chloroform extract was dried over anhydrous sodium carbonate which was then evaporated under vacuum to yield a light yellow solid. The solid was sublimed at $50 \mathrm{C} / 0.05 \mathrm{~mm} \mathrm{Hg}$ to yield $2.79 \mathrm{~g}(66 \%)$ of 3-methoxy-1,2,4-triazine-1-oxide. 


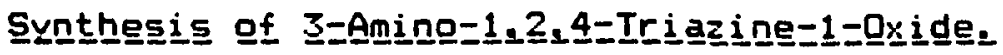

To $40 \mathrm{~mL}$ of cold methanolic ammonia was added $2.54 \mathrm{~g}$ (0.20 mol) of z-methoxy-1,2,4-triazine-1-oxide. This solution was placed in a sealed tube and heated in an oil bath at $100 \mathrm{c}$ for 6 hours. The tube was allowed to cool to room temperature and a solid precipitate was collected by vacuum filtration. A yield of $1.959(87 \%)$ of 3 -amino1,2,4-triazine-1-oxide was obtained.

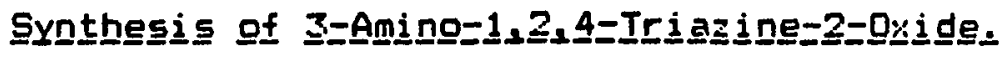

To a solution of $7.0 \mathrm{~g}(0.034 \mathrm{~mol}) \quad 85 \%$ metachloroperbenzoic acid in $60 \mathrm{~mL}$ of acetonitrile was added dropwise to $2.85 \mathrm{~g}$ of 3-amino-1,2,4-triazine in $120 \mathrm{~mL}$ of acetonitrile. The resulting solution was placed in an $80 \mathrm{C}$ oil bath for 5 hours. This solution was allowed to cool to room temperature and was evaporated to dryness under vacuum. The solid material was triturated with $100 \mathrm{~mL}$ of ether and $100 \mathrm{~mL}$ of benzene. The yellow powder was sublimed to yield 2.9g (B7\%) 3-amino-1,2,4-triazine-2-oxide.

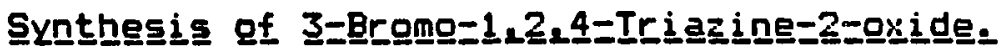

To a solution of $1.12 \mathrm{~g}(0.01$ mol) 3-amino-1,2,4triazine-2-oxide in $100 \mathrm{~mL}$ of $2 \mathrm{~N}$ hydrobromic acid at $O \mathrm{C}$ was added dropwise to a solution of $4.14 \mathrm{~g}(0.06 \mathrm{~mol})$ in $20 \mathrm{~mL}$ water. After addition the dark brown solution was maintained at 0 C for 2 hours and was then extracted with $5 \times 100 \mathrm{~mL}$ 
portions of methylene chloride. The methylene chloride extract was washed with $50 \mathrm{~mL}$ of a saturated solution of sodium carbonate the dried over anhydrous sodium carbonate. The methylene chloride extract was evaporated to dryness under vacuum to yield a white solid which was sublimed. A yield of $0.96 \mathrm{~g}$ (55\%) of इ-bromo-1,2,4-triazine-2-oxide was obtained.

Syntheses gf Some Subgstitultegd Fyrazinges.

Synthesis of 2=Amingeyrazinge.

To $50 \mathrm{~mL}$ of methanolic ammonia was added $1 \mathrm{~g} \quad 10.0087$ mol) of 2-chloropyrazine and the solution was heated in a sealed tube for 6 hours. After heating the tube was allowed to cool to room temperature and the solution was evaporated to dryness under vacuum to yield a white solid. This solid was sublimed at $70 \mathrm{C} / 0.05 \mathrm{~mm} \mathrm{Hg}$ to yield $0.73 \mathrm{~g}(89 \%)$ of 2 ami nopyrazine.

Synthenesis gef 2-Methonoxyeyrazinine.

To a solution of $10 \mathrm{~g}(0.43 \mathrm{~mol})$ sodium metal in $200 \mathrm{~mL}$ of anhydrous methanol was added dropwise with stirring $5 g$ $10.043 \mathrm{~mol})$ of 2-chloropyrazine in $100 \mathrm{~mL}$ of anhydrous methanol. The resulting solution was stirred at room temperature for 48 hours. The solution was fractionally distilled to remove the methanol and the resulting residue was added to $100 \mathrm{~mL}$ water. The water solution was extracted with methylene chloride and the methylene chloride extract 
was dried over anhydrous sodium carbonate. The dried extract was evaporated to dryness under vacuum to yield $3.29(67.6 \%)$ of z-methoxy pyrazine. 
V. References

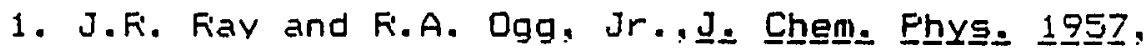
2ó, 1452 .

2. E.E. Holder and M.F. Klein. J. Chem. Fhys. 1으르. 23.3, 1956 .

J. (a) E.M. Schmidt, L.C. Erown, and D. Williams, I. Mol Spectro오드. 195ㅇ. 2,551. (b) ibid, I. Mol. Spectetross. 1959,

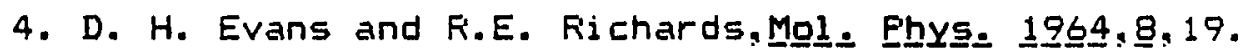

5. M. Bose, N. Das, and N. Chatter jee, J. Mol. Segectross. 196 드, 18, 32 .

6. M. Witanowski, T. Urbanski and L. Stefaniak, I. Am.

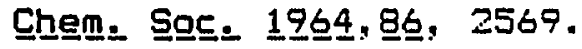

7. W. M. Litehman, M. Alei Jr., and A. E. Florin, I.

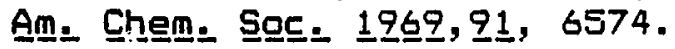

8. M. Alei Jr., A.E. Florin and W.M. Litchman, J. Am.

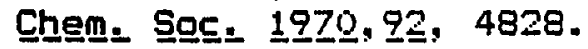

9. M. Alei Jr., A.E. Florin, W.M. Litchman and F. O’Brian, J. Phys. Chem. 1971. 75. 9:32.

10a. R.0. Duthaler and J.D. Roberts, J. Am. Chem. Sog. 1978. 100. 4969 .

b. W.M Lichter and J.D. Foberts, J. AM. Chem. Sog. $19 \underline{1} 1,9 \underline{3}, 5218$.

c. H. Saito, Y. Tanaka, and S. Ngata, I. Am. Chem.

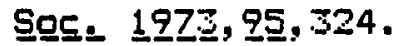

11a. I.I. Schuster, C. Dyllick-Erenzinger and J.D.

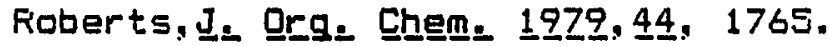

b. I.I. Schuster and J.D. Roberts, J. 마. Chen. $1979,44.3864$.

c. H. Sajto and K. Nukada, J. Am. Chem. Soc. 1971, Q.3. 1072 .

12. H. Kato, H. Kato and T. Yonezawa, Bul1 1 _ Chem. Sog.

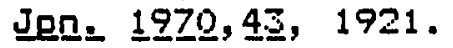

13. M. Witanowski, L. Stefaniak and G.A. Webb, Ann. Reg. NMR. Segetrog. 1977

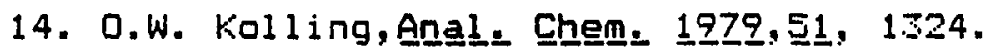


15a. M. Witanowski, L. Stefaniak, and H. Januszewski, "Nitrogen NMRi.", ed M. Witanowski and G.A. Webb. Plenum Fress, London, 1973.

b. M. Witanowski, L. Stefaniak, and H. Januszewski,

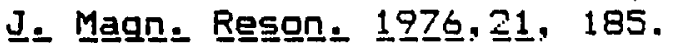

16a. A.J. Digioia, G.T. Furst, L. F'sota and F.L. Lichter. J. Phys. Chen. 1 197 므, 82, 1644.

b. I. Yavari and J.D. Foberts, 마. Magan. Reeson. 197요. 12., 87 .

17a. M. Witanowski, L. Stefaniak, H. Januszewski, $Z$. Grabowski and G.A. Webb, Ietrahedron 1972, 29. 6.77 .

b. M. Witanowski, T. Saluvere, L. Stefaniak, $H$. Januszewski, and G.A. Webt, Mol Phys. 1972. 25. 1071.

c. M. Witanowski, L. Stefaniak, $H$. Januszewski, and G. A. Webb, I. Magn. Feesgn. 1974.16. 69.

d. M. Witanowski, L. Stefaniak and G.A. Webb, J. Magn Reson. 1979, 3․ㅡ, 227.

e. M. Witanowski, L. Stefaniak, H. Januszewski and G.A. Webb, Iettrahedron 1971, 27, $\$ 129$.

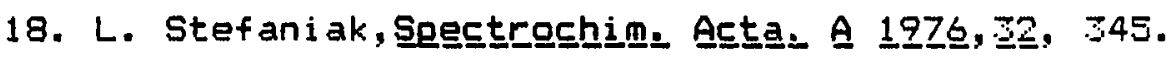

19. W. Stadeli, W. von Fhilipsborn, A.Wick and I.

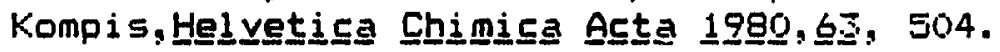

20. M Witanowski, L. Stefaniak, E. Kamienski, and G.A. Webb, ro. Maqn. Regeson. 19280, 14, 305.

21a. W. Stadeli and $w$. von Philipsborn, grg. Magn.

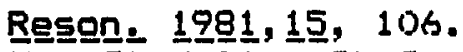

b. W. Stadeli, Fh.D. Thesis, University of Zurick, 1980.

22. S. Tobias, F. Schmitt and $H$. Gunther Chem. Eer. 19을, 11토, 2015 .

23. F. Escudero, 0 . Mo, and M. Yanez, ‥ Chem. Sog.

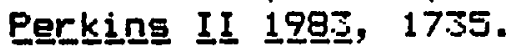

24. M. Witanowski, L. Stefaniak, H. Januszewski and

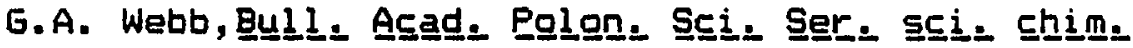
$19 \underline{\underline{9}}, 2 \underline{1}, 17$.

25. M. Witanowski, S. Szymanski, G.A. Webb and L.

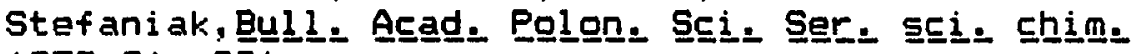

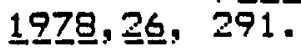

26. M. Witanoski, L. Stefaniak, and J. Wielgat, Eull1 1 -

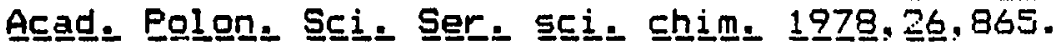


27. W.W. Faudler, E.S. Hand and S. Zachow, J. Org. Chenem. 197Z. 42, 3577 .

28. W.W. Faudler and E.S. Hand, Qrg. Magng. Eegson. 19으., 14,52 .

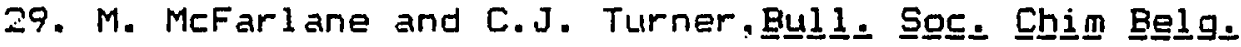
1으그. 므. 271 .

30. W.W. Fiaudler and M.V. Jovanovic, Qrg. Maggn. Reson. 198로. 19. 192 . 
TABLE I

COMFAFISON OF NITROOGEN-14 TO NITEOGEN-15

$\begin{array}{lcc}\text { SFIN QUANTUM NUMBEF } & \text { N-14 } & \text { N-15 } \\ \text { NATURAL ABUNDANCE } & 1 & 0.37 \% \\ \text { SENSITIVITY FELATIVE TO FRIOTON-1 } & 0.00101 & 0.00194 \\ \text { SENSITIVITY RELATIVE TO CARBON-1. } & 17.22 & 0.0214 \\ \text { AT NATURAL ABUNDANCE } & & 20.272 \\ \text { NMF FFEQUENCY AT 4.7 TESLA } & 14.452 & \end{array}$


TABLE I I

NITFOGEN-14,-15 CHEMICAL SHIFTS FOF SOME AZOLES

\begin{tabular}{|c|c|c|c|}
\hline COMFOUND & SOLVENT & $\operatorname{SHIFT}(A)$ & FEF \\
\hline F'YFIR'OLE & DMSO & $N-1 \quad 155.6$ & B \\
\hline N-METHYL FYRROLE & $\begin{array}{l}\text { NEAT } \\
\text { METHANDL } \\
\text { DMSO } \\
\text { DMSO }\end{array}$ & $\begin{array}{ll}N-1 & 147 \\
& 145 \\
& 150 \\
& 149.9\end{array}$ & $\begin{array}{l}A \\
A \\
B \\
C\end{array}$ \\
\hline INDOLE & NEAT & $N-1 \quad 1.30$ & $A$ \\
\hline N-METHYL INDOLE & DMSO & $N-1 \quad 126.6$ & C \\
\hline FYFAZOLE & CDCL.3 & $N-1,2248.0$ & B \\
\hline N-METHYL F'YRAZOLE & METHANDL & $\begin{array}{l}N-1200 \\
(N M E) \\
N-2=0 \\
N-1200.9 \\
(N M e) \\
N-2306.5\end{array}$ & $A$ \\
\hline ISOXAZOLE & NEAT & 380 & A \\
\hline ISOTHIAZOLE & NEAT & 298 & $A$ \\
\hline IMIDAZDLE & DMSO & 212.6 & $\mathbf{B}$ \\
\hline N-METHYLIMIDAZOLE & $\begin{array}{l}\text { NEAT } \\
\text { DMSO } \\
\text { DMSO }\end{array}$ & $\begin{array}{ll}N-1 & 157(\mathrm{Me}) \\
N-3 & 255 \\
N-1 & 162.6(\mathrm{Me}) \\
N-3 & 260.7 \\
N-1 & 161.5(\mathrm{Me}) \\
N-3 & 262.1\end{array}$ & $\begin{array}{l}\mathrm{B} \\
\mathrm{C}\end{array}$ \\
\hline OXAZOLE & $\begin{array}{l}\text { METHANOL } \\
4 / 1 \mathrm{~V} / \mathrm{V}\end{array}$ & 25.3 & A \\
\hline THIAZOLE & NEAT & 322 & A \\
\hline $1,2,3$-TFIAZOLE & $\begin{array}{l}\text { DMSO } \\
\text { CDCL3 }\end{array}$ & $\begin{array}{l}N-1,3.311 .2 \\
N-2,304.3 \\
N-1,351.2 \\
N-2 \equiv 18.3\end{array}$ & $\begin{array}{l}\mathrm{B} \\
\mathrm{B}\end{array}$ \\
\hline
\end{tabular}


TABLE II CONTINIUED

\begin{tabular}{|c|c|c|c|}
\hline COMPOUND & SOLVENT & SHIFT (D) & FEF. \\
\hline $\begin{array}{l}\text { 1-METHYL-1, } 2,3- \\
\text { TFIIAZOLE }\end{array}$ & $\begin{array}{l}\text { NEAT } \\
\text { DMSO (E) } \\
\text { DMSO }\end{array}$ & $\begin{array}{ll}N-1 & 236 \\
N-2 & 368 \\
N-3 & 350 \\
N-1 & 237.2 \\
N-2 & 363.9 \\
N-3 & 349.5 \\
N-1 & 236.9 \\
N-2 & 364.9 \\
N-3 & 351.8\end{array}$ & C \\
\hline $\begin{array}{l}\text { 2-METHYL-1, }, 2, \bar{J}- \\
\text { TRIAZOLE }\end{array}$ & $\begin{array}{l}\text { NEAT } \\
\text { DMSO }\end{array}$ & $\begin{array}{ll}N-1,3 & 327 \\
N-2 & 248 \\
N-1,3 & 326.2 \\
N-2 & 245.2\end{array}$ & C \\
\hline THIA-2, 3-DIAZOLE & ACETONE & $\begin{array}{ll}N-2 & 436 \\
N-3 & 410\end{array}$ & A \\
\hline OXA-2,5-DIAZOLE & $\begin{array}{l}\text { NEAT } \\
\text { ACETONE }\end{array}$ & $\begin{array}{l}N-2.5 \quad 347 \\
N-2.5 \quad 346\end{array}$ & $\begin{array}{l}A \\
A\end{array}$ \\
\hline THIA-2,5-DIAZOLE & $\begin{array}{l}\text { NEAT } \\
\text { ETHEF }\end{array}$ & $\begin{array}{l}N-2,5 \\
N-2,5345 \\
346\end{array}$ & $\begin{array}{l}A \\
A\end{array}$ \\
\hline $1,2,4$-TRIAZOLE & DMSO & $\begin{array}{ll}N-1,2 & 252.8 \\
N-4 & 245.5\end{array}$ & $\mathrm{E}$ \\
\hline $\begin{array}{l}\text { 1-METHYL-1, } 2,4 \\
\text { TRIAZOLE }\end{array}$ & $\begin{array}{l}\text { NEAT } \\
\text { DMSO } \\
\text { DMSO }\end{array}$ & $\begin{array}{ll}N-1 & 185 \\
N-2 & 295 \\
N-4 & 249 \\
N-1 & 208.9 \\
N-2 & 298.0 \\
N-4 & 252.1 \\
N-1 & 208.9 \\
N-2 & 298.3 \\
N-3 & 252.8\end{array}$ & C \\
\hline $\begin{array}{l}\text { 4-METHYL-1, 2,4- } \\
\text { TRIAZOLE }\end{array}$ & $\begin{array}{l}\text { METHANQL } \\
\text { DMSO } \\
\text { DMSO }\end{array}$ & $\begin{array}{ll}N-1,2 & 298 \\
N-4 & 158 \\
N-1,2 & 319.9 \\
N-4 & 16.5 .5 \\
N-1,2 & 320.4 \\
N-4 & 162.4\end{array}$ & $\mathrm{~B}$ \\
\hline
\end{tabular}


TABLE I I CONTINUIED

\begin{tabular}{|c|c|c|c|}
\hline COMFOUND & SOLVENT & SHIFT & REF. \\
\hline $1,2,4-O X A D I A Z D L E$ & $\begin{array}{l}\text { ETHER } \\
1 / 1 \vee / V\end{array}$ & $\begin{array}{ll}N-2 & 360 \\
N-4 & 240\end{array}$ & $A$ \\
\hline $1,2,4$-THIADIAZQLE & $\begin{array}{l}\text { ETHER } \\
1 / 3 \vee / V\end{array}$ & $\begin{array}{ll}N-2 & 274 \\
N-4 & 310\end{array}$ & A \\
\hline QXA-S, 4-DIAZOLE & NEAT & $N-3.4298$ & $A$ \\
\hline THIA-S, 4-DIAZOLE & $\begin{array}{l}\text { ETHER } \\
1 / 1 \mathrm{~V} / \mathrm{V}\end{array}$ & $N-3,4370$ & $A$ \\
\hline
\end{tabular}

(a). See Ref. 25

(b). Nitrogen-15 data from: D.S. Wofford, D.M. Forkey and J.G.Russel 1, J. Qrq. Chem. 1982, 47, 5132 .

(c). Nitrogen-15 data from: L. Stefaniak, J.D. Roberts, M. M. Witanowski and G.A. Webb, Drg. Magn. Kesgn. 1984.22, 215.

(d). All shifts have been corrected to anhydrous ammonia and and are recorded in parts per million (ppm).

(e). DMSO is dimethyl sulfoxide. 
TABLE II I

NITROGEN-14,-15 CHEMICAL SHIFT DATA FOF AZINE-N-OXIDES(d)

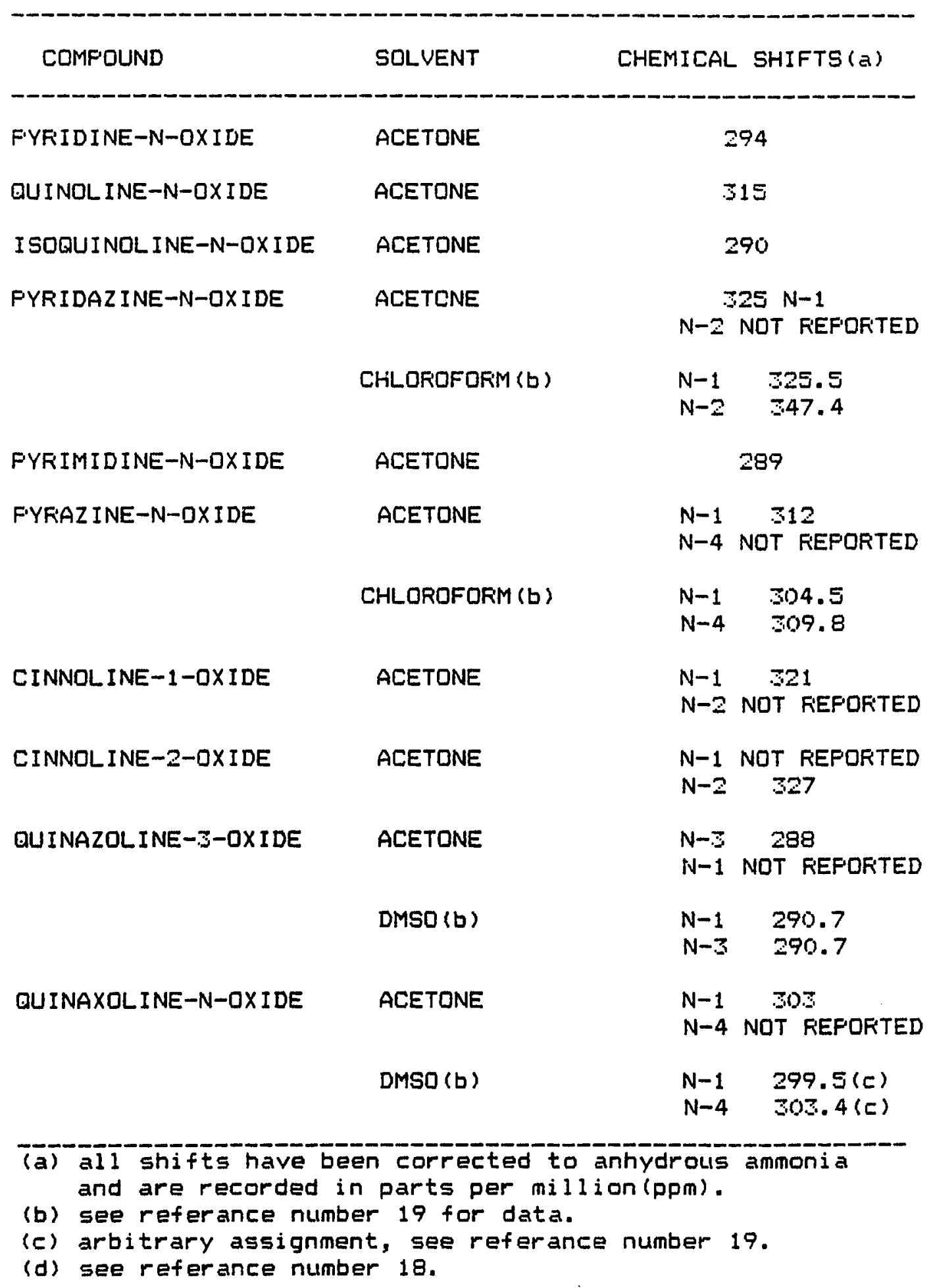


TABLE IV

NITFOGEN-15 CHEMICAL SHIFTS OF SOME FOLYAZAINDENES(a)

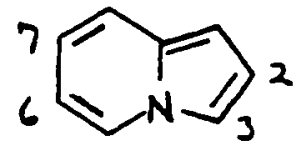

\begin{tabular}{|c|c|c|c|c|}
\hline COMFOUND & $N-1$ & $N-2$ & $N-3$ & $N-4$ \\
\hline FYYAAZOLOL2, उa]FYRIDINE & --- & -- & 305 & 239 \\
\hline IMIDAZOL $1,5 a]$ PYRIDINE & --- & 244 & --- & 195 \\
\hline IMIDAZOL 1, 2a]FYFIDINE & 248 & -- & --- & 202 \\
\hline $\begin{array}{l}1,2,3-T R I A Z O L O[1.5 a]- \\
\text { FYFIIDINE }\end{array}$ & --- & 39 & 411 & 260 \\
\hline $\begin{array}{l}1,2,4-T F I A Z O L O[2,3 a]- \\
\text { PYRIDINE }\end{array}$ & 230 & -- & 286 & 239 \\
\hline $\begin{array}{l}1,2,4 \text {-TKI AZOLO[ } 4,3 a]- \\
\text { PYRIDINE }\end{array}$ & $\$ 19$ & 262 & -- & 194 \\
\hline $\begin{array}{l}1,2,3,4-T E T F A Z O L D[1,5 a] \\
\text { PYRIDINE }\end{array}$ & 514 & $\$ 66$ & 506 & 247 \\
\hline
\end{tabular}

(a) referance number $17 d$ 
TABLE $V$

NITROGEN-15 CHEMICAL SHIFTS OF SOME FOLYAZAINDENES<smiles>Sc1ccc2cccn2c1</smiles>

NITROGEN-15 CHEMICAL SHIFTS (AMMONIA=0)

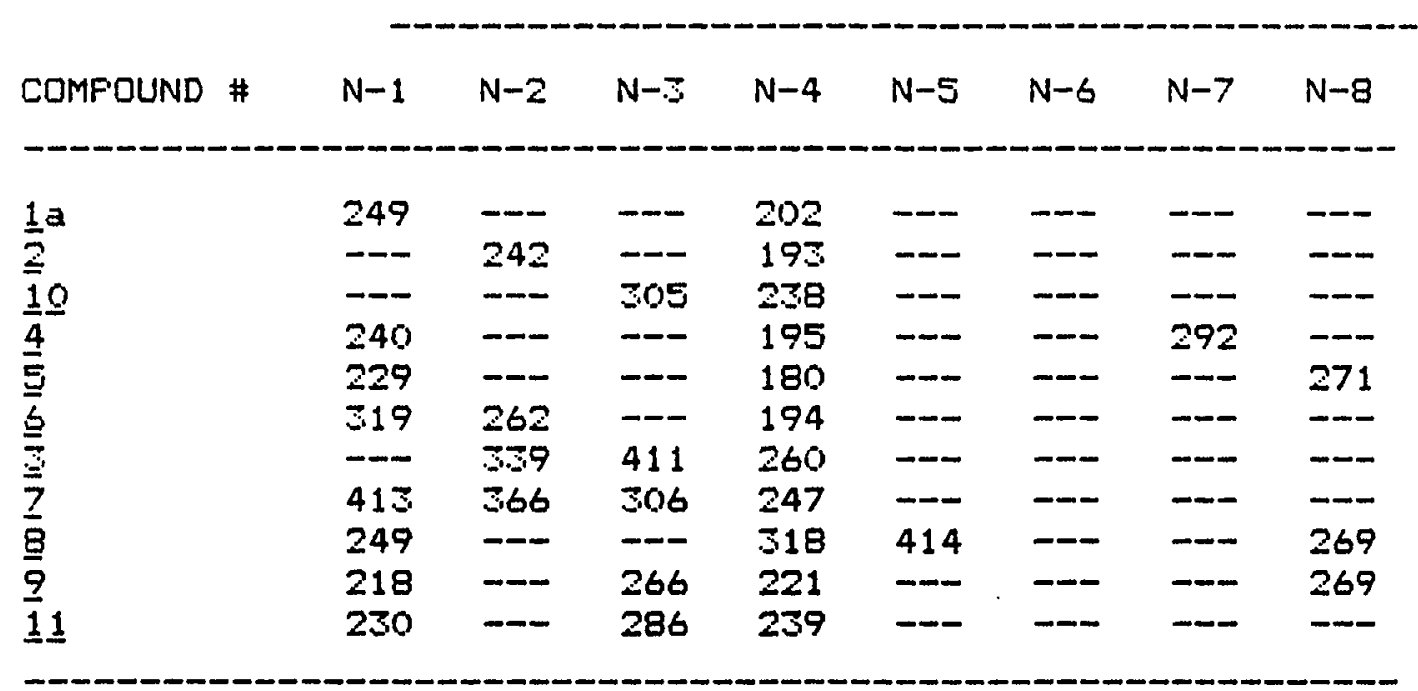

(a) our data is in DMSO with nitromethane (shift=380.23(ppm)) external standard

(b) nitrogen chemical shifts of six-membered heteroaromatic compounds employed in Figure 1: pyridine, 302; pyrimidine, 298; pyridazine, 400; pyrazine, 338; 1,2,4triazine, $N-1=420, N-2=382, N-4=318$ in chloroform, and all others are in DMSO 
TABLE VI

NITFOGEN-15 CHEMICAL SHIFT DATA OF SOME FYYRAZINES AND THEIF' $N$-OXIDES (C)

SUBST I TUENT<smiles>c1cnccn1</smiles>

N-1S SHIFTS(ppm)(b)

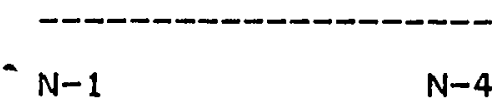

$\mathrm{H}$

2-methyl

2-methoxy

z-amino

2-chloro

2-carboxylic acid

2-amido

3-methyl,1-owide

2-methyl, 1-oxide

-chloro, 1-oxide

2-chloro, 1-oxide

Z-methoxy, $1-0 \times i d e$

j-amino, 1 -oxide

1-oxide

3.52 d

$324(3.31 .3) a$

$269(278.5)$ a

$265(273.5 a$

$316(323.0) \mathrm{a}$

$325(332.8) a$

$314(322.7) \mathrm{a}$

297

296

307

287

305

301

3.09
$\mathrm{N}-4$

(a). number in parathenses see reference 19.

(b). chemical shifts are given with respect to ammonia at 0 ppm, nitromethane=3BO.23 ppm, all compounds were run DMSO at 1 molar concentration.

(c). These compounds were prepared in accordance with the procedures in: S.A. Krueger and W.W. Faudler.J. Qreq. Cheng. 1972, 37,4188 .

(d). nitrogen-14 data from $17 e$ 
TABLE VII

NITFOGEN-15 CHEMICAL SHIFT DATA OF SOME 1,2,4-TRIAZINES AND THEIR N-OXIDES.<smiles></smiles>

N-15 SHIFT(a)

\begin{tabular}{|c|c|c|c|}
\hline SUBST ITUENT & $N-1$ & $N-2$ & $N-4$ \\
\hline 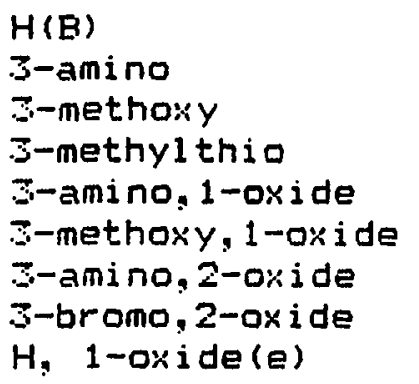 & $\begin{array}{l}420.0 \\
415.7 \\
416.0 \\
412.0 \\
328.9 \\
330.0 \\
341.0 \\
351.4 \\
337\end{array}$ & $\begin{array}{l}382.0 \\
319.0 \\
322.0 \\
351.0 \\
273.0 \\
282.9 \\
242.0 \\
309.0\end{array}$ & $\begin{array}{l}318.0 \\
250.0 \\
253.6 \\
282.0 \\
228.9 \\
232.0 \\
277.0 \\
305.8\end{array}$ \\
\hline
\end{tabular}

(a) see footnote $b$ in table 6

(b) nitrogen-14 data given are slightly different: $N-1=422$ $N-2=278$, and $N-4=298$

(c) the compounds were prepared by procedures given in: B.T. Keen, R.J. Radel and W.W. Paudler. J. Qrg. Chem. 1977., 42. 3498 .

(d) the deshielding of $\mathrm{N}-4$ with respect to the non-oxidized J-amino compound may will reflect the inductive electron-withdrawning effect of the $\mathrm{N}$-okide counteracting the shielding effect of the 3-amino group. 
TABLE VIII

NITROGEN-15 CHEMICAL SHIFT DIFFEFIENCES (pPm) BETWEEN FAFENT HETEROCYCLIC COMPOUNDS $(R=H)$ AND SUBSTITUTED HETEROCYCLIC ANALOGS.a

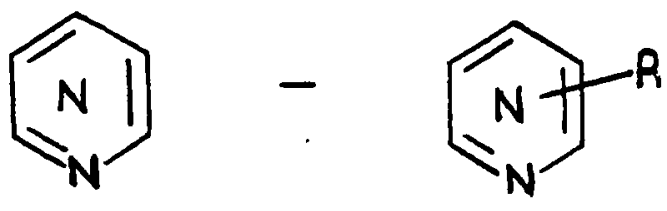

C-1S QRETHQ

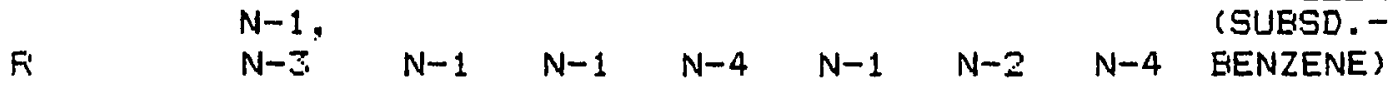

\begin{tabular}{|c|c|c|c|c|c|c|c|c|}
\hline amino & $=49$ & $=51.5$ & $=6$ I & -6 & -4.3 & $=6.5$ & -68 & $=15$ \\
\hline methoxy & $=41$ & $=49.2$ & $=6 \underline{ }$ & +5 & -4.0 & $=60$ & -64.4 & $=14.4$ \\
\hline f 1 Luro & $=47$ & $=\underline{4} . \underline{6}$ & \multicolumn{3}{|c|}{$-91.9 c-29.2 c---$} & --- & --- & $=12.9$ \\
\hline chloro & $=\underline{\underline{\theta}}$ & $=7.5$ & $=16$ & \pm 4 & -- & -- & -- & \pm 0.4 \\
\hline Eyano & \pm 19 & $=0.9$ & \multicolumn{3}{|c|}{$-46.5 c-44.5 c---$} & -- & -- & $\pm \underline{E}$ \\
\hline $\begin{array}{l}\text { methyl- } \\
\text { thio }\end{array}$ & $=1 \Xi$ & $=24$ & \multicolumn{3}{|c|}{$-6.3 .7 c-47.8 c-8.0$} & $=1$ & \multicolumn{2}{|l|}{$=30.0$} \\
\hline $\begin{array}{l}\text { methyl - } \\
\text { carb- } \\
\text { oxylate }\end{array}$ & $\pm 1 \Xi$ & \pm 11.9 & \multicolumn{3}{|c|}{$-47.8 c-45.0 c--$} & -- & --- & $\pm 2 \pm 1$ \\
\hline methyl & --- & $=0.4$ & $=8$ & -6 & -- & -- & --- & \pm 0.7 \\
\hline
\end{tabular}

(a) Negative numbers indicate shielding with respect to the parent compound; underlined numbers refer to nitrogens ortho to the substituted carbon.

(b) Data from: G.C. Levy and G.L. Nelson, "Carbon-1S Nuclear Magnetic Resonance For Organic Chemists.", Wiley Interscience, New York, NY, 1972, p.81 and references cited therin. See text comment in connection with. these data. (c) see reference 22 . 
TABLE IX

DIFFERENCE NITFIOGEN-15 SHIFT = SLOFE * (DIFFERENCE CAREON-1S SHIFT - INTERCEPT)

$\begin{array}{lll}\text { COMFOUND } & \text { SLOPE } & \text { INTERCEPT } \\ \text { PYRAZINE } & 3.66(3.05) \mathrm{a} & -14.13(-9.86) \mathrm{a} \\ \text { FYFIDINE } & 3.14(3.52) \mathrm{b} & -4.70(-1.87) \mathrm{b} \\ \text { PYRIMIDINE } & 3.52(2.89) \mathrm{b} & +1.76(-0.49) \mathrm{b} \\ 1,2,4-T R I A Z I N E & -11.65 \pm 0.5] \mathrm{est} . \\ & & \end{array}$

(a) see reference 22

(b) see reference 21 
TABLE $X$

NITFOGEN-15 CHEMICAL SHIFT DIFFERENCE (pPm) EETWEEN SOME SUBSTITUTED HETEROCYCLIC COMPOUNDS AND THEIR N-OXIDES

A. SUBSTITUTED FYFIAZINE N-OXIDE

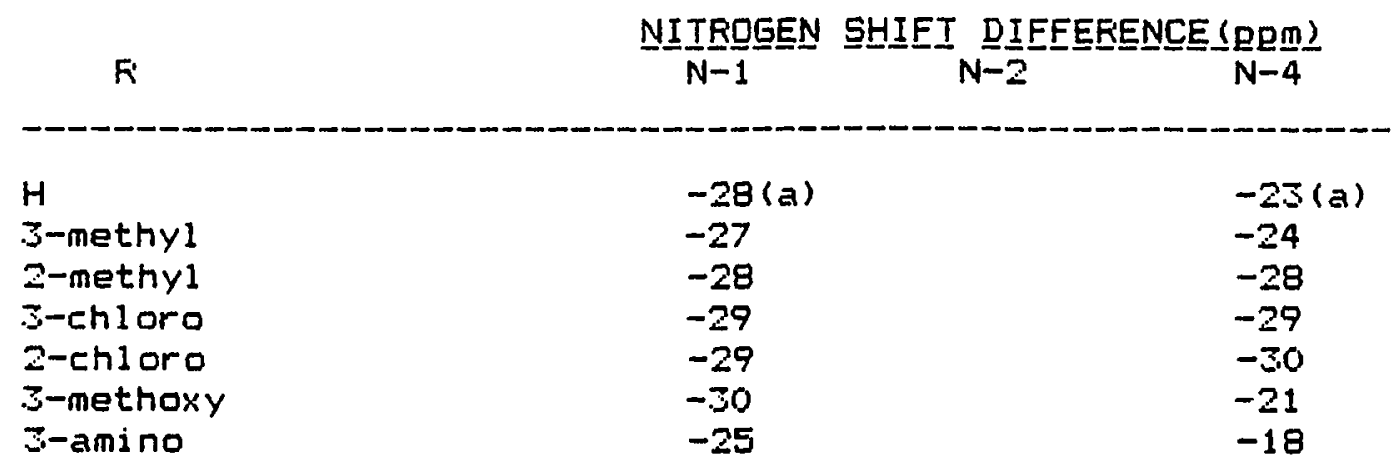

B. SUBSTITUTED $1,2,4-T R I A Z I N E$ 1-OXIDE

$\mathrm{R}$

H

3-methoxy

-78 (a) unpubl i shed unpublished

Z-amino

$\begin{array}{lll}-71 & -39 & -27\end{array}$

$\begin{array}{lll}-87 & -46 & -21\end{array}$

C. SUBSTITUTED 1,2,4-TRIAZINE 2-OXIDE

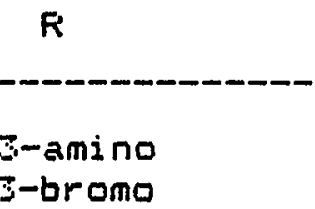

$\begin{array}{lll}-75 & -76 & +27 \\ -69 & -73 & -13\end{array}$

(a) see reference 20 


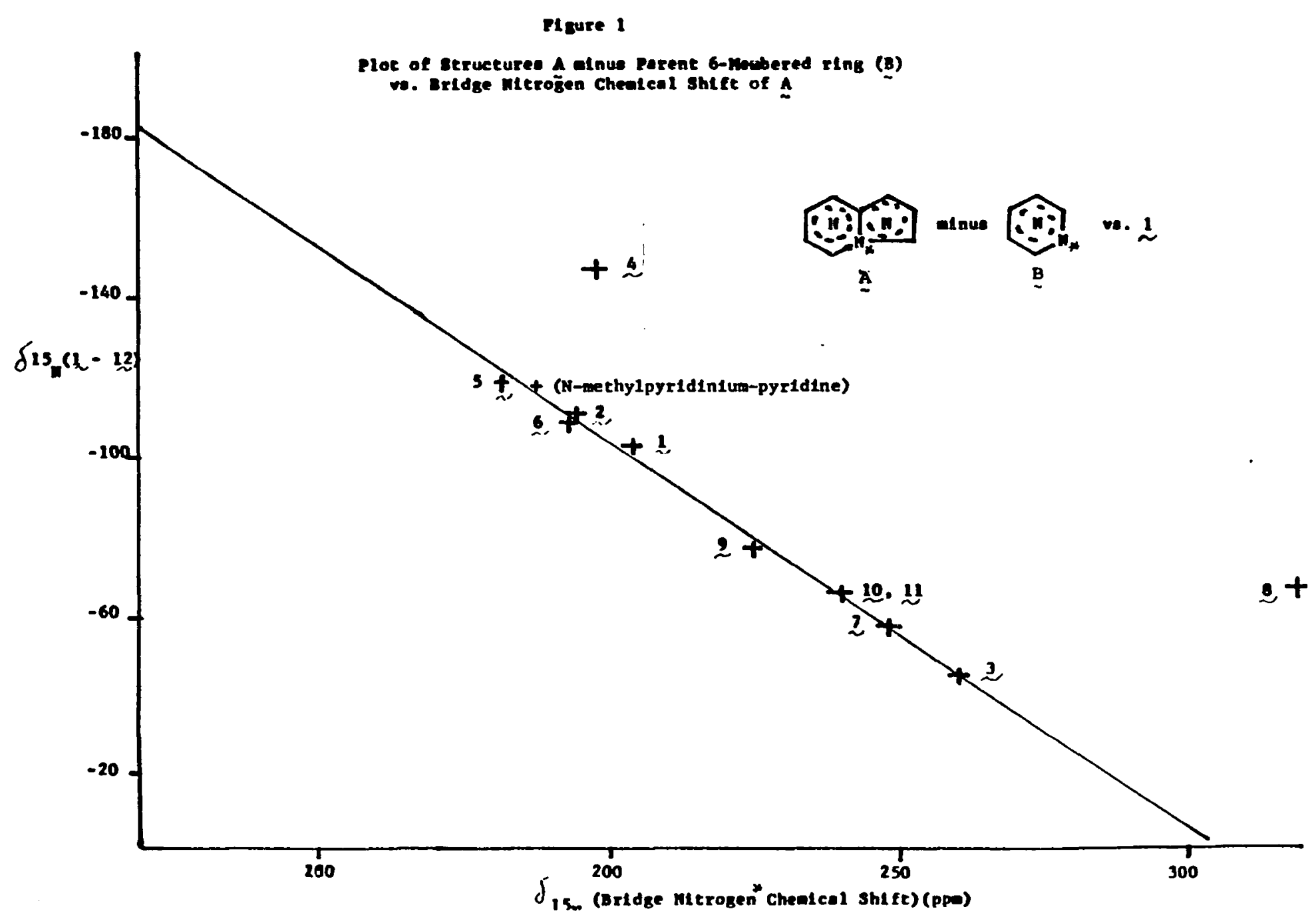




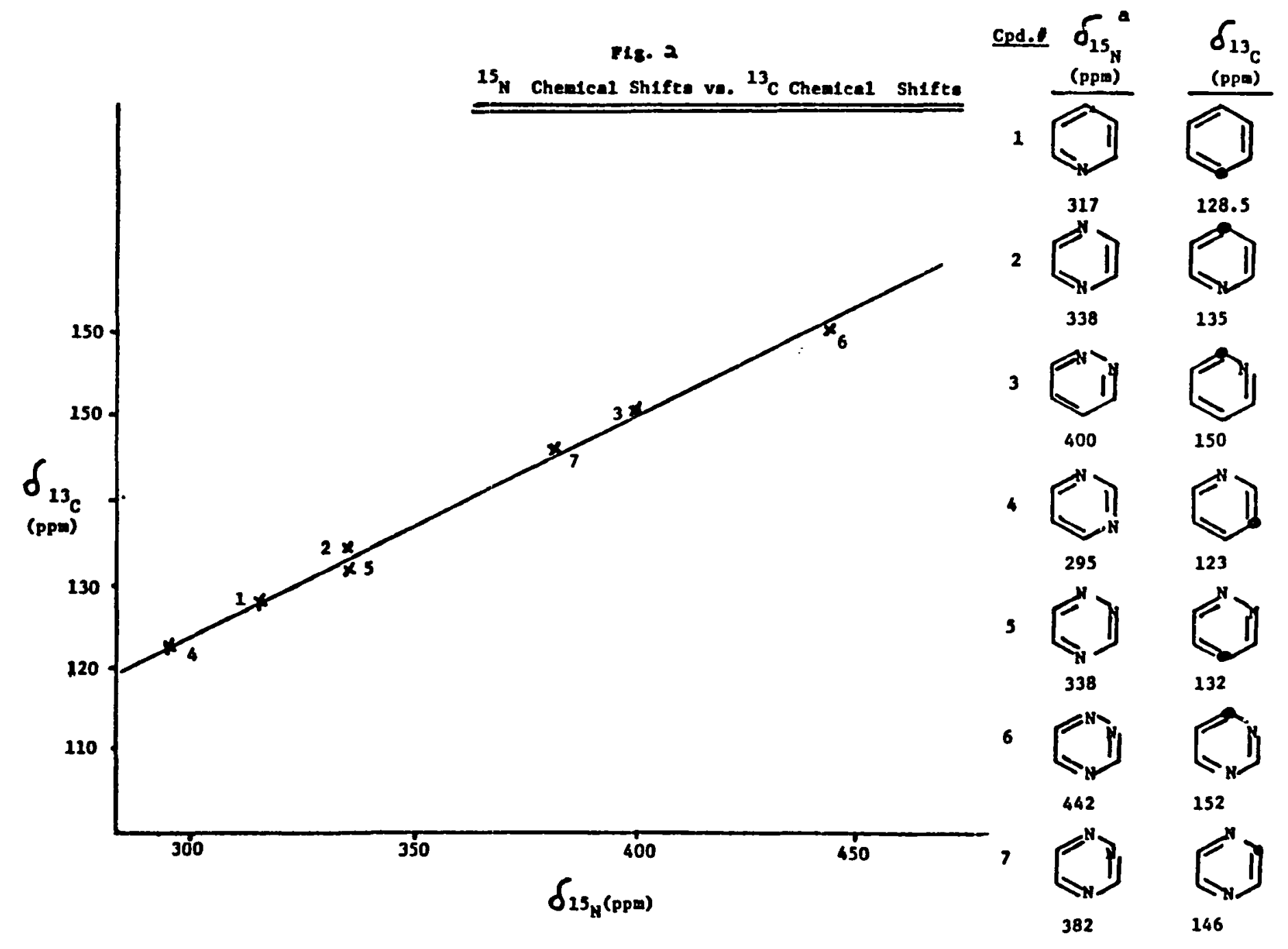

